\title{
Über den Einfluß der Umwelt auf die Eierstöcke der Tritonen.
}

Ein Beitrag zur Frage nach der Vererbbarkeit erworbener Eigenschaften und der Parallelinduktion.

Von

H. Stieve,

Halle a. $\mathrm{S}$.

(Untersuchungen, ausgeführt mit Unterstützung aus der Samson-Stiftung der Bayrischen Akademie der Wissenschaften in München.)

Mit 12 Abbildungen auf Tafel $I$ und II und 2 Tabellen.

(Eingegangen am 9. Februar 1921.)

Inhaltsübersicht.

Einleitung . . . . . . . . . . . . . . . . 179

Versuchsanordnung . . . . . . . . . . . . . . 187

Der gewöhnliche Verlauf der Fortpflanzungstätigkeit . . . . . . . . 189

Die normalen Jahresveränderungen des Eierstockes . . . . . . . . . . 192

Die Versuche. . . . . . . . . . . . . . . 100

1. Der Einfluß der Umgebung . . . . . . . . . . . . . 197

2. Der Einfluß der Ernährung . . . . . . . . . . . . . . . 206

3. Der Einfluß der Wasserwärme . . . . . . . . . . . . . . 211

4. Der Einfluß des Lichtes. . . . . . . . . . . . . . . . 215

5. Sonstige Versuche .................. . 217

Besprechung der Befunde. . . . . . . . . . . . . . 218

1. Der Verlauf der Eiablage . . . . . . . . . . . . . 218

2. Die Veränderungen an den einzelnen Oocyten ........ 228

3. Das Verhalten und die Bedeutung des Fettkörpers. . . . . . . . 239

4. Zusammenfassung der Befunde . . . . . . . . . . . . . . 244

Erwähnte Arbeiten . . . . . . . . . . . . . . . . . . . 264

Erklärung der Abbildungen .................. 266

\section{Einleitung.}

Die Forschungen über die Vererbbarkeit erworbener Eigenschaften sind auf einem toten Punkt angelangt. Schroff und anscheinend unüberbrückbar stehen sich heute zwei Anschauungen gegenüber; nur ein geringer Teil der Forscher rechnet noch mit der Möglichkeit einer Ubertragung von neu, während des Lebens entstandenen Eigenschaften auf die Nachkommen. Die meisten Biologen stehen vielmehr auf dem Standpunkt, daß die Umwandlung der Arten ausschließlich durch Auslese erfolgt, daß es also keine Ubertragung erworbener Eigenschaften gibt. Alle Vorkommnisse aber, die eine solche zu beweisen scheinen, sind nach ihrer Ansicht nur der Ausdruck für die 
hochgradige Variabilität der Lebewesen und zeigen, daß der als Folge des äußeren Einflusses erworbene, innerhalb der Variationsbreite gelegene Zustand sich in gleicher Weise auf die Nachkommen vererbt. Ziemlich allgemein wird dabei wohl angenommen, daß der Reiz, der die fraglichen Veränderungen am Körper des Lebewesens bedingt, angeblich auch die Keimzellen in gleicher Weise beeinflußt und deshalb auch an ihnen die nämlichen Umgestaltungen hervorruft, die dann erst bei der Entwicklung der Nachkommen in Erscheinung treten. Man bezeichnet ja diesen Vorgang nach Detto (1904) als Parallelinduktion, da Körper und Keimzellen, und mit diesen auch die Nachkommen, in gleicher Weise beeinflu Bt, also auch verändert werden ${ }^{1}$ ).

Von manchen Seiten, in erster Linie von Semon (1912), wird allerdings die Möglichkeit einer solchen Parallelinduktion bestritten und zwar auf Grund der Erwägung, daß niemals ein Reiz, der den Gesamtorganismus eines Lebewesens oder auch nur eine umschriebene Körperstelle trifft, die Keimzellen in gleicher Weise beeinflussen kann, wie diejenigen Körperzellen, die der sichtbaren Abänderung unterliegen. Dagegen habe ich (1918) geltend gemacht, daß es niemals der äußere Reiz selbst ist, der eine Veränderung irgendeiner, sei es auch noch so kleinen Stelle des Körpers bewirkt, sondern stets nur die Antwort des Gesamtkörpers auf den Reiz. Jede, auch die kleinste äußere Beeinflussung bedingt ja eine Umgestaltung in der Zusammensetzung des ganzen Körpers, ihr Erfolg ist für uns jedoch nur an denjenigen Teilen zu erkennen, die auf Grund ihrer anererbten Beschaffenheit abänderungsfähig sind. Selbstverständlich betreffen die Veränderungen des ganzen Körpers auch die Keimdrüsen, die ja wie jedes andere Organ hinsichtlich der Ernährung dem Gesamtorganismus untergeordnet sind und demnach auch an allen Änderungen teilhaben, denen dieser unterworfen ist.

Die Ümgestaltungen treten an den Keimdrüsen aber nicht unmittelbar in Erscheinung, sondern machen sich erst bei der Entwiclslung der Nachkommen wieder in der Ausbildung derjenigen Gewebsarten geltend, die befähigt sind auf die stattgehabte Veränderung mit einer entsprechenden Umgestaltung der Form zu antworten. Sie $m u ß$ in der gleichen oder wenigstens in ganz ähnlicher Weise wie

1) Roux hat schon erklärt (1911), daB die Parallelinduktion auf die von Detto angenommene Weise unmöglich ist und zwar deshalb, weil so verschieden besehaffene Gebilde wie Keimzellen und die bereits differenzierten Zellen der entwickelten Organe durch dieselbe Einwirkung nicht in gleicher Weise verändert werden und nicht in gleicher Weise anf sie reagieren können. Auf Grund seiner Annahme von Keimplasma in den differenzierten Zellen weist Roux aber auf die Möglichkeit einer anderen, der bigermplasmatischen Parallelinduktion hin. 
die künstlich erzeugte Veränderung des Muttertieres vom Durchschnitt der Art abweichen, jedoch gleichfalls stets innerhalb der Variationsbreite des betreffenden Lebewesens gelegen sein.

Diesen Vorgang bezeichne ich als körperliche Gleichbeeinflussung (somatogene Parallelinduktion), da als Folge der durch den Reiz bedingten Veränderung des Gesamtorganismus in gleicher Weise einerseits die abänderungsfähigen Zellen des Körpers, andererseits die ganzen Keimzellen umgestaltet werden. Dadurch lassen sich ohne weiteres zwanglos alle diejenigen Fälle erklären, die heute als Beispiele für die Vererbung erworbener Eigenschaften angeführt werden.

Die durch den veränderten äußeren Einfluß bewirkten Umgestaltungen des Gesamtkörpers sind zunächst wohl chemischer Art. Wir müssen hier, wie auch Fick (1921) betont, an den EinfluB von den Reizstoffen ("Inkreten odex "Hormonen") ähnlichen Substanzen denken, die wir zwar noch nicht darstellen können, wohl aber aus ihren Wirkungen kennen. Dabei ist jedoch zu beachten, daß nicht nur diejenigen Organe, die wir heute als Drüsen mit innerer Sekretion bezeichnen, zur Absonderung solcher Stoffe befähigt sind; sondern alle Teile des Körpers, jede Zelle, mit Ausnahme vielleicht der obersten verhornten Hautschuppen, nehmen am Gesamtstoffwechsel des Körpers teil: sie entziehen einerseits dem Blut und Lymphstrom bestimmte Stoffe, die sie zur Ernährung notwendig haben und scheiden andererseits ihre Schlacken in den allgemeinen Säftestrom aus. Beide Vorgänge, so unbedeutend sie in vielen Fällen sein mögen, bedingen doch stets eine gewisse Wirkung auf die Zusammensetzung des Gesamtkörpers. Dieser befindet sich für gewöhnlich hinsichtlich seiner Reizstoffe in einem Gleichgewichtszustand, der augenblicklich gestört wird, sobald irgendein, auch noch so kleiner Bezirk des Körpers hinsichtlich seiner Aufnahmen und Abgaben verändert wird. Erst Umgestaltungen, die den Gesamtorganismus betreffen, können dann wieder einen Gleichgewichtszustand schaffen, der den neuen Bedingungen entspricht. An allen diesen Schwankungen müssen sich aber auch die Keimzellen beteiligen, sind sie doch organisch, in bezug auf ihre Ernährung dem ganzen Körper untergeordnet.

In meinen früheren Ausführungen habe ich im AnschluB an die Angaben anderer Forscher des weiteren dargelegt, daB nach dem heutigen Stande unserer Kenntnisse schon allein ans dem Grunde nicht von einer Vererbung erworbener Eigenschaften gesprochen werden kann, weil im Versuch noch niemals gezeigt werden konnte, daß irgendein Lebewesen befähigt sei, eine wirklich ganz neue Eigenschaft während seines Lebens zu erwerben. Alles was bisher unter der obigen Bezeichnung zusammengefaßt wurde, ist nichts anderes, als die Antwort des Gesamtkörpers auf einen bestimmten äußeren Einfluß, die aber 
für uns nur an umschriebenen Körperstellen durch die dort statthabenden Umgestaltungen erkennbar wird. Die Fähigkeit, auf den Reiz mit solchen Abänderungen zu antworten, ist in der ganzen Anlage des Organismus bedingt, also angeboren. Die erkennbaren Umgestaltungen stellen größtenteils Schutzmaßnahmen vor .äußeren Schädigungen dar, stets sind sie in ihrer Ausdehnung begrenzt und können auch bei langer Versuchsdauer niemals ein gewisses Maß überschreiten. Die Grenzen sind wieder vererbt, in der ganzen Anlage des Lebewesens bedingt und nur innerhalb dieser bestimmten Schranken ist der Körper variabel, durch äuBere Reize veränderlich. Niemals ist es bisher gelungen an irgend einem Lebewesen durch veränderte äußere Bedingungen eine wirklich neue Eigenschaft zu erzeugen, zu der die Veranlagung nicht schon von vornherein vorhanden war.

Nur durch schwere Eingriffe gelingt es Verletzungen und Verstümmelungen zu setzen, die tatsächlich eine neue Eigenschaft darstellen. Thre Nichtvererbbarkeit ist zweifellos bewiesen. Der Versuch Semons (1912), die Möglichkeit einer Vererbung von Verletzungen zu zeigen, darf ohne weiteres als vollkommen mißglückt bezeichnet werden.

Wir sehen ja auch, daß zu den Versuchen über die Vererbbarkeit erworbener Eigenschaften immer wieder die nämlichen Arten des Pflanzen- und Tierreiches benutzt werden, nämlich ausschließlich solche, denen eine hohe Abänderungsfähigkeit innewohnt, deren Körper also ererbterweise imstande ist, auf Veränderungen in der Umgebung mit mehr oder weniger tiefgreifenden Umgestaltungen bestimmter Teile oder aber mit der Abänderung bestimmter physiologischer Betätigungen zu antworten. Unter den Wirbeltieren sind es, um nur ein Beispiel herauszugreifen, in erster Linie die Amphibien, bei denen sich Veränderungen in der Farbe, der Lebensweise und der Fortpflanzungsart erzielen lassen. Die Lurchen sind eben, wie ein Vergleich mehrerer im Freileben beobachteter Tiere der gleichen Art beweist, in hohem Maße abänderungsfähig, sowohl in Hinsicht auf die Färbung und die Lebensweise, als auch ganz besonders auf die Art ihrer Fortpflanzung, sie sind meist auch im Freileben "poikilothok «. Die im Versuche erzielten Veränderungen sind daher auch bei ihnen niemals neu er worbene Eigenschaften, sondern nur Varianten, die innerhalb der angeborenen, in der ganzen Anlage des Lebewesens bedingten Variationsbreite liegen.

Im Versuch herbeigeführte Veränderungen einer der genannten Eigenschaften treten meist in gleicher, häufig auch nur in abgeschwächter Form bei den Nachkommen der beeinflußten Tiere auf, da eben die Antwort des Gesamtorganismus auf die Beeinflussung, die schon bei den Eltern die betreffende Umgestaltung bewirkte, auch 
die Keimzellen als Teile des Gesamtorganismus abändert. Als Folge dieser Tatsache müssen dann bei den Nachkommen, die sich aus den abgeänderten Keimzellen entwickeln, auch die nämlichen Eigenschaften wie bei den Eltern zur Ausbildung kommen.

Die von mir geforderte körperliche Gleichbeeinflussung unterscheidet sich demnach von der hauptsächlich auf Grund der Versuche Towers (1906) angenommenen Parallelinduktion in grundlegender Weise. Bei dieser ist es der Reiz selbst, der die gleichsinnige Veränderung an bestimmten Teilen des Körpers und an den Nachkommen bewirken soll, bei der körperlichen Gleichbeeinflussung dagegen bedingt der Reiz selbst nur eine Umgestaltung des Gesamtkörpers und diese erst bewirkt die für uns erkennbaren Veränderungen an Eltern und Nachkommen.

Verschieden ist diese Anschauung selbstverständlich auch von der Ansicht derjenigen Forscher, die mit der Möglichkeit einer Vererbung erworbener Eigenschaften rechnen. Sie nehmen ja an, daß der Reiz selbst die Veränderung einer umschriebenen Körperstelle bewirkt. Diese wird dann erst auf dem Wege über den Gesamtkörper den Keimzellen übermittelt und bedingt bei ihnen wieder eine gleichsinnige Umgestaltung, und zwar nicht der ganzen Keimzellen, sondern nur der dem betreffenden Körperteil entsprechenden Anlage.

Roux (1911) hat in klarer Weise gezeigt wie verwickelt sich ein solches Geschehen gestalten müßte; nicht weniger als drei verschiedene Vorgänge, die sich nacheinander abwickeln, kommen in Frage:

"1. Die Translatio hereditaria, die Ubertragung einer Veränderung des mehr oder weniger weit entwickelten Individuums auf den Keim.

2. die Implikation oder blastoide Metamorphose, die Umwandlung der neuen Eigenschaft des mehr oder weniger entwickelten Soma in eine dem Keimplasma entsprechende Eigenschaft und

3. die blastogene Insertion oder die keimbildende. Einfügung der neuen Determination an die geeignete Stelle des Keimes.«

Bei dem von mir angenommenen Geschehen gestalten sich dagegen die Verhältnisse wesentlich einfacher, bei ihm erfolgt die Translatio hereditaria gleichzeitig auf alle Teile des Körpers und ruft in den Keimzellen schon Veränderungen hervor in einer Zeit, in der sich an den abänderungsfähigen Stellen des Körpers die für uns erkennbaren Vorgänge abspielen. Dabei werden die Keimzellen als Ganzes, in einer den chemischen Veränderungen ähnlichen Art umgestaltet und erzengen deshalb ihrerseits wieder an den abänderungsfähigen Zellen des sich aus ihnen entwickelnden neuen Lebewesens, sobald diese entstehen, die nämlichen Veränderungen wie bei den Eltern.

Die Möglichkeit einer Parallelinduktion im früheren Sinne ist von den Anhängern der Vererbung erworbener Eigenschaften vielfach 
bestritten worden und zwar mit Recht. Die Reize, nach deren Anwendung man Umgestaltungen am tierischen und pflanzlichen Körper auftreten sah, waren zumeist das Licht, die Wärme oder die Feuchtigkeit der Luft, schließlich noch Beeinflussung der Instinkthandlungen und Veränderungen der Ernährung. Dabei läßt es sich besonders von den beiden zuerst genannten leicht nachweisen, daß sie selbst niemals in gleicher Weise auf die Hautdecken wie auf die Keimzellen einwirken können. In mühsamen Untersuchungen hat vor allem Šecerow (1912/1913) festgestellt, daß nur etwa der hundertdreiundsiebzigste Teil der Lichtmenge, die die Haut eines Feuersalamanders trifft, tatsächlich bis zu den Keimdrüsen vordringt. Aber auch nicht in unveränderter Form, sondern in weitgehender Weise umgestaltet durch die Schicht der durchdrungenen, zum Teil stark gefärbten Körperteile.

Es hätte aber dieser schwierigen Feststellungen gar nicht bedurft, um die Unmöglichkeit der Parallelinduktion in diesem Falle darzutun, nachdem ja durch zahlreiche Versuche, in letzter Zeit besonders auch durch die Arbeiten von Fischel (1920) bekannt ist, daß die Veränderungen in der Farbverteilung der Haut beim Feuersalamander nicht durch die unmittelbare Einwirkung des Lichtes auf die Epidermis, sondern auf die Augen bewirkt werden: bei geblendeten Tieren bleibt trotz stärkster Beeinflussung jede Farbverändérung aus. Der äußere, umgestaltende Reiz wirkt hier also ausschließlich auf die Netzhaut ein, er bedingt von dort aus Veränderungen des Gesamtkörpers, die nur für uns bloß an der Haut zu erkennen sind, von denen aber zweifellos auch die Keimzellen beeinflubt werden müssen. Denn warum sollte der Erfolg des Reizes, der vom Kopf bis zur Schwanzspitze an der ganzen Körperoberfläche zu erkennen ist, gerade an den Eierstöcken und Hoden spurlos vorüber gehen, sind sie doch dem Empfangsorgan; nämlich der Netzhaut wesentlich näher gelegen als viele der nachweisbar abgeänderten Bezirke?

Das Nämliche läßt sich auch hinsichtlich der Wirkung von Wärmereizen zeigen. Zwar ist es klar, daß bei wechselblütigen Tieren Veränderungen in der Wärme der umgebenden Luft oder des Wassers auch eine entsprechende Abänderung der Körpertemperatur bewirken können, die dann auch die Keimzellen betrifft. Aber auch hier gelangt der äußere Reiz, die veränderte Wärme nicht ohne umgeformt zu werden zu den meist tief im Körper gelegenen Eierstöcken und Hoden, er erfährt zum mindesten eine starke Abschwächung. In jedem Falle bedingt er aber eine wesentliche Umgestaltung im ganzen Stoffwechsel des beeinflußten Lebewesens und diese erst bewirkt die erkennbaren Veränderungen am Körper der Eltern und Nachkommen. Bei warmblütigen Tieren vollends wird jede Schwankung in der Luft- 
wärme, soweit sie sich innerhalb gewisser Grenzen bewegt, die das Leben noch ermöglichen, durch die dem Körper innewohnende Fähigkeit der Wärmeregulation mehr oder weniger vollkommen ausgeglichen. Bei hoher Außenwärme sind die Stoffwechselvorgänge andere, als bei niedriger Lufttemperatur. Die Veränderungen aber, die wir gleichzeitig an der Haut und am Haarkleid der behandelten Tiere auftreten sehen, sind niemals der Erfolg der unmittelbaren Wärmewirkung auf die Körperoberfläche, sondern erst der Erfolg der Antwort des Gesamtkörpers auf den äußeren Reiz; und von ihr müssen die Keimzellen in gleicher Weise wie die Körperzellen betroffen werden. Haben doch die Untersuchungen von Congdon (1912) gezeigt, wie hoch das Wärmeausgleichvermögen bei den Süugetieren, wie groß also die Anpassungsfähigkeit des Körpers auf äußere Einflüsse ist.

Semon zieht nun aus der von Congdon (1912) ermittelten Tatsache, daß bei Hausmaus und Wanderratte einer Erhöhung der Luftwärme um 10 Grad nur eine Erhöhung der Körperwärme um ungefähr 1,5 Grad entspricht, den Schluß, daß der Wärmereiz um $85 \%$ abgeschwächt zu den Keimdrüsen gelange und deshalb an ihnen nicht die nämlichen Vèränderungen, wie an der Haut setzen könne. Diese Folgerung ist in ihrem zweiten Teil zweifellos falsch. Denn nicht die erhöhte oder erniedrigte Wärme an sich ist die Ursache für die Veränderungen an der Haut, den Keimdrüsen und den Nachkommen, sondern die veränderte Zusammensetzung des ganzen Körpers, die dieser infolge der Wärmeveränderung erfährt, ist für beide Erscheinungen verantwortlich zu machen. Wie ganz anders müssen die Stoffweehselvorgänge sich bei einer um 10 Grad verschiedenen Außenwärme abspielen, wenn sich trotzdem die Eigenwärme des Körpers nur um 1,5 Grad verändert!

Die Möglichkeit einer Parallelinduktion im bisherigen Sinne besteht also tatsächlich nicht, ein äußerer Reiz selbst kann niemals in völlig gleicher Weise auf die Körperoberfläche und die Keimdrüsen einwirken und kann deshalb auch niemals an beiden Organen vollkommen gleichsinnige Veränderungen setzen. Schon allein deshalb nicht, da ja der Reiz selbst die Veränderungen auch an den oberflächlich gelegenen Organen nicht bedingt, auch sie werden erst durch die Antwort des Gesamtkörpers auf den äußeren Reiz bewirkt.

Es kann auch heute nicht mehr bezweifelt werden, daß irgendwelche Umgestaltungen des Körpers Veränderungen an einzelnen Organen zur Folge haben können, ohne daß der übrige Organismus in nachweisbarer Weise beeinflußt wird. Ich erinnere nur an die verschiedene Ausbildung der Haut und des Haarkleides, die wir bei verschiedener Ernährung beobachten, ich verweise des weiteren auf 
die oben besprochenen Umgestaltungen im Farbkleid des Feuersalamanders, welche die Antwort auf einen die Netzhaut, also das Zentralnervensystem treffenden Reiz darstellen. Fraglich könnte es allerdings erscheinen, ob eine solche Veränderung des Gesamtkörper auch von Einfluß auf die Keimzellen sein kann. Allerdings nicht für den, der sich eingehend mit ihrem feineren Bau und ihrer Entwicklung beschäftigt hat. Denn die Keimdrüsen sind zweifellos die empfindlichsten Organe des ganzen Körpers, häufig genug stellen sie auch dann ihre Tätigkeit ein, wenn der Gesamtorganismus durch änßere Einflüsse getroffen wird, die alle übrigen Organe in keiner nachweisbaren Weise verändern. Schon Darwin hat auf diese Erscheinung aufmerksam gemacht und führte als Beleg für sie die bekannte Tatsache an, $\mathrm{da} B$ freilebende Tiere in der Gefangenschaft häufig nicht zur Fortpflanzung sehreiten. Ganz besonders treffe dies für den Elephanten $\mathrm{zu}^{1}$ ).

Eine ganze Reihe weiterer Beispiele für die hohe Empfindlichkeit der Keimdrüsen habe ich schon früher (1918) angegeben und auch in zahlreichen Versuchen gezëigt, daß selbst bei so hochgradig domestizierten Tieren, wie bei Haushühnern, eine ganz geringe Veränderung in der Umgebung genügt, um die Fortpflanzungstätigkeit zu unterbrechen. Der Stillstand in der Eiablage ist bedingt durch Rückbildungsvorgänge an den Eierstöcken (ich habe damals nur weibliche Hühner untersucht). Als Folge rein psychischer Beeinflussung, unter Ausschaltung aller anderen Bedingungen konnte ich also bei den Hühnern schwere, anatomisch nachweisbare Veränderungen an den Keimdrüsen feststellen. Schon dadurch war die Möglichkeit einer körperlichen Beeinflussung der Keimdrüsen bewiesen.

Es lag mir aber daran zu zeigen, daß auch das Licht, die Wärme und andere Reize anatomisch nachweisbare Veränderungen an den Keimdrüsen bewirken können, ohne sonst zu tiefgreifenden Umgestaltungen des Körpers zu führen. Ich wollte dabei hauptsächlich den Einwand Semons widerlegen, daß veränderte äußere Bedingungen zuerst Veränderungen an umschriebenen Stellen des Körpers setzen und daß diese dann erst auf die Keimdrüsen übertragen werden. Meine Versuche sollten nur dartun, daß alle Veränderungen in der Umgebung eines Lebewesens, gleichgültig welcher Art sie auch seien, die Keimdrüsen selbst, natürlich auf dem Wege über den Körper, beeinflussen können und so den Vorgang der körperlichen Gleich-

1) Inzwischen ist es allerdings gelungen, auch diesen bei entsprechender Pflege im Zoologischen Garten zur Fortpflanzung zu bringen, ein Umstand, der die Darwinsohen Angaben nicht widerlegt, sondern nur zeigt, daß eine Gewöhnung an die veränderten Bedingungen eintreten kann und daß dann die Schädigung und mit ihr die Störung in der Tätigkeit der Keimdrüsen fortfällt. 
beeinflussung wahrscheinlich machen. Auch sollten sie die Annahme widerlegen, daß äußere Reize wegen der schützenden Wirkung des Körpers nicht, oder nur in stark abgeschwächtem und deshalb unwirksamen Zustand auf die Keimzellen einwirken können. Die Lösung dieser Fragen erschien mir in Hinblick auf die Entwicklungsmechanik des Körpers von Bedeutung.

\section{Versuchsanordnung.}

Meine Versuche wurden im Frühjahr 1905 begonnen und seit dieser Zeit, allerdings mit langen Unterbrechungen, die hauptsäohlich durch den Krieg bedingt waren, fortgesetzt. Stets wurden Tritonen sowohl in Gefangenschaft gezüohtet, als auch im Freien beobachtet, und zwar die drei gewöhnlichen einheimischen Arten: Triton vulgaris, cristatus und alpestris. Die Versuchstiere stammten zum größten Teil aus der näheren und weiteren Umgebung von München, erst seit dem Jahre 1918 aus der Umgebung von Leipzig. Die überwiegende Mehrzahl der Beobachtungen, über die hier berichtet wird, wurden an Triton vulgaris ausgeführt, und zwar einesteils deshalb, weil diese Art wenigstens im Frühjahr jederzeit ohne Schwierigkeit in großer Menge zu beschaffen ist und auch leicht im Freien beobachtet werden kann, anderenteils aber auch deshalb, weil bei ihr die Eierstöcke dank der geringen Größe die histologische Untersuchung recht wesentlich erleichtern.

Die eigentlichen Versuche wurden selbstverständlich an Tieren ausgeführt, die in Aquarien gehalten wurden; zur Nachprüfung verwendete ich nur Molche, die ganz frisch gefangen und sofort konserviert worden waren.

Während und vor der Fortpflanzungszeit hielt ich die Molche in Glasaquarien von 15-20 Liter Inhalt. Behälter, bei denen Eisenteile mit dem Wasser in Berührung kommen, sind ungeeignet. Der Boden der Gefäße wurde mit Flußsand bestreut und dann mit einer Schlammachicht bedeckt, zur Bepflanzung verwendete ich ausschließlich die gewöhnliche Wasserpest (Elodea canadensis). Sie wird gerne zur Anheftung des Laiches benutzt und bietet den großen Vorteil, daB jedes Ei leicht an dem zu seiner Befestigung umgeknickten Blatt erkannt werden kann. Bei einmaliger täglicher Durohsicht gelingt es so stets, die Zahl der abgelegten Eier festzustellen, bzw. zu ermitteln, ob überhaupt eine Eiablage stattfindet. Die friseh gelegten Eier werden, wenn nötig, jeweils mit der Sohere entfernt. In jedem Behälter befindet sich eine kleine, moosbedeokte Korkinsel, die das Verlassen des Wassers jederzeit ermöglicht. Uber die Fütterung werde ich weiter unten noch ausführlich berichten. Die eben beschriebenen Aquarien bezeichne ich der Einfachheit halber als Normalbehältier.

Außerhalb der Laichzeit wurden die Molche in feuchten Terrarien, deren Boden mit Moos und Steinen belegt war, gehalten. Ein großes, mit Wasserpflanzen dicht besetztes Gefäß aus Glas oder Ton ermöglicht jederzeit die Rückkehr ins Wasser.

Zum Zweck der Versuche wurde der Wechsel in den äußeren Bedingungen erstens durch die verschiedene Einrichtung der Behälter geschaffen, zweitens durch die Aufstellung in verschiedenen, teils nach Norden, teils nach Süden gelegenen Räumen. Diese bedingt auch verschiedene Wärme des Wassers. Soweit dies notwendig war, wurden die Aquarien mittels der gewöhnlichen Heizvorrichtungen gewärnt, nach der Kriegszeit wegen des Mangels an Brennstoffen durch Eintauchen einer roten elektrisohen Kohlenfadenbirne in das 
Wasser; allerdings bietet diese letzte Art der Beheizung gewisse Nachteile, nämlich insofern, als die Wärmewirkung stets mit einer Lichtwirkung verbunden ist. Um diese auszuschalten, umgab ich die Lampe mit einem Holzkästchen; Blech darf auch zu diesem Zweck nicht verwendet werden.

In der Regel wurden die Behälter nur mit wenigen Tieren besetzt, in der Fortpflanzungszeit kamen auf 5 Liter Wasser höchstens ein Paar Molche. In vielen Fällen, besonders natürlich dann, wenn die Zahl der abgelegten Fier ermittelt werden sollte, wurden die Paare einzeln gehalten. Kein Versuch wurde mit weniger als drei Weibchen und Männchen ausgeführt, die meisten mit wesentlich mehr Tieren. War die Eiablage vollständig zum Stillstand gekommen, so wurden der Einfachheit halber, falls die Versuchsanordnung dies gestattete, auch mehr als drei Weibchen in einem Behälter zusammengebracht, natürlich nur solche, die in gleicher Weise beeinflußt waren.

Eine Sonderung der Weibchen von den Männchen erfolgte bei den Versuchen stets erst nach der Laichzeit, also frühestens Ende Juni. Ich konnte jedoch beobachten, daß eine vorübergehende Entfernung der männlichen Tiere ohne jeden Einfluß auf den Ablauf der Fortpflanzungstätigkeit bei den Weibchen bleibt. Selbst 3-4 Wochen nach der Entfernung des Männchens sind die Eier häufig noch befruchtet, offenbar werden eben genügend Spermatozoen in den Samenbehältern aufgespeichert. Ich vermied jedoch eine solche Absonderung der Weibchen bei den eigentlichen Versuchen, es wäre ja immerhin möglich, daß der Ausfall der geschlechtlichen Erregung doch einen gewissen Einfluß auf die Fiablage ausïbt. Groß könnte dieser allerdings nioht sein, legen doch selbst junge Weibchen, wenn die sonstigen Bedingungen günstig sind, in der ersten Laichperiode, ohne jemals mit einem Männchen in Berührung gekommen zu sein, rejchlich sogenannten Notlaich ab, der dann natürlich nicht entwicklungsfähig ist.

$\mathrm{Zu}$ den eigentlichen Versuchen wurden auch stets nur vollkommen ausgewachsene Molche verwendet, die im gleichen Jahre frisch gefangen worden waren. Bei Tieren, die längere Zeit auch unter den besten und anscheinend vollkommen natïrlichen Bedingungen gehalten werden, ist nämlich die Zahl der abgelegten Eier meist eine wesentlich geringere als bei frisch gefangenen, sie nimmt fortschreitend von Jahr zu Jahr ab. Es mag sein, daß es sioh dabei um eine physiologische Folge des Alterns handelt, schen wir doch auch sonst allenthalben im Tierreich die Fruchtbarkeit mit zunehmendem Alter zurückgehen. Besonders deutlich läßt sich dies ja bei Haushühnern feststellen. Jedenfalls mußte, dieser Umstand, um Fehlerquellen zu vermeiden, ausgeschaltet werden, besonders da die Abnahme der Eierzahl mit entsprechenden Veränderungen der Ovarien einhergeht.

Die frischgefangenen Molche gewöhnen sich sehr rasch an das Gefangenleben und setzen die schon begonnene Fortpflanzungstätigkeit fort, wenn die zu ihrer Unterbringung verwendeten Behälter die entsprechende, oben besprochene Einrichtung besitzen. Nach dem Fang wurde jedes einzelne Weibchen einer Sonderbeobachtung unterzogen, ob es tatsächlich in der gewöhnlichen Art Laich ablegte, und erst wenn dies der Fall war, zu den eigentlichen Versuchen verwendet.

Die zur histologischen Untersuchung bestimmten Tiere wurden in Chloroformdämpfen getötet und von der Bauchseite her eröffnet. Dann wurde zunächst der Darm entfernt, hierauf beide Eierstöcke im Zusammenhang mit dem Fettkörper mittels Pinzette und Schere herausgenommen und im ganzen fixiert.

Abgesehen von den Eicrstöcken, die zum Zweck einer später noch vorzunehmenden Untersuchung, bei der Kern und Plasmastrukturen eingehend be- 
obachtet werden sollen, anderweitig behandelt wurden, fixierte ich alle Ovarien in Sublimateisessig (konzentrierte wässerige Sublimatlösung $+5 \%$ Eisessig) und bettete nach Härtung in steigendem Alkohol in Paraffin von $52^{\circ}$ Schmelzpunkt ein:

Alle Ovarien wurden in Schnittserien von $10 \mu$ Dicke zerlegt, die Schnittrichtung verlief in der Längsrichtung des Körpers. Auf diese Weise erhielt ich von jedem Eierstock eine ganze Reihe von Längsschnitten, die mit denen anderer Ovarien verglichen werden konnten und auch im mikroskopischen Bild noch einen Rückschluß auf die Größe der ganzen Keimdrüse ermöglichten. Gefärbt wurde in der Hauptsache mit Delafieldschem Hämatoxylin und Erythrosin.

Nach solchen Längsschnitten sind auch die Abbildungen auf Tafel I und II hergestellt, und zwar durchweg bei $10^{1} / 2$ facher Vergrößerung; sie können also unmittelbar miteinander verglichen werden und geben so ein Bild von den stattgehabten Veränderungen. Alle Abbildungen wurden von Frl. Berta Neresheimer in München ausgeführt, der ich auch an dieser Stelle für die vorzügliche, naturgetreue Wiedergabe der Zeichnungen meinen besten Dank ausspreche.

Desgleichen bin ich der Bayrischen Akademie der Wissenschaften in München zu großem Dank verpflichtet: sie hat mich durch die mehrmalige Verleihung eines Stipendiums aus der Samson-Stiftung zur Erforschung der Moral in die Lage gesetzt, meine begonnenen Versuche auch unter den jetzigen ungünstigen Verhältnissen zu Ende zu führen.

\section{Der gewöhnliche Verlauf der Fortpflanzungstätigkeit.}

Da eine Benrteilung der im Versuch erzielten Eierstocksveränderungen nur auf Grund einer Gegenüberstellung mit den régelmäßigen Entwicklungs- und Rückbildungsvorgängen möglich ist, die sich an den weiblichen Keimdrüsen im Verlaufe eines Jahres abspielen, so will ich mit ihrer Beschreibung beginnen.

Im Freien spielt sich das Leben von Triton vulgaris - nur diese Art wurde zu der Mehrzahl der Versuche verwendet - im großen und ganzen folgendermaßen $a b$ : Nach der Metamorphose im Herbst verläßt das junge, kaum $4 \mathrm{~cm}$ lange Tier das Wasser und führt dann ein verborgenes Landleben unter Steinen und in alten Baumstümpfen, teilweise weit entfernt von jeder Wasseransammlung.

Erst im Alter von fast 2 Jahren suchen die vollkommen geschlechtsreifen Molche das Wasser wieder auf und zwar stets im Frühjahr, unmittelbar nach der Schneeschmelze. Sie besitzen dann eine Körperlänge von 6-8 cm und ein Gewicht von 1,3-1,5 Gramm. Fälle von Neotenie sind im Freileben äuBerst selten, auch in der Gefangenschaft gelang es mir nie Triton vulgaris länger als I Jahr nach dem Ausschlüpfen im Larvenzustand zu erhalten. Bei $T$. alpestris dagegen ist Neotenie ein verhältnismäBig häufiges Vorkommnis : hier schreitet die Wasserform in besonderen Fällen auch zur Fortpflanzung. T. cristatus verhält sich wie $T$. vulgaris, doch suchen hier die jungen, einjährigen, noch nicht geschlechtsreifen Tiere häufig im Frühjahr zur Zeit der 
Fortpflanzung das Wasser auf und verbleiben mehrere Wochen, ja Monate in ihm.

Die eben besprochenen Tatsachen erschweren die Beobachtung bei den anderen Molcharten, nur bei $T$. vulgaris sind wir sicher, im Frühjahr im Wasser ausschließlich fortpflanzungsfähige, ausgewachsene Tiere zu finden.

Die Zeit, in der die Molche das Wasser aufsuchen, ist je nach der herrschenden Witterung, auch nach Gegenden verschieden. Gewöhnlich geschieht es unmittelbar nach der Schneeschmelze, also im März oder April, 3-4 Wochen später sind die Tiere, vorausgesetzt daß keine neuen Fröste eintreten, vollbrünstig, die Eiablage beginnt und dauert 4-8 Wochen, manchmal auch noch länger an. Dann verlassen die Molche abermals das Wasser um bis zum nächsten Frühjahr wieder auf dem Lande zu leben.

Die Zahl der von einem Weibchen in einem Frühjahr abgelegten Eier schwankt innerhalb weiter Grenzen, sie beträgt im allgemeinen 200-300, kann jedoch bis auf 600 steigen, häufig auch unter 200 bleiben. Zeller (erwähnt nach Krefft 1907) gibt als Höchstzahl der von einem Triton-Weibchen in einem Frühjahr gelegten Eier 720 an. Die Eimenge ist vollkommen abhängig von den äußeren Bedingungen unter denen das Tier lebt. Auch die tägliche Menge schwankt recht beträchtlich, sie kann bis zu 15 Eiern und darüber betragen, beläuft sich manchmal aber auch nur auf 5 und noch weniger.

Auch Krefft (1907) gibt ähnliche Zahlen an, desgleichen gelangte Wolterstorff, wie er mir brieflich in liebenswürdigster Weise mitteilte, zu gleichen Zahlenergebnissen. Dem gegenüber erscheint also die Feststellung von Dürigen (1897), die Zahl der von einem Molchweibchen gezeitigten Eier betrage nach seiner Wahrnehmung 7 bis 24 Stück, als falsch. Dürigen hat offenbar seine Beobachtungen an frisch gefangenen Tieren ausgeführt, die lediglich ihre Bauchhöhlen und Eileitereier absetzten, dann aber wegen ungeeigneter Pflege die Fortpflanzungstätigkeit einstellten.

In der eben geschilderten Art und Weise vollzieht sich das Leben der Molche auch in der Gefangenschaft, jedoch nur dann, wenn sie unter Verhältnissen gehalten werden, die denen des Freilebens gleichkommen. Die Tiere müssen nach Beendigung der Eiablage Gelegenheit haben das Wasser zu verlassen und auf dem Lande zu leben. Im Wasser verlieren sie nach der Laichzeit fast stets die Freßlust, magern stark $a b$ und gehen spätestens im Herbst oder Winter zugrunde. Nur vereinzelte lassen sich an dauernden Wasseraufenthalt gewöhnen. Während des Landlebens muß die Ernährung reichlich sein, die Molche dürfen im Sommer nicht zu großer Hitze ausgesetzt werden und vor allem niemals für längere Zeit den prallen Sonnen- 
strahlen. Während des Winters müssen die Molche im ungeheizten Raum gehalten und nicht gefüttert werden. Sie versinken dann ebenso wie im Freien in den Winterschlaf. Im Frühjahr muß dann Gelegenheit geboten werden, das Wasser wieder aufzusuchen, die Fütterung muB anfangs spärlich sein und erst beim Eintritt wärmerer Witterung reichlicher werden.

Werden alle diese Bedingungen eingehalten, so gelingt es, wie schon gesagt, leicht die einheimischen Molcharten in der Gefangenschaft jahrelang gesund zu halten und auch zur Fortpflanzung zu bringen. Ebenso leicht gelingt es bei $T$. vulgaris, jedoch nur bei diesem, die Jungen aufzuziehen und auch sie wieder zur Fortpflanzung zu bringen. Uber $T$. cristatus besitze ich hinsichtlich der Aufzucht der Jungen keine Erfahrungen, wohl aber über $T$. alpestris. Bei ihm ist es mir niemals gelungen die Jungen wieder zur Fortpflanzung zu bringen, meine Erfahrungen decken sich, auch hier mit denen von Wolterstorff (1920),

Für alle diejenigen, die meine Versuche nachprüfen und erweitern wollen, seien hier noch kurz die hauptsächlichsten Fehler aufgezählt, die gewöhnlich bei der Haltung der Tritonen gemacht werden. Die meisten Untersucher betrachten die Molche als reine Wassertiere und geben ihnen dementsprechend keine Gelegenheit, nach Beendigung der Eiablage das Wasser zu verlassen. Bei dieser Behandlung gehen die Molche gewöhnlich ein, wenigstens soweit es sich um T. vulgaris handelt, cristatus und alpestris lassen sich leichter ans Wasserleben gewöhnen, schreiten dann aber im zweiten Jahr nur sohwer zur Fortpflanzung.

Ein weiterer Hauptfehler ist die Uberwinterung der Molche im geheizten Zimmer, also die Unterdrückung des Wintersehlafes. Die Molohe suchen dann gewöhnlich im Herbst, also dann, wenn sie sich im Freien zur Ruhe begeben, das Wasser wieder auf und schreiten in seltenen Ausnahmefüllen schon im November oder Dezember zur Fortpflanzung. Gewöhnlich aber verbleiben sie ohne Geschlechtstrieb zu äußern im Wasser und entwickeln nur ein hohes Nahrungsbedürfnis. Wird diesem nachgegeben, so mästen sich die Tiere oft in erstaunlicher Weise, sie werden dick tnd fett und verlassen im Frühjahr, gerado wenn der Züchter auf den Eintritt der Brunst wartet, das Wasser; manchmal verbleiben sie auch in ihm, niemals aber schreiten sie zur Fortpflanzung.

Für den günstigen Ausfall der Zuchtversuche ist also die Hauptbedingung eine möglichst genaue Anpassung der im Terrarium obwaltenden Verhälnisse an die im Freien herrsehenden Umstände. Im Sommer und Herbst Wärme und reichliche Fütterung, im Winter Kälte, natürlich nicht so stark, daß die Tiere erfrieren, und Hunger. Auf Einzelheiten werde ich bei Besprechung der Befunde noch zurückkommen.

Das eigentliche Leben der Tritonen spielt sich in der Ümgebung von München in der Zeit von Mitte April bis Mitte September ab, in der Umgebung von Leipzig in der Zeit von Mitte März bis Ende September. In der übrigen Zeit verharren die Molche im Winterschlaf, er währt 5-7 Monate und während seiner Dauer kommen die Lebensvorgänge fast vollkommen zum Stillstand. 


\section{Die normalen Jahresveränderungen des Eierstockes.}

Am Eierstock der ausgewachsenen Molche - auf die bei jugendlichen Tieren obwaltenden Verhältnisse will ich hier nicht eingehen spielen sich im Verlaufe eines Jahres tiefgreifende Veränderungen ab. Mit ihrer Beschreibung will ich nunmehr beginnen, da ihre Kenntnis die Grundlage für alle weiteren Beobachtungen bildet. Ich werde dabei jedoch zunächst nur die makroskopisch, beziehungsweise bei schwacher Vergrößerung erkennbaren Vorgänge besprechen, die feineren Strukturverhältnisse am Keimbläschen, den Chromosomen und Nukleolen sowie am Dotter jedoch größtenteils unberücksịchtigt lassen.

Nach Beendigung des Winterschlafes, also im April, frühestens im März, dann, wenn die Tiere im Frühjahr das Wasser wieder aufsuchen, besitzt der Eierstock des geschlechtsreifen Weibchens eine Länge von ungefähr $15 \mathrm{~mm}$ bei einer Dicke von $4-6 \mathrm{~mm}$ (Abb. 1 ). Er besteht aus $70-100$ gelben, großen Follikeln von $0,5-1,3 \mathrm{~mm}$ Durchmesser, ihr Plasmaleib ist von großen Dotterschollen voll gepfropft. Daneben finden sich massenhaft kleinere Follikel in allen Größen bis herab zu den kleinsten Oocyten. In ihrem Plasmaleib hat noch keine Dotteransammlung stattgefunden, sie unterscheiden sich, wie auch aus den Abbildungen deutlich zu erkennen ist schon durch die chemische Reaktion grundlegend von den großen Follikeln. Diese erscheinen nämlich bei der angewendeten Doppelfärbung mit Hämatoxylin-Erythrosin rot, da sich die Dotterschollen mit dem sauren Erythrosin tränken, die kleineren Follikel aber sind bläulich, ihre Plasmastrukturen nehmen das alkalische Hämatoxylin auf.

Aus dem ganzen Bau des Eierstockes läßt sich erkennen, daß die Menge der großen Follikel dauernd vermehrt wird, dadurch $\mathrm{da} ß$ sich in den kleinen gelber Dotter ansammelt. Eine zahlenmäßige Bestätigung dieser. Beobachtung konnte ich jedoch nicht erbringen.

Wie in dem Eierstock jedes Tieres. so findet auch in dem der Molche dauernd physiologischerweise ein allerdings nur sehr geringer Untergang einzelner Follikel statt. Die atretischen Eierstockseier sind an ihrer leuchtend orangegelben Farbe leicht sohon mit bloßem Auge zu erkennen. Sie unterscheiden sich dadurch erheblich von den normalen Follikeln. An ihrer Oberfläche ist ein dichtes Blutgefäßnetz zu erkennen, während sich gewöhnlich hier nur einzelne feine Kapillaren finden. Während des Fortschreitens der Rückbildung färbt sich der Follikel dunkler und dunkler und erscheint schließlich nur noch als schwarzbrauner Knoten, der dann im Bindegewebe untergeht. Während der Atresie sammelt sich eine erhebliche Menge von Pigment an, das in groben Schollen mit jeder Konservierungsmethode darzustellen ist. Schon makroskopisch sind diese schwarzen Punkte 
deutlich auf dem Eierstock zu erkennen, sie sind auch auf Abb. 1, allerdings in sehr stark zurückgebildetem Zustand zu sehen.

Wichtig für die Beurteilung der Befunde ist noch das Verhalten des Fettkörpers. Er liegt bei Eierstöcken vom eben geschilderten Bau stets median und etwas dorsalwärts vom Ovar, besitzt die gleiche Länge wie dieses, jedoch nur ein Drittel bis ein Viertel seiner Dicke. Auch er erfährt im Frühling keine wesentlichen Umgestaltungen.

Mit dem Beginn der Laichzeit ändert sich das Bild des Eierstockes nicht wesentlich (Abb.2), man erkennt nur während der Eiablage, bei eingehender Untersuchung schon makroskopisch stets auch einige Follikel, in denen das Keimbläschen seine gewöhnliche zentrale Lage verlassen hat und gegen die Oberfläche zu wandert (Abb, 2, rechts). Die Anwesenheit solcher Follikel, die einige Stunden vor dem Platzen stehen, ist, wie schon Born (1894) angibt, stets ein untrügliches Zeichen dafür, daß bei dem betreffenden Tier die Eiablage noch im Gange ist. Schon wenige Stunden nach dem Einsetzen irgend einer Schädigung; die zur Unterbrechung der Eiablage führt, lassen sich keine solchen reifen Eier mehr im Eierstock nachweisen. Born ist nun der Ansicht, daß die Reifung der Eier in Schüben erfolge, er kannte ja noch nicht den Einfluß der äuBeren Bedingungen, fand aber auch im Freien häufig während der Laichzeit Molche, in deren Ovarien keine reifen Eier aufzufinden waren. Ich werde im folgenden zeigen, daß unter günstigen Verhältnissen die Eiablage der Molche fortlaufend erfolgt und daß jede Untorbrechung durch äußere Einflüsse bedingt ist.

Der Fettkörper verändert sich während der Laichzeit nicht, er vergrößert sich erst gegen ihr Ende zu etwas.

Bei Molchen die während der Fortpflanzungszeit getötet werden, finden sich stets einige, meist 2-8 Eier frei in der Bauchhöle, auBerdem in jedem Eileiter 10-15, selten mehr Eier in ziemlich regelmäBigen Abständen. Im Endteil der Tube, dem Uterus, der sich hinsichtlich seines histologischen Baues wie ich früher (1920a) nachgewiesen habe, nicht wesentlich von den kranialen Abschnitten unterscheidet finden sich gleichfalls $1-2$, höchstens 3 Eier, eine Stauung der Eier, die eine stärkere Auftreibung bedingt, findet für gewöhnlich nicht in ihm statt.

Die Laichzeit dauert im allgemeinen 2-3 Monate, während dessen sind anfangs keine wesentlichen Veränderungen am Eierstock zu bemerken. Weder nimmt die Zahl der atretischen Follikel zu, noch auch erfahren die großen reifen Follikel eine beträchtliche Verminderung. Fortwährend wachsen kleine Eierstockseier durch Dotteransammlung neu heran und ergänzen so den gesetzten Ausfall. Die geplatzten Hüllen bilden sich sehr rasch zurück, es kommt also nicht 
zur Ausbildung eines größeren gelben Körpers wie bei den Säugetieren.

Erst gegen Ende der Laichzeit von Mitte Mai ab, verringert sich die Zahl der großen Follikel etwas (Abb.3), ohne daß aber eine größere Zahl von ihnen dex Atresie verfällt. Es lassen sich dann im Eierstock nur noch $60^{\circ}-40$, selten weniger gelbe Eier nachweisen. Gleichzeitig verlangsamt sich das Wachstum der kleinen Follikel, die Anhäufung des gelben Dotters in ihnen kommt zum Stillstand. Der Eierstock weist dann eine große Anzahl kleiner Follikel, ohne jeden gelben Dotter, neben zahlreichen großen Follikeln auf, die Zwischenformen fehlen fast vollkommen.

Alle diese Vorgänge schreiten dauernd fort. Wenn schlieblich im Juni früher oder später, je nach den Witterungsverhältnissen, die Brunst ihr Ende erreicht, besteht der Eierstock nur noch aus 20 bis 40 großen Follikeln von $0,8-1,3 \mathrm{~mm}$ Durchmesser, daneben finden sich massenhaft kleinere, ohne jede gelbe Dotteranhäufung, und nur äußerst wenig $Z$ wischenformen. Die Zahl der atretischen ist manchmal in geringem Maße vermehrt, häufig fehlen sie jedoch vollkommen. So zeigt Abb. 4 den Eierstock eines Tieres, nach Ablage von fast 600, vielleicht sogar mehr Eiern, da nur die in der Gefangenschaft in der Zeit vom 24. April bis zum 1. Juni abgesetaten gezählt wurden. Er enthält verschwindend wenig zurückgebildete Follikel.

Durch welchen Umstand die Eiablage beendet wird, vermag ich nicht anzugeben. Aller Wahrscheinlichkeit nach spielen hier stets äußere Ursachen, wie die höhere Wasserwärme und Ähnliches eine Rolle. Auf keinen Fall wird die Laichzeit durch die Erschöpfung der Eierstocke beendet, also dadurch, daß alle großen Follikel ausgestoßen sind, die Ursachen können also nicht im Ovar selbst begründet sein. Während der letzten Wochen der Laichzeit vergrößert sich, wie schon erwähnt, der Fettkörper meistens in geringem Maße, niemals übertrifft er jedoch den Eierstock hinsichtlich seiner Ausdehnung. Dieser besitzt dann eine Länge von 10-12 $\mathrm{mm}$ bei einer Dicke von 3-4 mm. T. vulgaris und gewöhnlich auch die beiden anderen Arten verlassen nunmehr das Wasser.

Während des Landlebens gehen weitere wichtige Veränderungen des Eierstockes vor sich: durch Oogonienteilungen, die während der Laichzeit nur in spärlichem Maße stattfanden, werden reichlich neue Oooyten gebildet, die klcinen Follikel wachsen rasch heran und bald besitzt der Eierstock wieder den nämlichen Bau wie im Frühjahr vor der Eiablage (Abb. 1). Ich vermag jedoch nicht anzugeben, ob die nicht abgelegten reifen Follikel, so wie dies bei den Vögeln der Fall ist, jeweils nach der Laichzeit durchweg zurückgebildet werden, oder aber bis zum nächsten Frühjahr im Ruhezustand verharren. Auf 
jeden Fall erfährt, soweit ich dies beurteilen kann, die Zahl der atretischen Follikel nach der Eiablage eine unbedeutende Vermehrung. Der Fettkörper vergrößert sich bis zum Herbst in geringem MaBe.

Aus der vorhergehenden Beschreibung ist zu ersehen, daß der Eierstock der Molche im Verlaufe eines Jahres, wenigstens wenn wir das Gesamtbild im Auge haben, sich nicht sehr erheblich umgestaltet. Die Entwicklungsvorgänge spielen sich an ihm mehr gleichmäBig, fortlaufend und nicht schubweise $a b$, obgleich bei genauer Beobachtung während der verschiedenen Jahreszeiten doch Unterschiede im Verhalten der Oocyten festzustellen sind. In jedem Falle unterscheidet sich der Eierstock hinsichtlich seines Jahresverhaltens grundlegend von dem der Säugetiere und Vögel mit periodischer Brunst, der weit größeren Unterschieden hinsichtlich seines Baues unterworfen ist.

In ganz gleicher Weise wie eben geschildert gestaltet sich auch das Leben und dementsprechend auch die Veränderungen an den Eierstöcken bei Molchen, die in der Gefangenschaft unter Verhältnissen gehalten werden, die denen des Freilebens gleichkommen. Im allgemeinen sind ja die Molche nicht anspruchsvoll, sie verlangen nur, besonders während der Brunst reichliche Ernährung und entsprechend eingerichtete Behälter. Dann schreiten sic leicht zur Fortpflanzung und legen reichlich Eier ab. Die Eierstöcke zoigen dann auch den nämlichen Bau wie bei freilebenden Tieren, als Beleg dafür diene Abb. 4, sie zeigt das Ovar eines Molches, der längere Zeit in Gefangenschaft gelaicht hatte. Es unterscheidet sich hinsichtlich seines Baues nicht von den Eierstöcken einiger am gleichen Tage frischgefangenen Tiere.

Von besonderer Wichtigkeit. für die im folgenden beschriebenen Versuche ist auch noch der Umstand, daß alle Tritonenweibchen im gleichen Zeitpunkt stets den gleichen Ausbildungszustand der Eierstöcke zeigen. Die Jahresschwankungen verlaufen also bei Tieren der nämlichen Gegend vollkommen gleichsinnig. Rückbildungsvorgänge stärkeren Grades, wie sie im folgenden beschrieben werden, die nicht nur einzelne Follikel, sondern den ganzen Eierstock betreffen, fand ich im Freien nie. Geringe Unterschiede im Bau der Ovarien liegen im Bereiche der individuellen Schwankungen und kommen für die Beurteilung der Befunde nicht in Frage. Zur Nachprüfung habe ich mehrmals an einem Tage 50-100 weibliche Molche aus versohiedenen Tümpeln der nämlichen Gegend getötet und dabei niemals erhebliche Abweichungen vom oben beschriebenen Verhalten feststellen können. Bekanntlich findet man ja, wie schon Bronn (1873), Leydig (1867) und andere angeben, besonders im Hochsommer die Molche oft stundenweit von jeglicher Wasseransammlung entfernt, aber auch sie zeigen stets den gewöhnlichen Bau der Eierstöcke. 
Diese Tatsache war für mich von allergrößter Wichtigkeit, ich. konnte also stets ermitteln, wie die Eierstöcke meiner Versuchstiere am Tage des Versuchsbeginnes beschaffen waren und danach die stattgehabten Rückbildungen beurteilen.

\section{Die Versuche.}

Bei Innehaltung der oben angegebenen Richtlinien gelingt die Zucht der Molche in der Gefangenschaft leicht. Sehr häufig sehen wir aber aus anscheinend unerklärlichen Gründen die Brunst ganz ausbleiben oder frühzeitig zum Stillstand kommen. Dieser Fall tritt stets dann ein, wenn die äußeren VerhäItnisse, unter denen die Tiere gehalten werden, stärker von denen des Freilebens abweichen. Am sinnfälligsten und raschesten zu erkennen sind solehe Fehler natürlich während der Laichzeit, wo der Stillstand der Eiablage deutlich auf die Störung hinweist. Nach meinen Versuchen an Haushühnern (1918) war es nun äußerst wahrscheinlich, daß alle diese äußeren Veränderungen ihrerseits wieder von Veränderungen der Keimdrïsen begleitet, beziehungsweise durch sie bedingt sein mußten und es galt deshalb hauptsächlich die Art der Umgestaltungen festzustellen und gleichzeitig zu ermitteln, durch welche Einflüsse die fraglichen Erscheinungen bedingt sein sollten. Es lag mir also daran, die einzelnen Veränderungen in der Umgebung gegeneinander abzugrenzen und auf ihre Wirksamkeit zu prüfen.

Im ganzen kamen nur vier Faktoren in Frage, durch die die Fortpflanzungstätigkeit beeinflußt werden konnte: nämlich die Wasserwärme, die Ernährung, die Beleuchtung und schließlich ganz allgemein die Beschaffenheit des Aufenthaltsortes. DaB diese letzte von ausschlaggebender Bedeutung ist, hatte ich ja schon in meinen Hühnerversuchen nachgewiesen und gleichzeitig gezeigt, daß auch die Ernährung auf die Tätigkeit der Eierstöcke und Hoden einen gewissen EinfluB ausuibt. Fraglich war nur, $o b$ auch Veränderungen in der umgebenden Wärme einen Einfluß ausüben konnten, obwohl auch dafür schon gewisse Beobachtungen vorliegen. Wissen wir doch gerade vom Menschen, daß durch Klimawechsel die Tätigkeit der Fierstöcke beeinträchtigt werden kann; es ist dabei allerdings fraglich, ob es sich nur um die Veränderungen in der Temperatur handelt. Völlig unbekannt ist bisher noch ein Einfluß des Lichtes auf die Keimdrüsen.

Jede der genannten vier Bedingungen konnte also als schädigende Ursache in Frage kommen, ihr Einfluß konnte vorübergehend oder aber von längerer Dauer sein. Von Bedeutung war vor allem noch der Zeitpunkt, in dem die Beeinflussung stattfinden sollte. Die Wirkung mußte verschieden sein, je nachdem die Tiere vor, während oder nach der Laichzeit behandelt wurden. Die letzte Versuchsanordnung, 
eine Beeinflussung ausschließlich nach Beendigung der Eiablage, also in der Zeit vom Juli bis zum Winter, habe ich nur selten ausgeführt, und zwar deshalb, weil sich der EinfluB einer solchen Behandlung, falls die gesetzten Schädigungen keine zu tiefgreifenden waren und die. Tiere wieder unter gewöhnliche Bedingungen kamen, stets sehr rasch wieder ausglich.

Gerade während des Sommers und Herbstes sind die Molohe äußerst widerstandsfähig gegen alle äußeren Schädigungen, sie vertragen in dieser Zeit selbst langes Fasten, ja sogar starke Trockenheit recht gut. Ich fand im Jahre 1919 nach sechswöchentlicher Abwesenheit bei meiner Rüokkehr nach Leipzig im September fast alle Molchterrarien größtenteils vertrocknet, sie waren während meines Fortseins nicht gegossen, geschweige denn mit Futtertieren versehen worden. Die Molche erschienen teilweise vollkommen ausgetrocknet, fast leblos, erholten sich aber bei geeigneter Pflege rasch und schritten nach dem Winterschlaf im nächsten Frühjahr in gewöhnlicher Weise zur Paarung. Auf die Sommer-Herbstversuche, soweit ich solche überhaupt ausführte, werde ich im folgenden nur noch ganz kurz zurückkommen.

Wichtig für die Beurteilung der Befunde ist dagegen eine Unterscheidung der Zeit vor und während der Eiablage, da die einzelnen Sohädigungen in diesen Abschnitten zum Teil ganz verschiedene Wirkungen haben.

Selbstverständlich wurde bei jedem Versuch nur der Einfluß einer einzigen Bedingung geprüft, die übrigen Lebensverhältnisse waren gleichzeitig vollkommen gewöhnlich, das heißt sie entsprachen denen, die im gleichen Zeitabschnitt im Freien herrsohten. Im ganzen führte ich acht Hauptversuchsreihen aus, mit der Besprechung der Ergebnisse will ich nunmehr beginnen. Dabei werde ich jedoch nur die hauptsächlichsten ermittelten Tateachen anführen und in Anbetracht der jetzigen hohen Papierkosten auf eine Veröffentlichung aller Versuchslisten verzichten.

\section{Der Einfluß der Umgebung.}

Zunäehst soll derjenige Einfluß besprochen werden, der nach meinen Erfahrungen die stärkste Wirkung auf den Ablauf der Gesehleohtstitigkeit ausübt, nämlich die Beschaffenheit des Aufenthaltsortes. In großen, gut bepflanzten Glasbehältern, deren Boden dick mit Sand belegt ist, erholen sich die Tiere meist rasch, innerhalb weniger Stunden von den Anstrengungen, die für sie der Fang und die Beförderung in die Arbeitsräume mit sich bringt. Besonders günstig erweist sich eine dicke Sohlammschicht als Bodenbelag, die es den Tieren ermöglicht, sich einzuwählen und so vor allzu starker Sonneneinwirkung zu sehützen oder bei Annüherung von Mensehen zu verbergen. Den nämlichen Zweek erfüllt allerdings auch eine sehr dichte Bepflanzung, sie kann sogar die Bodenschicht vollkommen überflüssig machon, erschwert aber die Beobachtung und macht vor allem eine genaue Uberwachung der Eiablage unmöglich.

Molohe, die während der Laichzeit gefangen werden, setzen in solchen Behältern die Eiablage unmittelbar fort, und zwar heften sie die Eier einzeln in der gewohnten Weise an Wasserpflanzen an. In der ersten Nacht ist die Ablage meist reichlich, 20 Stück, manchmal auch mehr von jedem Weibchen. Dies beruht wahrscheinlioh darauf, daß während der Beförderung vom Fangorte bis in die Anatomie, die stets 4-8 Stunden in Anspruch nahm, sich eine größere Menge von Eiern in den Eileitern staute, die sonst in der gleichen Zeit abgelegt worden wäre. Gewöhnlich ist dann die Eiablage einige Tage lang spärlich, nur 2-6 Stück täglich, sie steigt bei guter Pflege jedoch rasch wieder. 
Als ungünstiges Zeichen ist es stets zu betrachten, wenn die Molche mehrere Eier auf einmal an ein Blatt anheften oder gar ganze Laichschnüre auf den Boden des Behälters fallen lassen. Dies ist stets ein Beweis dafür, daß eine größere Anzahl von Eiern im Uterus gestaut wurde, offenbar weil die äußeren Verhältnisse so ungünstig waren, daß sie die gewöhnliche Ablage verhinderten. Bei Molchen, die längere Zeit nach dem Fang in sehr ungeeigneten Behältern aufbewahrt werden, findet man bei der Eröffnung der Bauchhöhle oft beide Uteri vollgepfropft mit je 10-20 Eiern. Der Uterus ist infolgedessen stark spindelförmig erweitert, während der Eileiter vollkommen leer ist und auch keine Bauchhöhleneier nachgewiesen werden können. Desgleichen findet man bei solchen Tieren niemals Follikel, in denen das Keimbläschen oberflächlich liegt: alles Beweise dafür, daß duroh den Fang und die ungünstigen Aufenthaltsbedingungen sohon Veränderungen in der Tätigkeit und im Bau der Eierstöcke hervorgerufen werden. Molche, die größere Mengen von Laichschnüren ablegen, benötigen meist 8-10 Tage Aufenthaltes unter günstigen Verhältnissen, bis die Eiablage wieder voll in Gang kommt.

Versuch 1. Entfernung der Wasserpflanzen aus dem Wasser. Am 6. Mai 1910 fing ioh eine größere Anzahl von T. vulgaris in einem Tümpel in der Nähe Münchens. Die Eiablage hatte Ende April begonnen. Die Tiere werden zu je drei Paaren in Normalbehälter gebracht und legen in der Nacht vom 6. - 7. Mai reichlioh Laich ab; bis zum 9. Mai geht die Eiablage in der gewohnten Weise vor sich. An diesem Tage werden sämtliche Pflanzen aus einem Teil der Behälter entfernt, ebenso alle Steine und auch die Schlammschicht, die den Tieren als Versteck dienen konnte. Am 10. Mai findet keine Eiablage statt, am 11. Mai wird in den veränderten Behältern reichlich Schnurlaich abgelegt, ebenso noch in der Nacht vom 11.-12. Mai. Von diesem Tage an kommt die Eiablage völlig zum Stillstand. Vom 28. Mai an verlassen die Tiere das Wasser und halten sich dann gröBtenteils auf der Korkinsel auf. Sie sehen bis zu diesem Zeitpunkt gesund und wohlgenährt aus, von da vermindert sich die Freßlust, die Tiere magern ab. Ein Teil von ihnen wird zum Zweok der histologischen Untersuchungen getötet, ein Teil in Terrarien gebracht, wo sie sich rasch erholen und gut überwintern. Die Utberlebenden schreiten im Jahre 1911 in gewöhnlicher Weise zur Fortpflanzung.

In anderen Versuohsreihen wurden die Wasserpflanzen durch Steine und Felsstïcke ersetzt; in diesem Falle geht die Eiablage weiter, kommt aber gewöhnlich früher zum Stillstand, als bei Molchen, die in bepflanzten Behältern gehalten werden. Vielfach verletzen sich dio Weibohen beim Anheften der Eier an den Steinkanten die Kloake, ein Umstand, der stets zur Beendigung der Eiablage führt.

Die Entfernung der Wasserpflanzen, bzw. aller Gegenstände, die Unterschlupf gewähren und das Anheften der Eier ermöglichen, hat also unmittelbar den Stillstand der Eiablage bedingt; auf die histologischen Veränderungen, die diesen Ausfall hervorrufen, werde ich gleich zu sprechen kommen.

Versuch 2. Entfernung der Bodenschicht aus den Behältern. Eine Anzahl von Molchen, die am 5. Mai 1918 in einem Tümpel in der Nähe Leipzigs gefangen wurden, werden zu je drei Paaren in Normalbehälter gebracht. Die Tiere laichen in gewohnter Weise weiter. Eine zweite Gruppe von Molehen aus dem nämlichen Fang wird unter sonst gleichen Bedingungen in Aquarien gebracht, in denen die Bodenschicht fehlt, die jedoch spärlich mit Wasserpflanzen besetzt sind. Die Tiere heften in der Nacht vom 5.-6. Mai reichlich, vom 6.-7. Mai wenig Laich an die Wasserpflanzen, einige von ihnen legen Schnurlaich ab. Vom 7. Mai ab kommt die Eiablage vollständig zum Stillstand, nur ein Weibchen von den 15 zum gleichen Versuch benützten laicht 
bis zum 14. Mai weiter. Ende Mai verlassen die Molche das Wasser, ein Teil wird getötet; die übrigen, in gewöhnliche Bedingungen gebracht, schreiten im Jahre 1919 in normaler Weise zur Fortpflanzung ${ }^{1}$ ).

Versuch 3. Aufenthalt in Behälern ohne Bodenbelag und ohne Wasserpflanzen. Eine Anzahl von Molohen des gleiohen Fanges wie die zu Versuch 2 benützten, vom 5. Mai 1918 werden in Aquarien gebracht, die keinerlei Einrichtungen enthalten. Die Weibchen legen durchweg am 6. und 7. Mai Notlaich ab, von da an nicht mehr. Schon am 20. Mai verlassen einzelne der Tiere das Wasser, die Mehrzahl Ende Mai. Ein Teil wird überwintert und schreitet im nächsten Jahre in der gewohnten Weise zur Fortpflanzung, nachdem der Aufenthaltsort entsprechend eingerichtet wurde.

Bei den bisher besprochenen Versuchen wurden also Molche während der Laichzeit in veränderte Umgebung gebracht. Als Folge davon kam bei allen Tieren die Eiablage unmittelbar zum Stillstand. Als Ursache für die Unterbrechung kommt ausschließlich die Veränderung in der Beschaffenheit des Aufenthaltsortes in Frage, die bei den Tieren offenbar das Gefühl des Unbehagens, der Angst auslöst. Andere Einflüsse seitens der Ernährung, der Wasserwärme und der Beleuchtung kommen nioht in Betracht. Auffallend ist dabei jedoch das Verhalten der Weibohen im Gegensatz zu dem der Männchen. Diese erweisen sich nämlich wesentlich widerstandsfähiger,-sie führen häufig noch 8-10 Tage nach dem Einsetzen der Schädigung in der gewohnten Weise ihre Liebesspiele aus, setzen auch Samenpakete ab, ohne jedoch bei den Weibchen auf eine Erwiderung ihrer Neigungen zu stoßen. Die weiblichen Tiere sind also wesentlich empfindlicher.

Die anatomische Untersuchung der Eierstöcke bei den beeinflußten Tieren zeitigte folgendes Ergebnis, und zwar bei Versuch $1-3$ in ganz gleicher Weise.

Schon 10-20 Stunden nach dem Einsetzen der Schädigung finden sich keine Bauchhöhleneier mehr, die Eileiter sind leer und nur die Uteri stark aufgetrieben, vollgepfropft mit $10-20$ Eiern.

Die Eierstöcke selbst lassen bei oberflächlioher Betrachtung noch keine Veränderungen erkennen, bei genauer Untersuchung bemerkt man jedoch auch mit freiem Auge oder bei LupenvergröBerung, daB schon jetzt Follikel mit peripher gelegenem Keimbläschen fehlen, nur ganz ausnahrusweise kann ein solcher noch nachgewiesen werden. Auf die eben besprochenen Tatsachen macht auch Born (1894) aufmerksam. Sie sind ein untrüglicher Beweis dafür, daß sehon durch die kurzdauernde Schädigung, wie sie ein mehrstündiger

1) Um versehiedenen Einxänden, die mir hauptsächlich von Aquarienliebhabern gemacht wurden, zu begegnen, will ich hier gleich betonen, daß sehr reichliche Bepflanzung, die den Tieren Unterschlupf gewährt und sie nicht zwingt, sich auf dem Boden der Behälter aufzuhalten, die Bodensehicht ersetzen kann und deshalb die Wirkung des Versuchs beeinträchtigt. Gerade bei der beschriebenen Anordnung tritt außerdem nicht allzuselten eine Gewöhnung an die veränderten Bedingungen ein, und zwar besonders dann, wenn die Molche ganz zu Anfang der Laichzeit, also im April, in die Behälter ohne Bodenschicht gebracht werden. Man kann dann häufig beobachten, daß anfangs zwar die Eiablage in der geschilderten Weise unterbrochen wird, nach 14 Tagen bis 3 Wochen aber wieder beginnt. So legte ein Weibchen, das am 8. April 1913 gefangen war, unter den geschilderten Verhältnissen bis zum 10. April 23 Eier ab, von da ab laichte das Tier nicht mehr, setzte jedoch seine Liebesspiele mit dem Männchen nooh fort. Am 28. April begann es von neuem zu laichen und legte ohne jede Unterbrechung bis zum 5. Juni über 400 Eier ab. Ich komme auf solche Fälle noch zurück. 
Aufenthalt in den Reisegefäßen darstellt, die Eierstöcke selbst beeinflußt und im Ablauf ihrer Tätigkeit gestört werden.

Nach längstens dreitägiger Beeinflussung ist aller Laich aus dem Uterus ausgestoßen, die Eileiter sind leer, Bauchhöhleneier fehlen. Dieser Befund ändert sich in der Folgezeit nicht mehr. Die Eierstöcke erscheinen äuberlich unverändert, reife Eier mit peripher gelegenem Keimbläschen sind nicht mehr nachzuweisen (Abb. 5). Die Zahl der atretischen Follikel ist nicht nachweisbar vermehrt, das Wachstum der kleinercn Follikel, das Heranreifen gröBerer Eier durch Ansammlung von gelbem Dotter kommt dagegen fast vollkommen zum Stillstand, bzw. es schreitet nur noch sehr langsam fort, anderenfalls müßte nach dem Stillstand der Eiablage die Menge der großen Follikel dauernd rasch zunehmen. Dies trifft jedoch nicht zu, sie bleibt vielmehr zunächst gleich und beträgt in jedem Eierstock etwa 70-100. Auf die feineren Veränderungen des Kernbaues, die schon in diesem Zustand deutlich zu erkennen sind, will ich hier nicht eingehen. Der Fettkörper ist zunächst noch vollkommen un. verändert.

Nach sechstägiger Beeinflussung ist das Bild im großen und ganzen noch das gleiche. Die Zahl der Follikel hat sich im ganzen nicht verändert. Die Zahl der großen Follikel ist gleich geblieben, es hat demnach kein erneutes Follikelwachstum stattgefunden. Auch die atretischen Follikel haben keine wesentliche Zunahme erfahren, doch bemerkt man an einigen der größten Eierstockseier neben bestimmten Veränderungen am Kern, die hauptsächlich in einem Zerfall der Chromosomen bestehen, - daß sich das oberflächliche Blutgefäßnetz vergrößert und erweitert. Gleichzeitig lockert sich der Bau des Dotters auf, die einzelnen Schollen liegen nicht mehr so dioht beieinander und an der Oberfläche unmittelbar unterhalb des Epithels sammeln sioh feine, dunkelbraune Pigmentkömer an. Sie verleihen dem ganzen Gebilde ein ockergelbes Aussehen und machen es so schon bei LupenvergröBerung, nach weiterem Fortschreiten sogar schon bei Betrachtung mit freiem Auge erkenntlich. Es handelt sich hier um die ersten Zeichen der beginnenden Follikelatresie. Auch bis zu diesem Zeitpunkt erleidet der Fettkörper noch keine Verïnderung.

Die eben beschriebenen Erscheinungen nehmen in der Folgezeit dauernd zu, bei einem Tier rascher, beim anderen langsamer. Hier lassen sich ziemlich erhebliche Verschiedenheiten feststellen, jedoch nur hinsichtlich der Geschwindigkeit, mit der sich die Rückbildungsvorgänge abspielen, bzw. über den ganzen Eierstock ausbreiten.

Schon nach 12 tägiger Beeinflussung zeigen gewöhnlich alle großen Follikel von über $1 \mathrm{~mm}$ Durchmesser mehr oder weniger deutliche Zeichen der Rückbildung (Abb.6). Ihr Kern ist vollkommen zerfallen oder liegt als unregelmäBig gestaltetes, homogenes Gebilde im Plasmaleib, die Dotterschollen sind klein und sehr locker gelagert, das Epithel ist verdickt, das oberflächliche Blutgefäßnetz weit und dicht. Die Pigmentkörner unterhalb der Epithelschicht vermehren sich dauernd, die einzelnen Körner nehmen an Größe und Zahl zu. Schon bei Betrachtung mit freiem Auge zeigt der Eierstock jetzt ganz verändertes Aussehen: die meisten großen Follikel sind ockergelb bis schmutzigbraun, die Zahl der weiter zurückgebildeten, dunkelbraun bis schwärzlich gefärbten ist beträohtlich vermehrt. Dabei hat die Gesamtgrüße des Eierstockes abgenommen. An den kleineren Follikeln lassen sich dagegen keine Verändeänderungen feststellen und dauernd findet auch jetzt noch ein langsames Heranreifen never Follikel statt. Immer begegnet man auch noch vereinzelten Oogonienteilungen. Der Fettkörper bleibt noch immer unverändert.

Im eben beschriebenen Zustand verharrt nun der Eierstock längere Zeit, ohne daß sich sehr erhebliche Veränderungen an ihm feststellen lassen. Doch 
vermehrt sich die Zahl der zugrunde gehenden Follikel fortwährend, ihre Rückbildung schreitet aber nur äuBerst langsam vor. Gleichzeitig wachsen noeh immer vereinzelte kleine Follikel heran, in ihnen sammelt sich gelber Dotter an. Hand in Hand spielen sich also zwei ganz verschiedene Vorgänge in den Eierstöcken $a b$ : Rückbildung und Wachstum von Follikeln, und auf Grund dieser Tatsache erleidet das ganze Organ keine wesentliche Verkleinerung. Dagegen bildet sich der Fettkörper mehr und mehr zurück, er erscheint schließlich nur noch als achmaler gelber Strang an der medial-dorsalen Seite des Eierstockes. Die Tiere zeigen jetzt gewöhnlich nur noch geringe Freßlust und außerdem das Bestreben, das Wasser zu verlassen; sie magern dabei ab.

Nach 30 tägiger Beeinflussung, also bei den meisten meiner Versuchstiere gegen Ende Mai oder Anfang Juni, zur Zeit, in der sich bei nichtbeeinflußten Weibchen die Laichzeit dem Ende nähert, bemerkt man dann an den Eierstöcken sehr wesentliche Veränderungen. Sie werden rasch kleiner und besitzen bald nur mehr eine Länge von $8-10 \mathrm{~mm}$ bei einer Dicke von $1-2 \mathrm{~mm}$. Nur wenig große Follikel von gewöhnlichem Bau und Aussehen sind mehr zu erkennen, die meisten tragen deutliche Spuren von Rückbildung. Sehr groß ist die Zahl der atretischen im letzten Zustand des Unterganges, schon makroskopisch sind sie an der dunklen Färbung zu erkennen. Dabei finden sich recht erhebliche Unterschiede bei den einzelnen Tieren.

Abb. 7 und 8 zeigen je den rechten Eierstock von zwei Molehen, die beide am 5. Mai 1918 gefangen und in der gleichen Weise beeinflußt wurden. Der Behälter, in dem die Tiere sich befanden, war spürlich mit Wasserpflanzen besetzt, eine Bodenschicht fehlte (Versuch 2). Beide Weibchen hatten am 6., 7. und 8. Mai noch Eier, allerdings in geringer Zahl, an die Wasserpflanzen geheftet, von da ab nicht mehr; sie hatten seit Ende Mai das Wasser zeitweise verlassen. Am 3. Juni 1918, also nach 30 tägiger Beeinflussung, wurden sie getötet, Bei dem Tier, dessen Eierstock $A b b, 7$ darstellt, war der Fettkörper makroskopisch zu erkennen; in jedem seiner Ovarien finden sich noch gegen 60 größere Follikel von 0,5-1 mm Durchmesser, etwa ein Drittel von ihnen zeigt bei genauer Untersuchung Spuren der beginnenden Rïekbildung. Daneben finden sich zahlreiche Follikel in allen späteren Zuständen der Atresie, vereinzelte kleinere Eierstockseier wachsen noch durch Dotteransammlung heran, und auch hier finden sich noch Oogonienteilungen. Die Rückbildung der großen Eier geht also mit einer stïndigen Neubildung von Oooyten und dauerndem Wachstum kleiner Follikel Hand in Hand.

Ein ganz anderes Bild bieten die Eierstöcke des zweiten Tieres (Abb. 8). Sie sind $11 \mathrm{~mm}$ lang und kaum $1 \mathrm{~mm}$ dick, nur wenig große Follikel finden sich in ihnen und auch unter diesen zeigt die Mehrzahl schon durch das dichte aberflächliche Blutgefäßnetz und die ockergelbe Farbe die beginnende Rückbildung an. Allenthalben finden sich atretische Follikel, unter ihnen sehr viele in den letzten Stadien des Unterganges. Die Hauptmasse des Eierstockes wird von Oocyten gebildet, die einen Durchmesser von $0,08-0,5 \mathrm{~mm}$ besitzen. Daneben finden sich beiderseits je etwa 12 große Follikel von ungefähr $1 \mathrm{~mm}$ Durchmesser. Zwischenformen fehlen vollkommen. Desgleichen finden sich nur vereinzelte Oogonienteilungen und nur wenig kleinste Oocyten. Nur zwischen den angegebenen Werten von $0,08-0,5 \mathrm{~mm}$ sind alle Größen in reichster Menge vorhanden. Dies ist derjenige Zustand der Eizelle, in dem sich Kern und Plasmaleib ziemlich gleichmäßig, jedoch nur äußerst langsam vergröBern. Im Protoplasma finden sich während dieser Zeit noch keine gelben Dotterschollen, der ganze Kern ist von einem gleichmäBigen Chromatingerüst erfüllt. In dieser Form können die Oocyten sehr lange, mehrere Monate, vielleicht sogar Jahre, verharren. 
Der Fettkörper stellt bei diesem Molchweibchen nur einen dünnen, bindegewebigen Strang dar, in ihm finden sich ganz vereinzelte Fettzellen.

Solch erhebliche Unterschiede im Bau der Eierstöcke bei in gleicher Weise beeinfluBten Tieren finden sich nur in der Zeit, in der im Freileben die Eiablage beendet wird, also unter gewöhnlichen Verhältnissen in der zweiten Hälfte des Mai und der ersten des Juni, in der Umgebung von München 14 Tage bis 3 Wochen später.

Nach dieser Zeit sind die Befunde bei allen behandelten Tieren wieder vollkommen gleich. Stets bildet sich dann der Fettkörper ganz zurück und besteht nur noch aus langen, spindelförmigen Bindegewebszellen, zwischen denen ganz vereinzelte Fettzellen eingelagert sind. Im Eierstock schreitet die Rückbildung aller großen Follikel rasch fort, er besteht bald nur noch aus kleinen Oocyten von 0,08-0,4 mm Durchmesser. Zwischen ihnen liegen die Reste der zugrunde gehenden, stark pigmentierten atretischen Follikel, daneben vereinzelte Oogonienteilungen, Oogonien und kleinste Oocyten. Bei Betrachtung mit bloßem Auge erscheint der Eierstock jetzt glasig, fast durchsichtig, mit vereinzelten dunkelbraunen Punkten.

Nach spätestens 60 tägiger Beeinflussung hat die Rückbildung den Höhepunkt erreicht. Die Tiere fressen, falls sie nur im Wasser gefüttert werden, kaum mehr und magern infolgedessen sehr stark ab, oft beträgt das Körpergewicht nur noch 0,7-0,8 Gramm, also etwa die Hälfte des Durchsohnits.

Abb. 9 zeigt den Eierstock eines Weibchens der eben besprochenen Versuchsreihe (Nr.2). Es wurde am 5. Mai 1918 gefangen, laicht am 6. und 7. Mai noch in gewöhnlicher Weise und von da ab nicht mehr. Gegen Ende Mai verläßt es zeitweise das Wasser, die Freßlust nimmt ab, es wird jedoch im Aquarium belassen und nur im Wasser gefüttert, obwohl es sich von Anfang Juni ab dauernd auf der Korkinsel aufhält und sie kaum noch zum Zwecke der Nahrungsaufnahme verläßt. Am 2. Juli 1918, also nach 60tägiger Beeinflussung, wird es getötet. Der Sektionsbefund ist bei 20 am gleichen Tage untersuchten Tieren, die alle in nämlicher Weise beeinfluBt waren, vollkommen gleich.

Der Fettkörper ist zurückgebildet, die Eierstöcke besitzen eine Länge von $5-7 \mathrm{~mm}$ bei einer Dicke von $0,5-1 \mathrm{~mm}$. Sie sehen glasig durohsichtig aus, nur wenige atretische Follikel im letzten Zustand der Rückbildung sind als kleine dunkelbraune Pünktehen zu erkennen.

Die mikroskopisohe Untersuchung ergibt folgendes (Abb. 9): Die Hauptmasse des Eierstocks wird von Follikeln gebildet, die einen Durchmesser von 0,08-0,45 mm besitzen; größere Eierstockseier, besonderś auch solche, die mit gelbem Dotter beladen sind, fehlen vollkommen. Es finden sich zahlreiche Oogonien und vereinzelte Oogonienteilungen, dagegen nur wenige kleinste Oocyten von unter $0,08 \mathrm{~mm}$ Durchmesser. Daneben sind die letzten Reste der atretischen Follikel nachweisbar.

Abgesehen von diesen untrüglichen Zeichen der stattgehabten Rückbildungen gleicht der Eierstock nunmehr in Form, Größe und Aussehen, auch hinsichtlich seines histologisehen Baues, vollkommen dem eines jungen, noch nicht geschlechtsreifen Tieres kurze Zeit nach der Verwandlung. Nur finden sich bei diesem mehr Oogonien, Oogonienteilungen und kleinste Oooyten.

Die festgestellten Veränderungen haben sich am Eierstock dieses 60 Tage lang beeinfluBten Tieres in der Hauptsache während der letzten 30 Tage abgespielt, denn sie waren in der ersten Zeit des Versuches nicht so erheblich. $\mathrm{Um}$ die stattgehabten Veränderungen richtig beurteilen zu können, vergleiche man den in Abb. 9 wiedergegebenen Eierstook mit dem, den Abb. 4 darstellt; er zeigt den Bau, den das Ovar eines frei lebenden Tieres in der gleichen Zeit besitzt, jener den eines beeinflußten. 
Kurz zusammengefaßt läßt sich also sagen, daß durch die veränderten äußeren Bedingungen die Eiablage jäh zum Stillstand kommt und, von wenigen Ausnahmen bei Versuch 2 abgesehen, im gleichen Jahre nicht mehr fortgesetzt wird. Die Unterbrechung der Fortpflanzungstätigkeit ist durch nachweisbare Veränderungen im Bau der Eierstöcke verursacht. In ihnen reifen nur noch ganz vereinzelte Follikel heran, jedoch nur bis zu einem gewissen Grade. Die völlige Reife, gekennzeichnet durch die Oberflächenwanderung des Keimbläschens, wird nicht mehr erreicht, es werden auch keine Eier mehr ausgestoßen. Während der eigentlichen Laichzeit bilden sich ver. einzelte der größeren Follikel zurück, ihre Zahl vermehrt sich um so stärker, je länger die Schädigung einwirkt. Nach der Laichzeit werden alle großen Follikel rasch resorbiert, das Wachstum der kleineren kommt zum Stillstand und infolgedessen bildet sich der ganze Eierstock, nachdem vorher der Fettkörper geschwunden ist, auf einen dem jugendlichen sehr ähnlichen Zustand zurück.

Wie schon aus der Besprechung der Versuche zu ersehen ist, kann sich jedoch auch ein Tier mit so hochgradig veränderten Eierstöcken, wie sie Abb. 9 darstellt, im Verlaufe des Sommers vollständig erholen und im nächsten Frühjahr wieder zur Fortpflanzung schreiten, vorausgesetzt, daß es wieder in günstige Lebensbedingungen kommt. In diesem. Fall setzt sehr lebhaftes Follikelwachstum ein, ein Vorgang, der nichts Außergewöhnliches darstellt, spielt er sich doch auch am Eierstock des jungen Molches im 2. Lebensjahre in der gleichen Weise $a b$.

Es bleibt nun noch zu besprechen, wie sich die Verhältnisse gestalten, wenn die Schädigung anhält oder wenn nach kurzer Einwirkung eine Rückkehr in gewöhnliche Bedingungen erfolgt.

Werden die Molche in den ungeeigneten Behältern belassen, so geht die überwiegende Mehrzahl im Verlaufe des Sommers zugrunde. Nur ein kleiner Teil, 10-15\%, gewöhnt sich an das Wasserleben, bei ihnen stellt sich nach und nach wieder Freßlust ein, sie verlassen die Korkinsel häufiger, halten sich viel im Wasser auf und nehmen wieder an Körperfülle zu. Molche aus der Versuchsreihe 2 schreiten nach sachgemäßer Uberwinterung im nächsten Frühjahr häufig ohne weiteres zur Eiablage, bei den anderen Versuchsreihen tritt dies nur ein, wenn die Tiere im Vorfrühling in gut eingerichtete Behälter gebracht werden. Die Veränderungen an den Ejerstöcken sind bei den überlebenden Tieren in jedem Fall die gleichen. Es tritt erneutes Follikelwachstum ein und im Herbst zeigen die Eierstöoke den nämlichen Bau wie bei nichtbeeinfluBten Weibchen oder bei solchen, die wieder in gewöhnliche Bedingungen zurückversetzt waren.

Werden die Molche nach kurzer Einwirkung der Schädigung in Normalbehälter verbracht, so erfolgt noch im gleichen Jahre emeute Eiablage. Ich will hier nur die Ergebnisse einiger Reihen aus Versuch 3 schildern, da bëi ihnen die Wirkung am sinnfälligsten zutage tritt. Tiere der beiden anderen Versuche verhalten sich entsprechend; am leichtesten sind Molche, die nur in bodenschichtlosen Behältern gehalten wurden, zur Fortsetzung der Eiablage zu bringen.

Am 25. April 1918 brachte ich je drei Paare Molche aus einem Tümpel in der Nähe Leipzigs in Glasbehälter ohne Bepflanzung und ohne Bodenbelag. Die Weibohen legten am 26. und 27. April Laich in Sohnüren ab, von da ab nicht mehr. Am 5. Mai brachte ich drei Paare in Normalbehälter; die Weibchen begannen am 9. Mai zu laichen und legten bis zum 5. Juni regelmäßig weiter. Eine zweite Gruppe von drei Paaren wurde erst am 15. Mai in Normalbehälter gebracht, sie begannen am 20. Mai zu laichen und legten gleichfalls bis Anfang 
Juni weiter. Die Eierstöeke zeigten bei beiden Gruppen den nämlichen Bau wie bei freilebenden Tieren, nur fanden sich bei einem Weibchen von ruppe 2 , das am 24. Mai getötet wurde, auffallend viele atretische Follikel.

Der Rest der Tiere wurde am 24. Mai in Normalbehalter gebracht; sie führten noeh Liebesspiele aus, legten aber im gleichen Jahre keinen Laich mehr $a b$, sondern verlieBen Mitte Juni das Wasser. Am 15. Juni zeigte der Eierstock eines dieser Tiere gewöhnlichen Bau, rechts 85, links 93 große, gelbe Follikel, von denen aber mehr als ein Drittel in Rückbildung begriffen war; der Fettkörper zeigte die gewöhnliche Größe.

Aus diesen Versuchen läßt sich der Sohluß ziehen, daß eine vorübergehende Beinflussung im Anfang der Fortpflanzungszeit die Eiablage zwar unterbricht, jedoch nicht vollkommen hemmt, falls die Unterbrechung keine zu lange ist. Beim Eintritt gewöhnlioher Bedingungen kommt die Eiablage wieder in Gang, sie wird jedoch in der gleichen Zeit beendet, zu der auch bei nichtbehandelten Tieren die Fortpflanzungstätigkeit zum AbschluB kommt. Auf die Ursachen, die ihn bedingen, werde ich erst weiter unten bei Besprechung der Wärmewirkung noch zurückkornmen.

Bei den eben geschilderten Versuchen wurde die Veränderung in der Umgebung immer erst vorgenommen, wenn die Molche schon vollbrünstig waren und Laich ablegten. Hier ließ sich die unmittelbare Wirkung am leichtesten überwachen und am deutlichsten zeigen. Ganz ähnlich, wenn auch nicht so sinnfällig, ist nun der Einfluß der Veränderung in der Beschaffenheit des Aufenthaltsortes auf die Tritonen, wenn er schon vor der Brunst wirkt. Auch hier sind drei Versuchsreiben zu besprechen, deren Ergebnis sich im großen und ganzen deckt. Im Jahre 1920 begann die Eiablage im Freien Mitte des April; dank der frühen Schneeschmelze zeigten sich in der Umgebung Leipzigs die Molche schon Anfang März im Wasser.

Versuch 4. 12 Paar Molche, am 15. März 1920 frisch gefangen, wurden zu je drei Paaren in unbepflanzte Behälter gebracht, deren Boden mit Kies und Schlamm bedeckt war. Die Tiere führten keine Liebesspiele aus, schritten auch nicht zur Fortpflanzung und verlieBen Ende Mai das Wasser.

Versuch 5. 12 Paar am 15. Murz frischgefangener Molche wurden in spïrlich bepflanzte Behälter ohne Bodenschicht gebracht. Von den Männchen wurden drei gegen Anfang des April brünstig, führten Liebesspiele aus und setzten auch Samenpakete ab. Nur cin Weibehen begann am 12. April zu laichen und legte bis Fnde Mai über 300 Eier ab, dann verlieb es das Wasser. Die übrigen Tiere laichten nicht, verließen aber gleichfalls Ende Mai das Wasser.

Versueh 6. 12 Paar-am 15. März 1020 gefangener Molehe wurden in unbepflanzte Glasaquarien ohne Bodensohicht gebracht. Die Tiere wurden nicht brünstig, legten keinen Laich ab und verließen gegen Mitte Mai das Wasser.

- Werden Molehe in der eben beschriebenen Art beeinflußt und dann während des Herbstes und Sommers unter gewöhnlichen Bedingungen gehalten, so sohreiten sie, wie ich in den Jahren 1909 und 1910 feststellte, im Frübjahr in der gewohnten Weise zur Fortpflanzung.

Je drei Paar der Tiere von Versuch 4, 5 und 6 wurden am 25. April 1919 in Normalbehälter gebracht; im Verlauf der nächsten Tage stellte sich die Brunst ein, in der Zeit zwischen 1, und 5. Maj begannen die Weibchen zu laichen. Hierauf wurden die einzelnen Paare getrennt beobachtet; dabei zeigte es sich, daß ein Weibchen von Versuch 6 nicht brünstig war und auch keine Eier ablegte.

Weitere drei Paar der Tiere von Versuch 4, 5 und 6 wurden erst am 10. Mai in Normalbehälter gebracht. Die drei Weibchen von Versuch 5 und 
eines von Versuch 4 begannen nach einigen Tagen zu laichen, legten jedoch nur wenig Eier $a b$; sie verließen Anfang Juni das Wasser. Die Tiere von Versuch 6 und zwei Weibchen von Versuch 4 laichten im gleichen Jahre nicht mehr.

Das Ergebnis der anatomischen Untersuchung bei den letzten drei Versuchen läBt sich in wenigen Worten zusammenfassen: Bis Ende April zeigen die Eierstöcke aller behandelten Tiere aus Versuch 4, 5 und 6 keine nachweisbaren Veränderungen, sie verhalten sich wie die von freilebenden Molchen vor der Laichzeit. Von Ende April ab stellen sich dann die nämlichen Veränderungen ein, wie an den Eierstöcken der Tiere von Versuch 1, 2 und 3. Alle großen Follikel bilden sich zurück, und zwar spielt sich dieser Vorgang bei den Weibchen, die in leeren WassergefäBen gehalten werden, rascher $\mathrm{ab}$, als bei den anderen Versuchsreihen. So war bei einem Weibchen von Versuch 6, das am 16. Mai 1920 getötet wurde, schon ein großer Teil der Follikel atretisch, die Eierstöcke boten ein Bild, wie es Abb. 8 zeigt.

Duroh die Veränderung im Aufenthaltsort vor der Laichzeit wird also der Beginn der Brunst vollkommen unterdrückt. Eine Ausnahme machte, wie sohon erwähnt, nur ein Tier in Versuch 5, es hatte sich offenbar sehr rasch an die neue Umgebung gewöhnt. Auch hier stellten sich infolge der Schädigung anatomisch nachweisbare Veränderungen der Keim. drüsen ein, gleich denen der früheren Versuche. Die Eierstöcke bildeten sich auf einen, jugendlichen Verhältnissen ähnlichen Zustand zurück; das wesentliche an den Ergebnissen dieser Versuchsreihen ist aber der Umstand, daß die Rückbildungsvorgänge weit langsamer fortschreiten als bei solchen Tieren, die erst während der Eiablage der Schädigung ausgesetzt werden. In der ganzen Zeit vom 15. April bis zum 24. März, also in der eigentlichen Vorlaichzeit, ließen sich keine sinnfälligen Veränderungen feststellen, und erst von da $a b$, also ungefähr vom Beginn der gewöhnlichen Fortpflanzungszeit an, setzte die Rückbildung ein und verlief in den nämlichen Bahnen, wie wenn die Sohädigung erst an diesem Tage begonnen hätte. Neben den anatomischen Befunden zeigt auch der Umstand deutlich genug, daß die Beeinflussung der Ovarien vorher keine wesentliche war, weil fast alle Tiere, die am 25. April in normale Bedingungen gebracht wurden, in kürzester Zeit zu laichen begannen; ihre Eierstöcke konnten also nicht tiefgreifend verändert sein. Ja selbst nach dem 10. Mai wurde noch eine ganze Anzahl der Weibchen brünstig. Deutlich zeigte sich dabci aber, daß die Schädigung eine um so stärkere ist, je größer die Veränderungen in der Umgebung waren. Die Tiere von Versuch 6 waren, da sie nur in leeren Gläsern gehalten wurden, am tiefgreifendsten geschädigt. Dies beweist ja auch die rasche Rückbildung der Eierstöcke. Am wenigsten beeinflußt waren die Weibchen von Versuch 5, wie ja auch aus der Tatsache hervorgeht, daß eines von ihnen trotz des Fehlens einer Bodenschicht zur Eiablage schritt.

Im ganzen läßt sich also sagen, daß die Molche in der Zeit vor der Eiablage gegen Veränderungen der Umgebung wesentlich widerstandfähiger sind als während der eigentlichen Brunst. Eine geringgradige Veränderung schadet hier nichts, sofern die Molche zu Beginn der Laichzeit in gewöhnliche Lebensverhältnisse gebracht werden. Ja selbst schwere Beeinflussung wirkt nur insoweit schädlich, als sie bis in den Anfang der Laichzeit fortdauert; werden die Tiere rechtzeitig in geeignete Behälter gebracht, so.schreiten auch sie noch zur Eiablage.

Zu schwereren Rückbildungserscheinungen an den Eierstöcken kommt es in jedem Fall erst im Mai, also erst gegen die Zeit hin, in der sich die Eiablage bei freilebenden Tieren ihrem Ende nähert. 


\section{Der EinfluB der Ernährung.}

In zweiter Linie wurde die Wirkung verschiedener Ernährung auf die Eiablage geprüft. Die Molohe wurden mit Daphnien, Enchyträen und Bachröhrenwürmern, vor allem aber mit kleinen Regenwürmern, die sie am liebsten fressen, gefüttert. Auch Ackerschnecken, auf die Korkinsel gebracht, werden in der späteren Zeit des Jahres, wenn die Tiere zeitweise das Wasser verlassen, gerne genommen, desgleichen junge Wasserschnecken. Ein ganz ausgezeichnetes Futtermittel, das besonders bei der Mast vorzügliche Dienste lejstet, sind junge Kaulquappen, von denen ein einziger Molch oft erstaunliche Mengen versohlingt. In der Zeit vor dem Kriege fütterte ioh außerdem mehrere Molche mit langen Streifen mageren Rindfleisches; ich habe diese Versuche aber, so sohöne Ergebnisse sie auch zu zeitigen seheinen, nach dem Kriege aus begreiflichen Gründen nicht fortgesetzt. Alle Tritonen sind ungeheuer gefräßig und schnappen offenbar zwangsmäBig nach jedem kleinen Tier, das sich in ihrer Nahe bewegt. Ihre Mast gelingt deshalb auch ziemlich leicht durch Darreichung von großen Nahrungsmengen. Behälter, in denen die Molche überreichlich gefüttert werden sollten, wurden stets ganz dicht mit Daphnien und wenn möglich auch mit Kaulquappen besetzt, außerdem wurde jeden Abend eine größere Menge Regenwürmer in das Wasser geworfen, die übrig gebliebenen am Morgen entfernt.

Auoh die Ernährungsversuche gliedern sich naturgemäß in zwei Reihen, deren eine vor, die andere während der Laichzeit beginnt. Der Einfachheit halber bespreche ioh die zweite Anordnung auch hier wieder zuerst, da sich bei ihr der Erfolg leichter erkennen läßt. Die Einrichtungen wurden in folgender Weise getroffen: Die Hungertiere erhielten gar keine Nahrung, mäBig gefüterte Tiere jeden zweiten oder dritten Tag einen kleinen Regenwurm, in den Behältern der reichlich gefütterten Tiere waren dauernd Futtertiere im Ubermaß vorhanden.

Versuch 7. Hungerversuch. 9 Paar Molche, am 5. Mai 1918 in der Nähe Leipzigs gefangen, werden am gleichen Tage in Normalbehälter gebracht und von da ab nicht mehr gefüttert. Die Tiere beginnen in der Nacht vom 5. -6. Mai in der gewöhnlichen Art zu laichen und legen am 6. und 7. Mai durchschnittlich 10-15 Eier. Am 8. Mai sinkt die durchsohnittliche Eizahl auf 4 , von da ab werden nur noch vereinzelte Eier abgelegt, vom 10. Mai ab keine mehr. Bis gegen Ende Mai verändern die Tiere ihr Aussehen nieht wesentlich, doch magern gie ganz langsam ab. Gegen Ende Mai verlassen sie das Wasser und verlieren dann rasch an Körpergewicht. Fünf Weibchen werden zu verschiedener Zeit zum Zweek der histologischen Untersuchung getötet, von den übrigen vier gehen zwei im August, zum Skelett abgemagert, ein, die beiden anderen werden Mitte August in ein Terrarium gebracht und gut gefüttert; sie erholen sich raseh. Wie ich in früheren Versuchen feststellen konnte, schreiten auch solche Hungertiere, günstige Lebensverhältnisse während des Sommers und Herbstes vorausgesetzt, im nächsten Jahre wieder zur Fortpflanzung.

Eine weitere Reihe von 12 Paaren wurde nur mit Daphnien gefüttert, sio verhielten sich in jeder Hinsicht ebenso wie die Hungertiere, so das ich auch sie zu den Hungermolchen rechnen kann. Die Daphniennahrung allein genügt also nicht zur dauernden Ernährung der Molohe.

Die histologische Untersuchung der Eierstöcke zeitigt das nämliche Ergebnis wie bei Versuch 1,2 und 3: Bei einem am 8. Mai, also nach dreitägigem Hungern getöteten Tier finden sich keine Bauchhöhlen- und Tubeneier, dagegen noch vier Stück im linken, zwei im rechten Uterus. Im Ovar sind keine reifen Follikel. Bei einem anderen Tier sind am 11. Mai, also nach sechstägiger Be- 
einflussung, Eileiter und Uteri vollkommen leer, die Eierstöcke zeigen noch keine wesentlichen Veränderungen. Nach 12 tägigem Hungern, also am 17. Mai, ist die Zahl der atretischen Follikel in den Eierstöeken deutlich vermehrt, der Fettkörper vollkommen zurückgebildet, im Gegensatz $\mathrm{zu}$ den nicht hungernden Tieren der Versughe 1-3, In der Folge schreitet nun die Rückbildung der großen Follikel sehr rasch vorwärts, doch auch hier treffen wir wieder auf erhebliche individuelle Verschiedenheiten.

Am raschesten erfolgte die Resorption aller gelben Follikel bei einem Weibchen der eben besprochenen Versuchsreihe, das dauernd nur mit Daphnien ${ }^{1}$ ) gefüttert wurde. Es war am 5. Mai gefangen und hatte bis zum 8. Mai gelaicht, von da ab nicht mehr. Am 28. Mai, also nach 23 tägiger Beeinflussung, wurde es getötet. Die Eierstöcke sind etwa $8 \mathrm{~mm}$ lang und $1 \mathrm{~mm}$ dick, durchsichtig glasig, mit zahlreichen dunkelbraunen Punkten, den Resten der atretischen Follikel (Abb. 10). Sie bestehen ausschließlich aus kleinen Oocyten von 0,08 bis $0,5 \mathrm{~mm}$ Durchmesser, nirgends finden sich größere Follikel mit Dotteransammlung, dagegen sehr zahlreiche atretische, in den letzten Formen, desgleichen Oogonien, Oogonienteilungen und kleinste Oocyten.

In diesem Falle hatte sioh die Rückbildung während der Laichzeit in nur 23 Tagen vollzogen, in den meisten anderen Fällen dagegen erfolgte sie erst in der Zeit von Ende Mai bis Ende Juni, nachdem allerdings im Mai schon zahlreiche große Follikel zugrunde gegangen waren. Nach dem 1. Juli zeigten die Ovarien aller Tiere den gleichen Bau, wie er oben für die Endzustände der Versuchsreihen 1,2 und 3 beschrieben wurde und wie ihn $\mathrm{Abb} .10$ darstellt. Der Einfluß des Hungers auf die Eierstöoke ist also im Grunde genommen gleich dem der veränderten Umgebung, nur spielt sich in vielen Fällen die Rückbildung rascher $a b$, sie erfolgt in der Hauptsache aber auch hier erst nach der Zeit, in der physiologischerweise die Eiablage stattfindet.

Die Hungerversuche können jeweils dadurch unterbrochen werden, daß reichliche Nahrung geboten wird. Geschieht dies 10-14 Tage nach dem Versuchsbeginn, so kommt die Eiablage wieder in Gang und wird zur gewöhnlichen Zeit beendet, vorausgesetzt, daß bei Beginn der reichlichen Ernährung die Mitte des Monats Mai noch nicht überschritten ist.

Versuch 8. Mäßige Fütterung. Bei mäßiger Fütterung mit natürlicher Nahrung - auf die skünstliche Ernährung komme ich gleich zu sprechen vollzieht sich das Laichgeschäft in gewöhnlicher Weise. Die Molche legen täg. lich 3-8, selten mehr Eier, in einem Frühjahr 100-200. Die Fortpflanzungstätigkeit erreicht zur gewöhnlichen Zeit im Juni ihren Abschluß. Dementsprechend sind auch die an den Eierstöcken und am Fettkörper festzustellenden Veränderungen die gleichen wie bei freilebenden Tieren.

Versuch 9. Mast. 12 Paar Molche, am 23. April 1919 in der Umgebung von Leipzig gefangen, werden in Normalbehälter gebracht und stets überreichlich gefüttert. Die Weibchen laichen vom Tage des Versuchsbeginns an, sie legen täglich durchschnittlich 10-20 Eier, im ganzen je 500-600 Stück während des Frühjahrs. Gegen Ende Mai läßt die Laichtätigkeit nach, Anfang Juni verlassen die Tiere zeitweise das Wasser, die Brunst ist beendet. Die Veränderungen an den Eierstöcken sind die nämlichen wie bei freilebenden Tieren, denen ja auch gewöhnlich während der Laichzeit stets Nahrung in Uberfluß zur Verfügung steht. Abb. 4 zeigt den Fierstock eines Weibchens nach beendeter Brunst. Der Fettkörper erfährt bei gemästeten Molchen während des Monats Mai eine geringe Vergrößerung.

1) Diese Fütterung kommt auf die Dauer reinem Hunger gleich, nur mit Daphnien versehene Molche verhungern stets über kurz oder lang. 
Auch nach der Laichzeit verhalten sieh die Masttiere wie nichtbeeinfluBte, sie schreiten nach entsprechender Uberwinterung im nächsten Frühjahr leicht zur Paarung.

Die Versuche 7, 8 und 9 haben also gezeigt, daß die Fortpflanzungstätigkeit auch durch die Ernährung beeinfluBt wird, Sie kommt bei völligem Hunger rasch zum Stillstand, bei mäßiger Ernährung nimmt sie den gewöhnlichen Verlauf, durch sehr reichliche Fütterung wird die Zahl der Eier erheblich gesteigert. Bei Masttieren bleibt, wie ich des öfteren beobachten konnte, eine kurze Hungerzeit von 1-4 Tagen ohne jeden Einfluß auf den Ablauf der Eiablage. Erst nach dieser Zeit macht sich ein Rückgang in der täglich abgelegten Eizahl bemerkbar, der schließlich zum völligen Stillstand des Laichens führt.

Veränderungen am Fettkörper lassen sich gewöhnlich erst in der zweiten Hälfte der Brunst beobachten; hier verileinert er sich bei spärlicher, vergrößert sich aber bei reichlicher Frnährung. Offenbar dient er zum Ausgleich von Schwankungen, die während der Laichzeit in der Nahrungszufuhr eintreten.

Die zweite Versuchsreihe, in der ich den EinfluB der Ernährung zu prüfen bestrebt war, begann vor der Brunst, im Vorfrühling, unmittelbar nach der Schneeschmelze. Ich benützte zu ihr die ersten Molche, die joh im Jahre 1919 fangen konnte.

Versuch 10. Hungerversuch. 12 Paar Molche, am 15. März 1919 in der Umgebung Leipzigs gefangen, werden am gleichen Tage in Normalbehälter gebracht und nicht mehr gefüttert. Mitte April, als die Wasserwärme anstieg, werden einzelne der Tiere brünstig, zwei Weibchen legen Eier $a b$, jedoch nur 17 bzw. 23 Stück, dann kommt die Brunst wieder zum Stillstand. Von den übrigen Tieren werden vier Paare vom 15. April ab reichlich gefüttert, sie beginnen alle in der Zeit zwischen 19. und 23. April zu laichen, die weitere Fortpflanzungstätigkeit vollzieht sich in der gewohnten Weise. Vier Paare werden weiterhin ohne Nahrung gelassen, der Versuch geht dadurch in den Versuch 7 über.

Die anatomische Untersuchung ergibt, daB sich bis Ende April, also bis in die Zeit hinein, in der bei niohtbeeinflußten Tieren die Eiablage begonnen hatte, keine Veränderungen an den Eierstöcken abspielen; sie zeigen bei den Hungertieren den nämlichen Bau wie bei gewöhnlichen Weibchen, nur der Fettkörper erscheint klein.

Werden die Versuche in die Fortpflanzungszeit fortgeführt, so sind die anatomischen Veränderungen an den Eierstöcken die nämlichen wie bei Versuch 7: die großen Follikel bilden sich anfangs nur langsam und vereinzelt zurück; von Mitte Mai ab, nachdem der Fettkörper fast völlig geschwunden ist, breitet sich die Degeneration auf alle mit gelbem Dotter beladenen Oocyten aus und führt schließlich zur Rückbildung des Eierstockes auf einen Zustand, wie ihn Abb. 10 darstellt. Spätestens bis Mitte Juli sind die Rückbildungsvorgänge beendet.

Versuch 11. Spärliche Fütterung. 12 Paar Molche, gefangen am 15. März 1919, werden in Normalbehälter gebracht und spärlich gefüttert. Alle Tiere zeigen Mitte April, beim Ansteigen der Wasserwärme, Brunsterseheinungen, acht von den 12 Weibchen beginnen in der Zeit zwischen dem 12. und 16. April zu laichen, legen jedoch nur wenig Eier ab, je 40-60 Stück, und verlassen, soweit sie nicht zu anderen Versuchsanordnungen verwendet werden, Mitte Mai das Wasser.

Drei von den Weibchen werden vom 15. April ab, nach dem Beginn der Eiablage reichlich gefüttert und laichen in der gewohnten Weise bis Anfang Juni weiter; die durchnittliche Eizahl beträgt 300 . 
Von den vier Weibchen, die nicht zu laichen beginnen, obwohl sich auch bei ihnen Anzeichen der Brunst bemerkbar machen, werden zwei vom 25. April ab reichlich gefüttert; sie beginnen am 30. April zu laichen und legen bis Anfang Juni weiter. Die beiden anderen Weibchen werden am 28. April getötet, die Fierstöoke sind gro $\beta$ und enthalten je 80-100 dotterreiche Follikel von 0,6-1 mm Durchmesser, jedoch keinen einzigen reifen, mit oberflächlich gelegenem Keimbläschen. Der Fettkörper ist klein, jedoch nioht vollkommen zurückgebildet, Bauchhöhlen- und Tubeneier fehlen.

Einige weitere Molche, die in früheren Jahren in gleicher Weise beeinflußt waren und nicht zur Fortpflanzung sehritten, zeigten im Mai und Juni die nämlichen Rückbildungsvorgänge an den Eierstöcken, wie ich sie oben bei den Hungertieren beschrieben habe.

Versuch 12. Reichliche Fütterung. Am 15. März 1919 fing ich eine große Anzahl von Molchen in einem Tümpel in der Nähe Leipzigs und brachte 30 Paare in ein sehr großes, dicht bepflanztes Aquarium, dessen Boden dicht mit Kies und Schlamm bedeckt war. Auf jedes Paar Molche traf ungefähr 5 Liter Wasser, der Behälter stellte den denkbar günstigsten Aufenthalt dar. Die Wasserwärme war des Nachts etwa $5-8^{\circ}$ und stieg unter Tags, besonders unter dem Einfluß der Sonne, auf 8-12 ${ }^{\circ}$, selten höher. Die Molche nahmen, da sie überreichlich mit Daphnien, Regenwürmern und auch Kaulquappen gefüttert wurden, stark an Körperumfang $\mathrm{zu}$, und ich hoffte, die Laichzeit werde bei ihnen bald beginnen.

Am 29. März, also nach 14 tägiger Mast, tötete ich drei Weibchen, die mir durch die besonders ansehnliche Körperfülle auffielen. Beide Eileiter waren leer, die Eierstöcke zeigten bei der makroskopischen und mikroskopischen Untersuchung gewöhnlichen Bau: $80-100$ große Follikel, jedoch keine sprungfähigen reifen, daneben sehr viele kleine in allen Größen und ganz vereinzelte atretische. Auffallend war das Verhalten des Fettkörpers, er war sehr groß, eben so lang und fast gerade so dick wie der Eierstock.

Am 12. April 1919, in der Zeit, in der mäßig gefütterte Tiere mit den Liebesspielen begannen, zeigte sich bei keinem der Mastmolche das geringste Zeichen für den Beginn der Brunst. Sie waren sehr ruhig, wenig beweglich und nahmen ständig an Körperfülle zu. Von Mitte April ab, also in der Zeit, in der im Freien und in den mit spärlicher Nahrung versehenen Behältern die Eiablage begann, verließen die Masttiere das Wasser und hielten sich auf den Korkinseln auf, anfangs nur zeitweise, von Ende April ab dauernd.

Am 13. April, an dem Tage, an dem die ersten spärlich gefütterten Molche Eier ablegten, tötete ich eine Reihe der Masttiere; bei allon ergab die anatomische Untersuchung den nämlichen Befund. Bei Eröffnung der Leibeshöhle, sobald der prall mit Kot gefüllte Darm entfernt war, fiel die außergewöhnliche Größe der Fettkörper auf. Ihr Rauminhalt übertraf fast den eines gewöhnlichen Eierstockes; so betrug bei einem Weibchen die Länge des Fettkörpers $16 \mathrm{~mm}$, die. Breite $4 \mathrm{~mm}$ und die Dicke in dorsoventraler Richtung $5 \mathrm{~mm}$. Neben diesen erheblich vergrößerten Gebilden erscheinen die Eierstöcke nur klein, zusammengedrückt und auffällig schlaff. Sie bestehen aus 60-80 gelben Follikeln von 0,6 bis etwa $1 \mathrm{~mm}$ Durchmesser. Schon bei LupenvergröBerung ist zu erkennen, daß die überwiegende Mehrzahl von ihnen in Rückbildung begriffen ist; sie besitzen ockergelbe Farbe und sind von einem dichten, engen Blutgefäßnetz überzogen.

Die mikroskopische Untersuchung läßt folgendes erkennen (Abb. 12): Neben zahlreichen Oogonien finden sich nur ganz vereinzelte Oogonienteilungen, ein Umstand, der nicht als außergewöhnlich bezeichnet werden kann, da ja auch in den Eierstöcken freilebender Tiere vor und zu Beginn der Laichzeit kaum 
eine Oogonienvermehrung statt hat. Daneben sind Follikel aller Größen vorhanden, sowohl solche, die nur $0,60 \mathrm{~mm}$ im Durchmesser und darunter haben, bis zu solchen von 1,2 $\mathrm{mm}$ Größe. Die von mehr als $0,6 \mathrm{~mm}$ sind mit gelbem Dotter beladen. Die Mehrzahl der größten Follikel sind in Rückbildung begriffen. Das Keimbläschen ist in ihnen versohwunden oder nur noch als unregelmäBig geformter Fleck zu erkennen, das Blutgefäßnetz ist erweitert, im fortgeschrittneren Zustand zeigen sich Pigmentansammlungen im Dotter unter der Granulosa (Abb. 12 links). Nur ganz selten findet sich dagegen ein Follikel im Endzustand der Atresie mit größeren, dunkelbraunen Pigmentkömern. Reife Eier mit oberflächlich gelegenem Keimbläschen sind nicht nachweisbar, in den meisten Kernen der größeren Follikel zerfällt das Chromatin oder zeigt sonstige außergewöhnliche Bildungen.

Aus dem histologischen Bild läßt sich also erkennen, daB im Fierstock dieser Mastmolche zwar dauernd noch neue Follikel heranreifen, wenn auch nur in geringer Menge, daß jedooh die Mehrzahl der großen Follikel zurückgebildet wird. Die Ursache dafür, daß keine völlige Reifung und kein Platzen der Follikel erfolgt, läßt sich nicht erkennen.

Oberreichliche Ernährung im Vorfrühling verhindert also den Eintritt der Brunst. Ahnliohe Erscheinungen beobachten wir ja meistens auch bei solchen Molchen, die während des Winters im warmen Zimmer gehalten und dort reichlich gefüttert werden. Auch sie schreiten im Frühjahr gewöhnlich nicht zur Eiablage, sie verlassen vielmehr, falls sie nicht an dauerndes Wasserleben gewöhnt sind, sehon im April, spätestens im Mai das Wasser und benehmen sich weiterhin wie gewöhnliche Molche nach der Brunstzeit. Bei entsprechender Uberwinterung schreiten sie jedoch im nächsten Frühjahr wieder zur Fortpflanzung.

Bei den gemästeten Tieren bilden sich während des Sommers und Herbstes die Eierstöcke niemals so stark zurück wie bei den Hungertieren, vielmehr gehen bei ihnen stets nur die größten Follikel zugrunde, während das fortdanernde Wachstum kleiner Oocyten eine stärkere Rückbildung des ganzen Eierstockes verhindert.

In mehreren Versuchsreihen konnte ich bis jetzt feststellen, daß Molehe, die im März und Anfang April gemästet waren, selbst wenn die reichliche Nahrungazufuhr nur 14-20 Tage gedauert hatte, im gleichen Jahr nicht mehr zur Eiablage schreiten, auch dann nicht, wenn sie nach der Mast längere Zeit hungern. Stets sind die Tiere dann bestrebt, das Wasser zu verlassen; sie treten nicht mehr in Brunst. Finen Teil der Weibohen aus Versuch 12, die vom 15. März ab gemästet wurden, hielt ich vom l. April an bei spärlicher Fütterung; sie verweilten schon von Anfang April ab größtenteils auf den Korkinseln und zeigten keine Brunsterscheinungen, auoh dann nicht, als ich am 20. April einige hochbrünstige Männchen an Stelle der früheren in die Behälter brachte. Ihre Liebesspiele fanden nicht die geringste Gegenneigung.

Die Ergebnisse meiner Versuche über den Einfluß der Ernährung scheinen sich zunächst zu widersprechen, war dooh der EinfluB reichlicher Fütterung ein ganz anderer, je nachdem er vor oder während der Brunst in Wirkung trat. Ich werde auf diese Erscheinungen und die Erklärung dea in ihnen enthaltenen scheinbaren Widerspruohs noch zurückkommen.

Zusammenfassend läßt sich sagen, daß Hunger und spärliche Fütterung vor der Brunst nicht sohadet, sofern zu Beginn der Fortpflanzungszeit reiohliche Nahrungszufuhr erfolgt. Während der Brunst selbst bedingt Hunger den Stillstand der Eiablage, jedoch nicht plötzlich, sondern erst nach einigen Tagen, bei spärlicher Ernährung ist die Zahl der abgelegten Eier gering. Sehr reich- 
liche Fütterung vor der Brunst verhindert die Fortpflanzungstätigkeit, wohingegen sie während der Laichzeit die Eiablage steigert.

Bei spärlicher Ennährung und beim Hunger wird stets zuerst der Fettkörper aufgebraucht, erst dann lassen sich sehwerere Veränderungen am Eierstook nachweisen. Bei der'Mast vergrößert sich der Fettkörper erheblich, während sich der Eierstock niemals sehr beträchtlich verkleinert.

Zum Sohlnsse dieses Abschnittes will ich noch ganz kurz einige Versuche besprechen, die ich vor dem Kriege ausführte. Leider habe ich keine ausführlichen Aufzeichnungen darüber gemacht, sondern mir nur die Gesamtergebnisse bei der Besehreibung der einzelnen Eierstöcke vermerkt. Es handelt sich um Fütterungen mit Rindfleisch. Wie schon erwähnt, nehmen die Molche in feine Streifen geschnittenes rohes Fleisch gerne an und lassen sich bei soleher Ernährung gut am Leben erhalten. Toh habe jedoch stets die Bemerkung gemacht, daß in dieser Weise verpflegte Tiere niemals zur Fortpflanzung schreiten ja daß sogar die Eiablage rasch zum Stillstand kommt, wenn statt der natürlichen lebenden Nahrung nur Warmblüterfleiseh gereicht wird. Ioh besitze die Eierstöcke einiger Molche, die im Frühjahr 1908 gefangen wurden, im Aquarium gelaicht hatten, nach Beginn der Laichzeit aber nur noch Rindfleisch erhielten. Die Eiablage lam zum Stillstand; in den Eierstöeken finden sich keine reifen Eier, verhältnismäßig zahlreiche große Follikel sind in Rückbildung begriffen.

Nach den Ergebnissen dieser Beobachtung beeinflußt also auch unsachgemäße Fütterung, unabhängig von der Menge die Fortpflanzungstätigkeit, eine Tatsache, die uns nicht wundernehmen kann. Ubrigens finden sich auch in anderen Arbeiten Angaben darüber, daß Rindfleischfütterung den Urodelen nicht zusagt; die Tiere nehmen zwar diese Art von Nahrung gerne an, sio werden auch fett, schreiten aber nicht zur Fortpflanzung. So gibt Kammerer (1904-1908) an, daß junge Tiere von Salamandra atra und maculosa sich zwar leicht an ein Ersatzfutter aus rohen Fleischfasern gowöhnen lassen, bei solcher Ernährung auch rasch wachsen, jedoch niemals geschlechtsreif werden. Vielmehr bleiben die Keimäüsen dauernd auf jugendlichem Zustand stehen, der Fettkörper vergröbert sich beträchtlich. Allerdings läßt es sich bei dieser Beobachtung nicht mit Sicherheit entscheiden, ob die Entwicklungshemmung der Keimdrüsen von der Fleisehfütterung an sioh, oder aber von der überreich. lichen Nahrungszufuhr oder von sonstiger unsachgemäßer Pflege herrührt. Jedenfalls sind die bisherigen Beobachtungen angetan, einen Einflub im ersten Sinne anzunehmen, und es wäre deshalb wohl wünschenswert, wenn in Zukunft auch Versuche über versehiedenartige Fütterung ausgeführt würden.

\section{Der EinfluB der Wasserwärme.}

Meine Versuche über den EinfluB der umgebenden Temperatur kranken zum Teil an den unzulänglichen technischen Einrichtungen, immerhin lassen sich ihre Ergebnisse aber verwerten. Ich möchte dabei bemerken, daB ich es niemals unternommen habe, Molche langsam an höhere Wasserwärme zu gewöhnen. Durch vorsichtiges langsames Vorgehen ließe es sich sicher erreichen, einheimische Molche dauernd in geheizten Aquarien bei einer Temperatur von $25-30^{\circ}$ am Leben zu erhalten. $O b$ sie dabei allerdings zur Fortpflanzung schreiten, mag noch dahingestellt sein.

Auch zu den Wärmeversuchen benützte ich stets frisch gefangene Tiere, die zuerst in Normalbehältern auf die Laichablage geprüft wurden. Die Uberführung in kältere oder wärmere Umgebung erfolgte dabei stets verhältnismäßig rasch, im Verlaufe von 1-2 Tagen. Plötzlicher Temperaturwechsel, und zwar besonders von der Wärme in die Kälte, ist immer schädlich und kann, an 
mehreren Tagen nacheinander ausgeführt, den Stillstand der Eiablage zur Folge haben.

Versuch 13. Plötzliche Abkühlung. Im Jahre 1907 pflegte ich eine Gruppe von Molohen, die Mitte April in einem Tümpel in der Nähe Münchens gefangen waren und seit Anfang Mai regelmäBig laiohten. Die Normalbehälter, die ihnen zum Aufenthalt dienten, standen in einem Südrimmer am Fenster, die Wasserwärme betrug des Nachts $10-15^{\circ}$, unter tags $15-20^{\circ}$ und darüber. Vom 16. Mai ab ließ ich täglich in der Mittagszeit das Wasser aus den Aquarien $a b$ und ersetzte es durch Leitungswasser von $8^{\circ}$ Wärme. Schon vom 18. Mai an war die Zahl der abgelegten Eier geringer, am 20. kam die Eiablage ganz zum Stillstand. Vom 25. Mai ab unterließ ich den täglichen Wasserwechsel, die meisten der Tiere begannen darauf am 28. wieder zu laichen, einige wenige verließen aber das Wasser. Ihre Eierstöcke zeigten am 30. Mai den gewöhnlichen Bau, vereinzelte der großen Follikel bildeten sich zurück. Die übrigen Weibchen laichten bis zum 20. Juni weiter.

Einmalige plötzliche Abkühlung oder vorübergehende Erwärmung bleibt ohne schädliche Folgen. Dies beweist ja auch der Umstand, daß Molche, die für kurze Zeit nach dem Fang in ganz ungeeigneten Gefäßen gehalten werden, in Normalbehältern ohne weiteres ihre Legetätigkeit fortsetzen.

Den umgekehrten Versuch, dauernden Aufenthalt in kühlem und plötzliches Verbringen in warmes Wasser, habe ich nicht ausgeführt, und zwar deshalb, weil, wie joh gleich zeigen werde, niedrige Wasserwärme an und für sich schon die Laichtätigkeit unterdrückt.

Die eigentlichen Wärmeversuche wurden in vier Gruppen ausgefïhrt, und zwar auch wieder während und vor der Laichzeit.

Versuch 14. Wasserwärme dauernd unter $8^{\circ}$. Er wurde in der Art und Weise ausgeführt, daß ich die Behälter dauernd von Leitungswasser durchströmen ließ; seine Wärme schwankt in München zwischen $6-8^{\circ}$, stärkere Bestrahlung durch die Sonne wurde vermieden. Triton vulgaris liegt bei dieser Temperatur meist träge auf dem Boden des Behälters, wühlt sich, wenn dies geht, in den Schlamm ein und nimmt nur wenig Nahrung zu sich. Der Versuch wurde Ende April 1909 begonnen, an Molchen, die eben in die Laichzeit eingetreten waren. Bis Ende Mai 1908 zeigten die Molche keine wesentlichen Veränderungen, weder am Körper noch an den Eierstöcken, von da ab magerten sie ab. Im Juni versuchten sie das Wasser zu verlassen, Mitte Juli wurde der Versuch abgebrochen. Die Tiere verhielten sich ganz ähnlich wie Hungertiere, und dementsprechend waren auch die Veränderungen an den Eierstöcken fast geradeso wie bei diesen (Versuoh 7). Nur ging die Rüokbildung der großen Follikel wesentlich langsamer vor sich.

Versuch 15. Wasserwärme von $8-15^{\circ}$. Die betreffenden Behälter wurden in kühlen Nordzimmern aufgestellt, in denen die Wasserwärme nachts auf $6-8^{\circ}$ sank, unter Tags höehstens auf $15^{\circ}$ anstieg. Die Eiablage ist in solchen Behältern spärlich, kommt aber nicht ganz zum Stillstand, besonders dann, wenn die Wasserwärme unter Tags längere Zeit auf $12-15^{\circ}$ steigt. Besonders günstig macht sioh der Einfluß der Sonne geltend, auch wenn er keine höhere Erwärmung des Wassers bedingt. Werden die Behälter in kalten Südzimmern aufgestellt, so ist die Eiablage reichlicher und hält länger an, als in den Nordzimmeraquarien. Ich komme darauf noch zurück.

Bei dauernder Wärme von unter $10^{\circ}$ führt Triton vuigaris zwar noch Liebesspiele aus, die Männohen setzen noch Samenpakete ab, die Weibchen legen aber keine Eier. Auch diese Tatsache zeigt deutlich die höhere Empfindsamkeit der weiblichen Tiere, die ich in allen meinen Versuchen beobachten konnte. Triton alpestris, wenigstens solehe Tiere, die aus mehr als $1000 \mathrm{~m}$ 
Höhe stammen, mit anderen habe ich keine Kälteversuche ausgeführt, laicht dagegen noch bei einer Wasserwärme von $8-10^{\circ}$. Die Schwankungen in der Eiablage gehen meist mit geringerer oder größerer Freßlust Hand in Hand.

An den Eierstöoken dex Molche lassen sich bei den eben besprochenen Versuchen keine Abweichungen gegenüber nichtbeeinflußten Tieren feststellen, was ja auch verständlich ist. Gerade in der Umgebung von München beträgt ja, wenigstens im Anfang der Laichzeit, die Wasserwärme nur selten über $15^{\circ}$ und sinkt des Nachts häufig genug auf $8^{\circ}$ und darunter.

Versuch 16. Wasserwärme von 15-24. Die betreffenden Behälter wurden mit Hilfe einer eingetauchten Glühbirne geheizt und standen in einem Südzimmer; die Wasserwärme sank des Nachts gewöhnlich auf $15^{\circ}$ und stieg unter Tags auf $20-24^{\circ}$. In solchen Aquarien fühlen sich die Molche während der Laichzeit am wohlsten. Sie entwickeln große Freßgier und legen sehr zahlreiche Eier ab; allerdings kommt die Laichzeit meistens früh zum Stillstand, wenigstens stets dann, wenn der Aufenthalt in der Wärme schon im April begonnen hat. Die Molche veriassen dann Mitte oder Ende Mai das Wasser, außergewöhnliche Veränderungen an den Eierstöcken lassen sich nicht feststellen.

Versuch 17. Erwärmung des Wassers auf über 24․ Die Tiere werden hier sehr unrubig, schwimmen aufgeregt in den Behältern herum und gehen, wenn die Temperatur auf dieser Höhe bleibt, in wenigen Stunden zugrunde. Ich beobachtete diese Erscheinung mehrmals in verschiedenen Jahren an Molchen, die teils frisch gefangen waren, teils auch in Normalbehältern schon längere Zeit gelaicht hatten, wenn ich die Tiere in ein geheiztes Aquarium gebracht hatte. Ich bin aber, wiè schon gesagt, fest davon überzeugt, daß sich unsere einheimischen Molche auch langsam an solche Temperaturen gewöhnen lassen, beträgt doch Ende Juni die Wasserwärme in den Freitümpeln häufig genug $\mathbf{2 4}^{\circ}$ und darüber. Allerdings veranlaßt wohl dieser Umstand die Molche zum Abbrechen der Laichtätigkeit und zum Verlassen des Wassers. Immerhin bleiben ihre Larven aber so hohen Temperaturen ausgesetzt. Die Eierstöcke der durch Hitzo getöteten Molche zeigen keine deutlichen Rückbildungen, was bei der kurzen Dauer der Schädigung ja leicht zu erklären ist.

Anch vor der Brunstzeit hat die Wasserwärme hohen Einfluß auf die Fortpflanzungstätigkeit.

Versuch 18. Wasserwärme von $8^{\circ}$ und darunter. Die Molche verhalten sich auch hier träge, sie fressen meist wenig und führen, wenn die Laichzeit bei nioht beeinflußten Tieren beginnt, keine Liebesspiele aus. Die Brunst kommt also nicht in Gang, die Molche bleiben dauernd teilnahmslos, und so geht der Versuch ohne weiteres in den Versuch 14 über. An den Eierstöcken lassen sich schwerere Veränderungen erst von der Mitte des Mai nachweisen, sie sind dann gleich denen der Hungertiere, nur verlaufen sie langsamer.

Werden die Molche zu irgendeiner Zeit in wärmeres Wasser von $10-15^{\circ}$ gebracht - der Unterschied darf nicht zu groß sein, sonst gehen die Molche häufig zugrunde -, so stellt sich sehon nach wenigen Tagen große FreBlust ein, die Liebesspiele beginnen und häufig schon nach 4-6 Tagen nimmt die Eiablage ihren Anfang. Dieser Versuch gelingt jedoch nur in der Zeit zwischen Anfang April und Mitte Mai, ja man kann rubig sagen, daß die Molche in der Gefangenschaft am leichtesten zur Fortpflanzung schreiten, wenn sie bis Ende April in Normalbehältern bei $6-8^{\circ}$ gehalten werden und wenn dann die Wasserwärme im Verlauf von 2-3 Tagen auf $10-15^{\circ}$ erhöht wird. Damit komme ich schon zur Besprechung des nächsten Versuchs.

Versuch 19. Wasserwärme von 8-15\%. Werden die Molche Mitte März bei einer Wasserwärme von $8-15^{\circ}$ in Normalbehältern gehalten, so stellt sich 
innerhalb kurzer Zeit große Freßlust ein, die Tiere beginnen meist schon nach 8-10 Tagen mit den Liebesspielen und schreiten Ende März oder Anfang April zur Eiablage. Im Jahre 1919 laichten zahlreiche Molche, die am 15. März gefangen waren und in der eben beschriebenen Weise beeinfluBt wurden, vom 2. April an. Die Behälter standen in ungeheizten Südzimmern am Fenster, die Wasserwärme sank des Nachts auf $8-10^{\circ}$ und stieg unter Tags gewöhnlich auf 12-15. Soweit die Tiere nicht zum Zweeke der histologischen Untersuchung getötet wurden, laichten sie bis Ende Mai, also bis gegen den gewöhnlichen Abschluß der Laichzeit hin, weiter. Die Veränderungen an den Eierstöcken waren die nämlichen wie bei freilebenden Tieren, die Gesamtzahl der abgelegten Eier war sehr hoch, bei jedem Weibchen $400-600$. Ganz ähnlich waren die Ergebnisse des nächsten Versuchs.

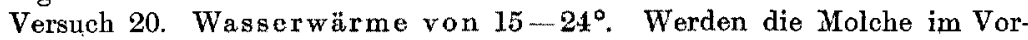
frühling, unmittelbar nach dem Fang, in eine solche Wasserwärme gebracht, so geht ein großer Teil von ihnen rasch zugrunde, besonders dann, wenn die Temperatur sich dauernd der letzten Zahl nähert. Von 30 Molchen, die ich am 6. März 1920 fing und in einen Normalbehälter brachte, dessen Wasser mittels einer eingetauchten Glühbirne dauernd auf $22-24^{\circ}$ erwärmt war, gingen 23 in der Zeit vom 7.-10. März zugrunde. Unter den Uberlebenden waren zwei Weibchen, die im gleichen Jahre nicht mehr zur Fortpflanzung schritten.

Weit besser gelingt der Versuch, wean die Molohe erst in Wasser von $10-15^{\circ}$ und dann langsam in höhere Temperaturen gebracht werden. In diesem Fall tritt fast stets eine Gewöhnung ein, die Tiere werden sehr hungrig und beginnen nach kurzer Zeit zu laiohen; sie legen dann bis zum gewöhnlichen Ende der Laichzeit bei entsprechender Fütterung eine große Zahl von Eiern ab, bis zu 600 und darüber. Durch die größere Wasserwärme kommt zweifellos auch hier die Brunst in Gang, jedoch nur, wenn die Temperaturerhöhtung erst gegen Ende März oder Anfang April erfolgt. In der Zeit vorher wirkt sie schädlich.

Versuch 21. Wasserwärme von über $24^{\circ}$. Auch in der Vorlajchzeit gehen die Tiere in solcher Wasserwärme stets rasch zugrunde.

Die Ergebnisse meiner Warmeversuche decken sich mit den Beobachtungen, die Wolterstorff (1920) machte. Nach seinen Erfahrungen wird die Lebenstätigkeit der Molche sim Aquarium bis zu $8^{\circ} \mathrm{C}$ herunter nur wenig beeinflußt. Ich habe gesunde Triton cristatus und Triton vulgaris nooh bei dieser Temperatur im Liebesspiel beobachtet; bei $7-8^{\circ}$ fressen Molche, die lange nicht gefüttert waren, noch, obwohl ihre Bewegungen ungelenkig werden. Erst wenn die Temperatur unter $7^{\circ} \mathrm{C}$ sinkt, werden die Tiere matter und fressen nicht mehr. ... Eier werden bei einer Temperatur unter $8-10^{\circ} \mathrm{C}$ nur selten und nur in geringer Anzahl abgelegt. \&

Im ganzen lassen sich die aus den Wärmeversuchen gewonnenen Erfahrungen folgendermaßen zusammenfassen: Wasserwärme von über $24^{\circ}$ wird nicht vertragen, unter $8^{\circ}$ erfolgt keine Eiablage. Niedrige Temperatur verhindert den Beginn der Laichzeit und unterdrückt die Eiablage, wenn sie schon im Gange ist. Eine Wasserwärme von über $8^{\circ}$ befördert im Vorfrühling, sofern die Erhöhung der Temperatur nicht zu rasch nach Beendigung des Winterschlafes erfolgt, den Eintritt der Brunst; die Eiablage ist um soreichlicher, je höher die Wasserwärme ist, vorausgesetzt, daB sie nicht die oberste Grenze von $20-24^{\circ}$ überschreitet. Durch frühzeitige Erhöhung der Wasserwärme, 14 Tage bis 3 Wochen nach Beendigung des Winterschlafes, kann im Vorfrühling der Beginn der Laichzeit verfrüht werden, es findet dabei aber keine vollkommene Versohiebung der Fortpflanzungszeit statt, sondern sie 
wird, da sie bis Ende Mai fortdauert, durch den frühzeitigen Beginn im ganzen verlängert.

Dabei ist jedoch stets zu berücksichtigen, daß alle diese Wärmeversuche insofern nicht den ausschließlichen Einfluß der verschiedenen Temperaturen zeigen, als die Unterschiede in der Wasserwärme ja stets auch von erheblichem Einfluß auf die Nahrungsaufnahme sind. Die ausschließliche Bedeutung der Wärme hätte sich nur dann ermitteln lassen, wenn die Molche in den verschieden erwärmten Behältern ganz gleiche Mengen von Nahrung zu sich genommen hätten. Dies ließ sich jedoch nicht erreichen, da die Tiere in den kälteren Behältern wesentlich wenigér Hunger hatten, als in den wärmeren. Künstliche Fütterung habe ich vermieden. Beim „Stopfen « müssen die Molohe angefaßt werden, dies bedeutet jedesmal eine erhebliche Störung im Allgemeinbefinden und ist deshalb für die hier beschriebenen Versuche unbrauchbar. Molohe, die täglich angefaßt und gestört werden, laichen niemals.

\section{Der EinfluB des Lichtes.}

In einer weiteren Versuchsreihe wurde die Bedeutung des Lichtes geprüf; die ermittelten Ergebnisse sind hier vor und während der Laichzeit so gleichsinnig, daß ich bei ihrer Besprechung die bisherige Scheidung nicht vorzunehmen brauche.

Versuch 22. Dunkelversuch. Werden die Molche in völliger Dunkelheit gehalten, was durch Uberdeckung der Aquarien mit schwarzen Papphülsen leicht zu erreichen ist, so nehmen sie keine Nahrung auf, sie bewegen sich nur wenig und verhalten sich hinsichtlich der Fortpflanzungstätigkeit und der anatomischen Veränderungen der Eierstöeke wie Hungertiere. Die Brunst kommt weder in Gang, noch dauert sie nach ihrem Beginn an. Aus den oben angeführten Gründen habe ich es unterlassen, bei dieser Versuchsanordnung die Tiere künstlich zu ernähren.

Die Molche bleiben in den Dunkelbehältern manchmal ziemlich lange, oft 3-4 Monate am Leben, sie magern ab, und zwar um so rascher, je höher die Wasserwärme ist. Auch die Rückbildung der Eierstöcke vollzieht sich um so schneller, je wärmer die Tiere gehalten werden.

Versuch 23. Dauernde Beleuchtung. Molche, die dauernd im Hellen gehalten werden, unter Tags bei natürlicher, nachts bei künstlicher Beleuchtung, verhalten sich wie nicht beeinflußte Tiere. Wird der Behälter jedoch in einem vom Tageslicht abgeschlossenen Raum - ich benutzte dazu eine Dunkelkammer - aufgestellt und dauernd mittels einer Glühbirne von 25 Kerzenstärke, $2 \mathrm{~m}$ über dem Behälter aufgehängt, erleuchtet, so kommt, falls die Beeinflussung im Vorfrühling beginnt, die Brunst nicht in Gang. Nimmt der Versuch während der Laichzeit seinen Anfang, so wird die Eiablage rasch unterbrochen, die Molche verhalten sich dann ähnlich wie Hungertiere. Ausführlicher besprechen will ich noch die folgende Versuchsanordnung.

Versuch 24. Sehattenversueh. 6 Paar Molche, am 5. Mai 1918 in der Nähe Leipzigs gefangen, wurden am gleichen Tage in Normalbehältern untergebracht. Die Aquarien standen in einem Nordzimmer, $3 \mathrm{~m}$ vom Fenster entfernt; der Raum wurde an kalten Tagen geheizt, so daß keine größeren Wärmeschwankungen vorkamen. Bis Mitte Mai betrug die Wasserwärme unter Tags $12-16^{\circ}$, des Nachts einige Grade weniger; unter Tags stieg sie später häufig bis auf $22^{\circ}$. Bei reichlicher Fütterung zeigten die Molche große Freßlust und verhielten sich auch sonst in gewöbnlicher Weise. Am 6., 7. und 8. Mai legten die Weibchen reichlich Laich ab, von da ab wurde die Eiablage spärlicher und kam zwischen dem 12. und 15. Mai völlig zum Stillstand. Noch am 19. Mai jedoch führten 
die Männchen ihre Liebesspiele aus und setzten Samenpakete ab. Die Frê. lust war bei allen Tieren unvermindert, alle Molche nahmen an Körperfülle zu. Am 28. Mai tötete ich zwei der Weibchen, bei beiden waren die Eileiter leer, es fanden sich weder Bauchhöhleneier, noch sprungreife Follikel. Die Eierstöcke zeigten gewöhnlichen Bau, jedoch war eine auffallend große Anzahl der gelben Follikel in Rückbildung begriffen, so daß das Ovar etwa ein Bild bot, wie es Abb. 6 wiedergibt. Die Fettkörper waren sehr groß.

In der Folgezeit bildeten sich nun, obwohl die Tiere reichlich Nahrung zu sich nahmen, die Eierstöoke zurück, und zwar ganz ähnlich wie bei den Molchen, die in unbepflanzten Behältern gehalten wurden. Die letzten beiden Weibohen aus diesem Versuch wurden am 7. Juli 1918, also nach 60tägiger Beeinflussung, getötet. Bei beiden sind die Eierstöcke (Abb. 11) klein, glasig durchsichtig und enthalten keine großen, mit gelbem Dotter beladenen Follikel. Dagegen sind sie übersät mit dunkelbraun gefärbten atretisehen, im letzten $\mathrm{Zu}$ stand der Rückbildung. Die Länge eines Eierstockes beträgt etwa $7 \mathrm{~mm}$, die Dicke etwa $1-1,5 \mathrm{~mm}$.

Im Gegensatz dazu sind dic Fettkörper sehr groß, etwa $15 \mathrm{~mm}$ lang und 3-4 $\mathrm{mm}$ dick, von tiefdunkelgelber Farbe.

Die mikroskopische Untersuchung bestätigt auch hier das bei makroskopischer Betrachtung festgestellte Verhalten (Abb. 11). Der ganze Eierstock besteht fast ausschließlich aus kleinen Follikeln von $0,07-0,6 \mathrm{~mm}$ Durohmesser, Größen von 0,4-0,6 mm Durchmesser sind allerdings in sehr reichlicher Menge vor handen, und in dieser Hinsicht unterseheidet sich der Eierstoek von dem des gleichlang beeinflußten Molches (Abb.9), der in ungeeignetem Behälter gepflegt wurde und wenig gefressen hatte, bei dem diese Größen selten sind. Daneben fällt die beträchtliche Menge der atretischen Follikel auf; sie befinden sich durchweg im letzten Zustand der Rückbildung und stellen dementsprechend nur kleine, stark pigmentierte Klumpen dar. Oogonienteilungen sind nur in geringer Menge nachzuweisen, desgleichen finden sich nur ganz wenig kleinste Oooyten.

Um die eben geschilderte Versuchsanordnung nochmals auf ihre Richtig. keit zu prüfen, stellte ich im Jahre 1919 Normalbehälter mit Molchen, die am 15. März in der Nähe von Leipzig gefangen waren, in einem an kalten Tagen geheizten Nordzimmer, teilweise unmittelbar am Fenster, teilweise $3 \mathrm{~m}$ von ihm entfernt auf. Die Wasserwärme schwankte des Tags zwischen 10 und $15^{\circ}$, stieg von Anfang Mai ab aber häufig auf $20^{\circ}$ nnd darüber. In den Kontrollbehältern, die unter sonst ganz gleichen Bedingungen an süd- und südwestlich gelegenen Fenstern aufgestellt waren, begannen die Molche bei einer Wasserwärme von $10-15^{\circ}$ am 22. März zu laichen (Versuch 19). In den Sohattenbehältern beobachtete ich zwar in der Zeit von Ende April bis Ende Mai zeitweise Liebesspiele, vereinzelte der Männohen setzten auch Samenpakete ab, es kam jedoch nicht zur Eiablage. Gegen Ende Mai nahm die Freblust bei den Molchen ab; sie verlieBen das Wasser.

Bis Anfang Mai ließen sich an den Eierstöcken keine wesentlichen Veränderungen feststellen, erst von dieser Zeit ab bildeten sie sich langsam in der oben beschriebenen Art und Weise zurück; auch hier erreichte die Rückbildung keinen so hohen Grad wie bei Hungertieren. Im Gegensatz zu diesen vergrößerten sich auch hier dịe Fettkörper.

Es ist klar, daß es sich bei diesen Schattenversuchen nur um die fehlende Beeinflussung durch die Sonnenstrahlen handeln kann, eine Wirkung von seiten der Wärme kommt nicht in Frage, da ja in anderen Behältern, die zeitweise der Sonne ausgesetzt waren, bei gleichen Temperaturen die Molche regelmäßig laichten. Auch diese Beobachtungen können in bezug auf ihre Ergebnisse nicht 
merkwürdig erscheinen, ist es doch schon seit langem bekannt, daß Tiere und Pflanzen, von besonderen Sohattenformen abgesehen, nicht dauernd im Sohatten leben können, geschweige denn zur Fortpflanzung schreiten.

Kurz zusammengefaßt läßt sich sagen, daß dauernde Dunkelheit die Fortpflanzung hemmt, dauernde Beleuchtung die Lebenstätigkeit nicht beeinträchtigt. Für den gewöhnlichen Ablauf der Fortpflanzungstätigkeit ist zeitweise Besonnung der Behälter notwendig, dauernder Sehatten wirkt hemmend.

\section{Sonstige Versuche.}

Ganz kurz will ich noch einige weitere Versuche besprechen, sie betreffen zum Teil Erfahrungen, die ich anläBlich meiner Zuchtversuche machen konnte, zum Teil aber neue Anordnungen, die bis jetzt nooh nicht völlig abgeschlossen sind, aber doch schon gewisse Rückschlüsse zulassen.

Bei allen meinen Versuchen machte ich zunächst die Erfahrung, daß zu dichte Besetzung der Behälter schädlich auf den Ablauf der Fortpflanzungstätigkeit wirkt. Bei Triton vulgaris müssen für jedes Paar in einem dichtbepflanzten Aquarium wenigstens 3 Liter Raum zur Verfügung stehen, bei Triton cristatus mindestens die doppelte Menge. Wird diese Bedingung nicht erfüllt, so gelingt es niemals, die Molche zur Ablage einer großen Anzahl von Eiern zu bringen. Die Tiere stören sich gegenseitig, besonders trifft dies auf die Männchen zu; bei der Fütterung entstehen heftige Kämpfe, alles das bringt große Unruhe mit sich, vielfach werden die Weibchen auch während der Eiablage selbst durch die Männohen belastigt und meistens kommt deshalb in zu dicht besetzten Behältern nach wenigen Tagen das Laichen zum Stillstand. Zum Teil mag ein solcher Umstand wohl auch dadurch vorgetänscht sein, daß die zahlreichen abgelegten Eier von den Insassen der Behälter gefressen werden. Durch entsprechende Versuche, in denen ich Weibchen, die einige Zeit in solchen Massenunterkünften gehalten waren, in Einzelbehälter setzte und genau bewachte, konnte ich mir jedoch Gewißheit verschaffen, daß bei ihnen infolge der Beunruhigung die Brunst tatsäohlich unterbrochen war und erst nach einigen Tagen wieder in Gang kam.

Des weiteren suchte ich auch den Einfluß kennen zu lemen, den Verletzungen irgendwelcher Art auf die Eierstöcke und damit auf den regelmäßigen Ablauf der Geschlechtstätigkeit auszuäben vermögen. Ich entfernte zu diesem Zweck bei verschiedenen Weibchen, die in voller Eiablage standen, teils ganze GliedmaBen, teils kleinere oder größere Stücke des Schwanzes. Die genauen Ergebnisse dieser Versuche gedenke ich, wie schon erwähnt, erst später, wenn ich über genügend Erfahrung verfüge, zu veröffentlichen. Hier nur so viel, daß kleine Verletzungen ohne Einfluß auf die Fortpflanzungatätigkeit bleiben, wohingegen schwerere Eingriffe sie sofort zum Stillstand bringen. Inwieweit aber die Schnelligkeit, mit der sich die Regeneration vollzieht, durch den versohiedenen Entwicklungszustand der Keimdrüsen beeinflußt wird, vermag ich bisher noch nicht anzugeben. Vor allem bin ich auch noch nicht in der Lage, zu überblicken, ob durch eine leichtere, die Fortpflanzungstätigkeit als solche nicht beeinflussende Schädigung die Beschaffenheit der Nachkommen in irgendeiner Weise verändert wird. In Frage käme natürlich niemals eine Vererbung der Verstümmelung an sich, sondern nur die Folgen einer allgemeinen Keimschädigung. Sie wäre eben durch die Verletzung und damit Schädigung des elterlichen Körpers bedingt, die ihn gerade während der Fortpflanzungstätigkeit betrifft. 


\section{Besprechung der Befunde.}

\section{Der Verlauf der Eiablage.}

Die soeben im einzelnen beschriebenen Befunde zeigen ganz übereinstimmend, daß bei Molchen der gewöhnliche Verlauf der Fortpflanzungstätigkeit sehr leicht in irgendeiner Weise gestört werden kann. Während der Brunst bedingt die Störung in kürzerer oder längerer Zeit eine Unterbrechung der Eiablage; beginnt sie dagegen sohon vor der Brunst und dauert in die eigentliche Laichzeit hinein fort, so unterdrückt eine äußere Schädigung die Fortpflanzungstätigkeit vollkommen.

Als Ursache für diese Erscheinungen wurden die verschiedensten Veränderungen in den Lebensbedingungen ermittelt. Dabei mag es bei oberflächlicher Betrachtung wohl den Anschein haben, als sei das Ergebnis der Versuche in einzelnen Fällen ein ganz verschiedenes, bei genauer Berücksichtigung der Einzelheiten ergibt sich jedoch stets die Tatsache, daß jede erhebliche Abweichung von den im Freileben herrschenden Bedingungen, soferne sie längere Zeit anhält, den gewöhnlichen Ablauf der Fortpflanzungstätigkeit abändert oder vollkommen unterbricht.

Im Freien ist ja gewöhnlich im Vorfrühling die Wasserwärme niedrig, sie beträgt $4-8$ Grad und steigt nur unter Tags unter dem Einfluß der Sonne höher. Die geringe Wärme bedingt auch, daß diejenigen Tierarten, die den Molchen zur Nahrung dienen, sich noch größtenteils verborgen halten, zum Teil auch im Puppenzustand verharren und sich jedenfalls nicht stärker vermehren. Dementsprechend ist die Nahrungsaufnahme im Vorfrühling eine nur geringe, ganz abgesehen davon, da $B$ bei niedriger Wasserwärme das Nahrungsbedürnnis selbst kein sehr hohes ist. Erst beim Ansteigen der Wasserwärme regt sich in den Molchen größere Freßlust, sie kann dann auch befriedigt werden, da nunmehr die Futtertiere in größerer Menge auftreten.

Bleibt dann die Wasserwärme längere Zeit auf einer gewissen Höhe, sinkt sie auch des Nachts nur mehr selten unter $8 \mathrm{Grad}$, so bessert sich, teils als Folge der höheren Temperatur selbst, hauptsächlich aber infolge der reichlicheren Nahrungsaufnahme der Allgemeinzustand der Molche so erheblich, daß schon nach verhältnismäßig kurzer Zeit die Brunst in Gang kommt. Ein gewisser Zeitabschnitt nach dem Winterschlaf ist jedoch stets erforderlich um den ganzen Körper zur Fortpflanzung geeignet $\mathrm{zu}$ machen. Dies beweisen deutlich genug Beobachtungen, die ich an freilebenden Tieren machen konnte. Tritt wie z. B. im Jahre 1920 die Erwärmung des Wassers sehr früh, schon Ende Februar 
oder Anfang März ein, so finden sich schon in den ersten Tagen des März Molche im Wasser, und doch vergeht noch eine erhebliche Zeitspanne bis die eigentlichen Liebesspiele und mit ihnen die Eiablage beginnt.

Offenbar verbraucht der Körper der Molche während des Winterschlafes eine gewisse Menge von Nahrungsstoffen und sammelt Schlacken in sich an. Im Frühjahr müssen dann zunächst diese ausgestoßen, jene ersetzt werden und erst dann kann die Fortpflanzungstätigkeit beginnen. Der Verbrauch während der kalten Jahreszeit kann allerdings kein sehr großer sein, oder wenigstens nicht die Keimdrüsen und Fettkörper beeinträchtigen, denn beide zeigen im Herbst den nämlichen Bau und die nämliche Größe wie im Frühjahr.

Der Beginn der Brunst wird eine bestimmte Zeit nach Beendigung des Winterschlafes durch das Zusammentreffen von zwei Bedingungen veranlaßt: Durch das Ansteigen der Wärme und die reichliche Nahrungszufuhr.

Auch im Freien sind die Molche während des Vorfrühlings den verschiedensten Schädigungen ausgesetzt; häufig genug tritt, nachdem schon längere Zeit warme Witterung herrschte, neuerdings Schneefall und Frost ein. In Gebirgsgegenden frieren manchmal im April die Laichtümpel noch mehrere Tage lang zu und durch solche Einflüsse wird die Entwicklung der Geschlechtsreife für längere oder kürzere Zeit verschoben. Veränderungen in den äußeren Bedingungen während der Vorlaichzeit gehören also im Leben der Molche zu den gewöhnlichen Vorkommnissen und dementsprechend sehen wir, daß ungünstige äußere Verhältnisse, mögen sie nun in ungeeigneter Beschaffenheit des Aufenthaltsortes, in mangelhafter Nahrungszufuhr, ungünstiger Beleuchtung oder niedriger Wasserwärme bestehen, verhältnismäBig gut vertragen werden. Die eben erwähnten Schädigungen verhindern während ihres Bestehens den Beginn der Fortpflanzungstätigkeit; währen sie zu lange, das heißt bis über den Anfang des Monats Mai hinaus, also über die Zeit, in der spätestens unter gewöhnlichen Verhältnissen die Brunst beginnt, an, so wird die Eiablage für das betreffende Jahr ganz unterdrückt.

Werden jedoch ron dem angegebenen Zeitpunkt an die Lebensbedingungen wieder günstig, so erweisen sich fast alle vorhergegangenen Beeinflussungen als unschädlich. Bei richtiger Beschaffenheit des Aufenthaltsortes kommt dann die Eiablage rasch in Gang, wenn die Wasserwärme dauernd über 8-10 Grad bleibt und die Ernährung reichlich ist.

Die Wirkungsweise der verschiedenen Schädigungen habe ich in übersichtlicher Weise in den beiden nachfolgenden Tabellen zusammengestellt und zwar getrennt nach Vorlaichzeit und Laichzeit. 
Wie nun Tabelle 1 zeigt, bedingt eine vorübergehende Schädigung im Vorfrühling nur in zwei Fällen die dauernde Unterdrückung der Fortpflanzungstätigkeit für das betreffende Jahr: nämlich erstens längerer Aufenthalt in völliger Dunkelheit und zweitens zu reichliche Nahrungszufuhr im ersten Vorfrühling bei geringer Wasserwärme.

Leicht zn verstehen ist dabei, daB der Aufenthalt im Dunkeln, der stets mit völligem Hunger verbunden ist, da die Tiere ja freiwillig keine Nahrung zu sich nehmen, eine schwerste Schädigung des Gesamtkörpers und damit die Unfähigkeit zur Eiablage im gleichen Jahr nach sich zieht. Die Beeinflussung ist hier eben eine zu tiefgreifende, sie bewirkt zu schwere Organschädigungen als daB sich ihre Folgen wieder rasch ausgleichen könnten. Wir haben es hier mit einer Art der Beeinflussung zu tun, der die Molche im Freien niemals ausgesetzt sind, ihr Körper ist also in keiner Weise, wenn man sich so ausdrücken darf, auf sie vorbereitet und muß ihr deshalb besonders leicht erliegen.

Weit schwerer verständlich ist die Tatsache, daß auch sehr reichliche Ernährung im Vorfrühling den Eintritt der Brunst verhindert. Es ist also wohl notwendig auf diesen Punkt etwas näher einzugehen. Wir erkennen einerseits, daß reichliche Ernährung verbunden mit Wärmeerhöhung den Beginn der Brunst erwirkt, beziehungsweise beschleunigt. Dieser Versuch gelingt jedoch nur an Molchen, die nach dem Winterschlaf schon einige Zeit (14-20 Tage) im Wasser gelebt haben. Wie ich ja schon oben zeigte, ruht während des Winterschlafes der Stoffwechsel fast ganz, ja man ist fast berechtigt zu sagen, daß während seiner Dauer das Leben fast unterbrochen ist. Die Abwicklung der eigentlichen Lebensvorgänge erstreckt sich demnach bei Molchen nur auf 6-7 Monate, in der Umgebung Münchens etwa auf die Zeit von Mitte April bis Mitte September, in der Umgebung Leipzigs auf die Zeit von Anfang März bis Ende September. Innerhalb eines halben Jahres vollziehen sich also am Körper, beziehungsweise an den Keimdrüsen die Veränderungen, die zur Erhaltung des Einzelwesens und der ganzen Art notwendig sind. Das ganze Jahresleben der Molche läßt sich demnach, wie das der meisten Tiere in die Zeit, der Fortpflanzung gliedern und in die beiden Zeitabschnitte, die vor, beziehungsweise nach ihr liegen In der Vorlaichszeit bereitet sich der Körper auf die Fortpflanzung vor, in der Nachlaichzeit erholt er sich von ihr und sammelt dabei wieder diejenigen Stoffe an, die ihn zur nächsten Fortpflanzung, vielleicht auch zum Winterschlaf befähigen. Die Winterruhe selbst unterbricht die gewöhnlichen Lebensvorgänge, sie ist aber zu ihrem normalen Ablauf nicht notwendig. Wird nämlich bei gefangen gehaltenen Tieren der Winterschlaf unterdrückt, so kann sich der eigentliche halbjährige Lebensvorgang zwei- 
Uber den Einfluß der Umwelt auf die Eierstöcke der Tritonen. 221

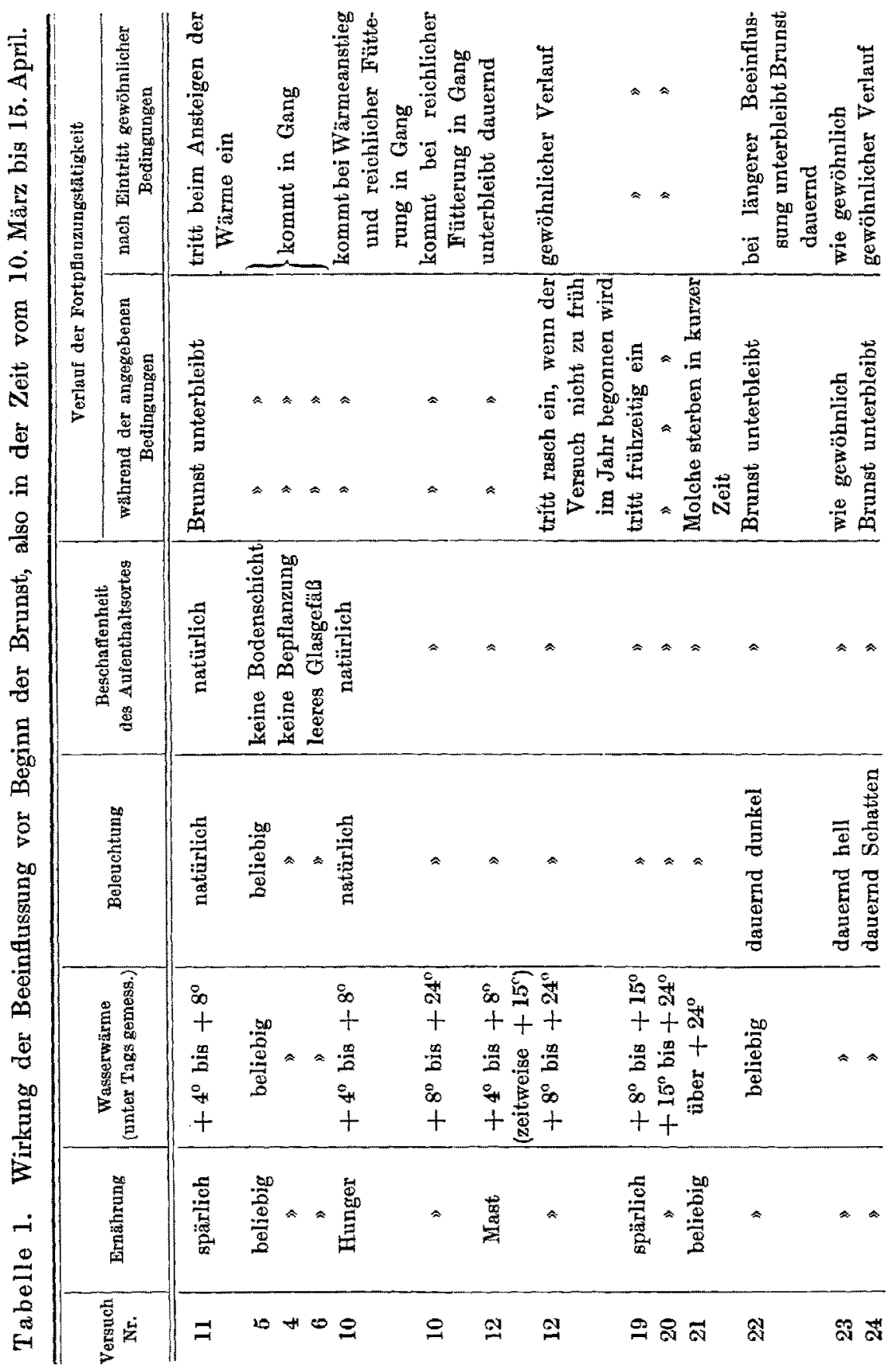


mal im Jahre wiederholen. Wir sehen dann unter entsprechenden Bedingungen die Molche im Frühjahr und im Herbst zur Fortpflanzung schreiten. In diesem Falle wird also der Winterschlaf durch die außergewöhnlich hohe Temperatur unterdrückt und gleichzeitig durch reichliche Nahrungszufuhr die Brunst ausgelöst.

Immer muß aber zwischen je zwei Fortpflanzungszeiten ein längerer Abschnitt liegen, in dem sich der Körper von der anstrengenden, alle Organe beeinträchtigenden Laichzeit erholt. Ist nun in dieser Zeit der Geschlechtsruhe die Nahrungszufuhr eine außergewöhnlich große, so speichert der Körper viel Fett in sich auf. Bei den Urodelen vergrößern sich in der Hauptsache die Fettkörper, aber auch das ganze Tier gewinnt wesentlich an Umfang und Gewicht. Tritt dieser Fall nach der Laichzeit ein, so sind offenbar durch die vorhergehende Absonderung von Keimzellen Hoden sowohl als auch Eierstöcke so sehr erschöpft, daß sie sich an der allgemeinen Massenzunahme des Körpers nicht beteiligen können. Es ist außerdem eine im ganzen Tierreich zu beobachtende Erscheinung, daß sich bei zu reichlicher Nahrungszufuhr die Keimdrüsen zurückbilden. Jeder Züchter weiß, daß Masttiere sich nicht zur Zucht eignen und eine ganze Anzahl von Versuchen haben ja gezeigt, dafs reichliche Nahrungszufuhr die Keimdrüsen selbst schädigt, ich erwähne nur die Arbeit Barfurths äber die Bachforelle (1886) und meine Mitteilung ïber Haushühner (1918).

Im ersten Vorfrühling, gleich nach Beendigung des Winterschlafes, sind die Keimdrüsen offenbar noch nicht dazu befähigt Eier oder Samenfäden hervorzubringen, obwohl sie anatomisch das nämliche Bild bieten wie einige Wochen später. Die überschüssig aufgenommene Nahrung, die später, wenn die Gonaden die volle Tätigkeit entfalten können, zum Aufbau der Keimzellen verwendet werden, kommen hier dem Körper selbst zu gute, sie werden im ganzen Organismus aufgespeichert und bedingen zunächst eine außergewöhnliche Vergrößerung des Fettkörpers. Durch diese unzeitgemäße Mast werden die Keimdrüsen offenbar so schwer geschädigt, daß sie im gleichen Jahr nicht mehr imstande sind Eier oder Samenzellen hervorzubringen.

Ganz ähnliche Erscheinungen sehen wir ja auch häufig genug bei Molchen und anderen Tierarten, die in Gefangenschaft gehalten werden. Hier wird der Winterschlaf gewöhnlich durch die hohe Wärme des Aufenthaltsortes verhindert und gleichzeitig erhalten die Tiere reichlich Nahrung. Sie setzen dann Fett an und schreiten trotz der anscheinend besten Pflege nicht zur Fortpflanzung.

Reichliche Fütterung während des Winters oder während des ersten Vorfrühlings bedingt also außergewöhnliche Nahrungszufuhr zu einer Zeit, in der die Keimdrüsen noch nicht befähigt sind, die dem Körper 
Uber den Einfluß der Umwelt auf die Eierstöcke der Tritonen. 223

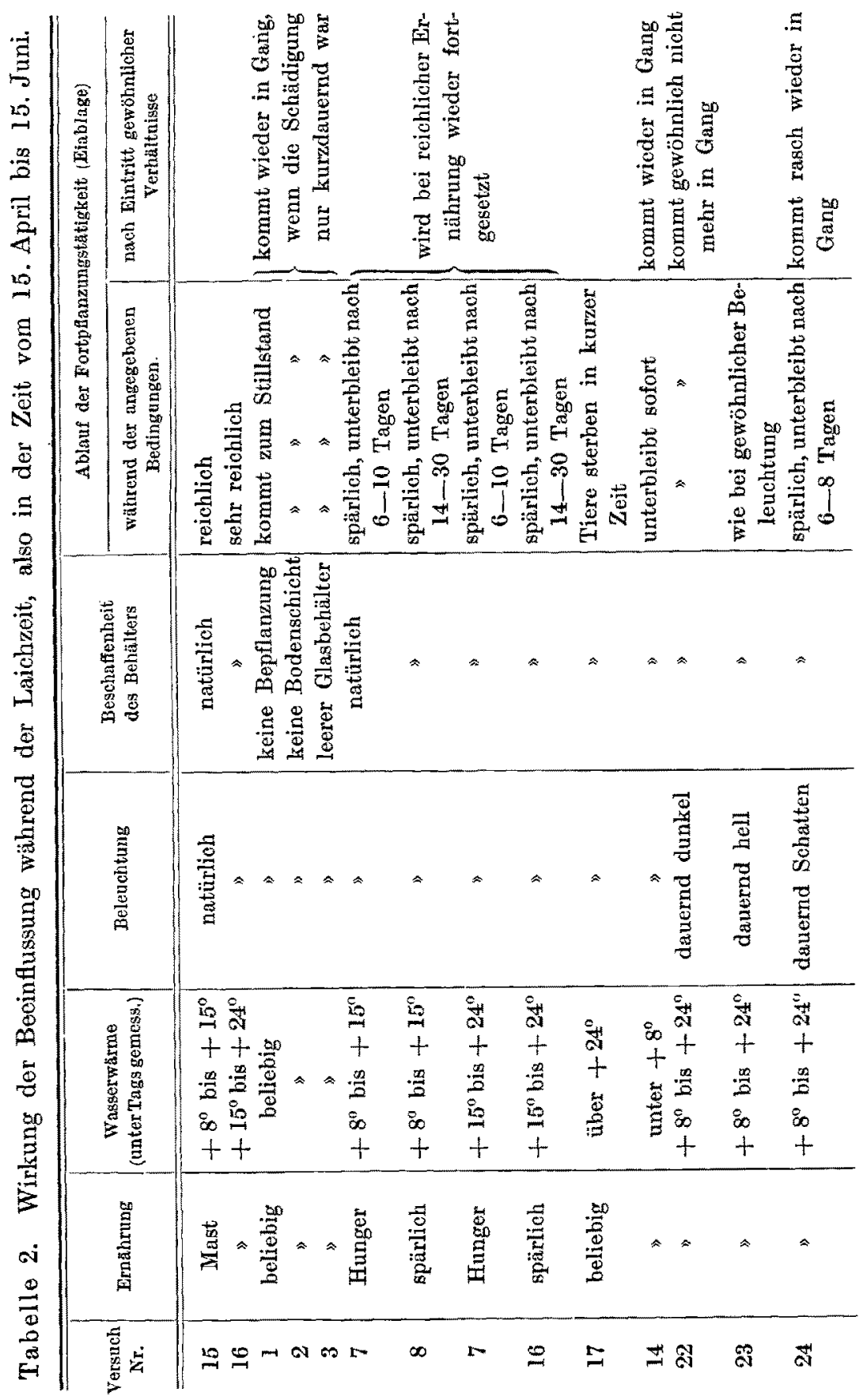


zugeführten Nahrungsmengen für sich zu verwerten. Diese regelwidrigen Vorgänge bewirken dann Fettablagerungen im Körper und dadurch eine längerdauernde Schädigung der Eierstöcke und Hoden. Sind dagegen einige Zeit nach dem Winterschlaf die während der langen Ruhezeit im Körper aufgespeicherten Schlacken ausgestoßen, so sind die Keimdrüsen zur Hervorbringung von Geschlechtszellen befähigt und benützen dann alle dem Körper überflüssig zugeführten Nahrungsmittel zum Aufbau der wachsenden Follikel und der reifenden Samenzellen. Erst wenn dieser Zeitpunkt eingetreten ist, bewirkt reichliche Ernährung den Beginn der Brunst.

Ist die Eiablage einmal im Gange, so machen sich die Folgen äußerer Schädigung natürlich rascher und leichter bemerkbar, führen sie doch stets in kürzerer oder längerer Zeit zum Stillstand des Laichgeschäftes. (Tabelle 2.) Auch hier vermögen wir jedoch die Ergebnisse der Versuche nur dann richtig zu verwerten, wenn wir die im Freien herrschenden Lebensbedingungen kennen. Es ist selbstverständlich, $\mathrm{da} B$ sich im Freien die Eiablage nur schwer überwachen läßt; immerhin findet man während der Brunstzeit in Tümpeln, die von Molchen belebt sind, die Wasserpflanzen gewöhnlich dicht mit Eiern besetzt und aus ihrem Entwicklungszustand lassen sich Rückschlüsse auf die Zeit der Ablage ziehen. Vor allem aber gibt uns der Sektionsbefund, den wir bei frisch gefangenen Molchweibchen gewinnen, sichere Anhaltspunkte.

Im Freien wird im allgemeinen die Brunst, ist sie einmal im Gange, nicht leicht wieder unterbrochen. Geringe und kürzere Schwankungen in der Wasserwärme, die gewöhnlichsten Störungen, denen die Molche ausgesetzt sind, bewirken nur eine Verlangsamung, nicht aber den völligen Stillstand des Laichgeschäftes. Immerhin ist aber auch im Freien eine völlige Unterbrechung der Brunst möglich, ja sogar nicht allzu selten. Ich konnte sie mehrmals beobachten, sie war in jedem Fall durch einen Wettersturz bedingt. Warme Wittérung im März bringt die Molche rasch in Hochbrunst, Anfang April werden reichlich Eier abgelegt. Frisch gefangene Molchweibchen zeigen dann Bauchhöhleneier und gefüllte Eileiter. Mitte April bis Anfang Mai setzt dann Frost und Schneefall ein, die Wasserwärme sinkt bis auf $4 \mathrm{Grad}$. Hält dies mehrere Tage an, so verkriechen sich die Molche im Schlamm, die abgelegten Eier entwickeln sich nur langsam weiter und gehen sicher auch großenteils zugrunde. In den frisch gefangenen Weibchen finden sich dann weder Bauchhöhlen noch Eileitereier, noch auch reife Eierstockseier, die Follikelentwicklung ist also zum Stillstand gekommen und nimmt erst beim Ansteigen der Wärme wieder ihren Fortgang.

Die eben erwähnten Tatsachen mögen auch der Grund für die An- 
nahme vieler Forscher sein, die Eiablage erfolge bei Tritonen in einzelnen Schüben. Diese Meinung ist an sich unrichtig, das Laichgeschäft vollzieht sich, wie ja die in Gefangenschaft genau überwachten Tiere beweisen, ohne Unterbrechung fortdauernd. Veränderungen in den äußeren Bedingungen können jedoch eine schubweise Eiablage vortäuschen, da sie eine zeitweise Unterbrechung der Brunst zur Folge haben. Sinkt in der Gefangenschaft die Wasserwärme für längere Zeit unter 8 Grad, so kommt auch hier die Eiablage zum Stillstand und setzt bis zum ermeuten Anstieg der Wärme aus. Wir sehen hier dann die nämlichen Verhältnisse wie im Freileben bei einem Wettersturz. $\mathrm{Zu}$ hohe Wasserwärme bedingt ebenso wie längerer Aufenthalt im Dunkeln die völlige Unterbrechung der Eiablage. Es handelt sich dabei um, außergewöhnliche Vorkommnisse, denen die Tiere im Freileben nicht ausgesetzt sind, ihr tiefgreifender EinfluB kann nicht verwundern.

Weit schwerer ist es wieder zu verstehen, daß auch die beschriebenen Veränderungen im Aufenthaltsort die Brunst unterbrechen. Umgestaltungen in den Stoffwechselvorgängen, wie sie bei stärkeren Schwankungen in der Nahrungszufuhr und der Wasserwärme zweifellos in Frage kommen, scheiden hier aus. Die Nahrungsaufnahme war ja bei allen diesen Versuchen gut und die Wasserwärme war die gewöhnliche. Auch ein Fortfall des geschlechtlichen Reizes kommt nicht in Betracht. Die Weibchen wurden ja stets mit Männchen zusammengehalten und diese führten oft noch lange Zeit ihre Liebesspiele aus, setzten auch manchmal noch Samenpakete ab und doch kam die Eiablage zum Stillstand. Uberhaupt scheint ja der Geschlechtsreiz bei der Fortpflanzungstätigkeit weiblicher Molche keine große Rolle zu spielen.

Der Grund für den Stillstand der Eiablage bei Veränderungen in der Beschaffenheit des Aufenthaltortes muB demnach ein anderer sein. Die ungewohnte Umgebung, das Fehlen der Verstecke erweckt in den Molchen offenbar das Gefuhl der Angst, der Unruhe. Dieses Unbehagen läßt in ihnen nicht die Stimmung aufkommen, die zum regelrechten Ablauf der Brunst notwendig ist. Auch diese Vorgänge sind offenbar wieder von entsprechenden Veränderungen der Körpersäfte begleitet, die sich in ihren Wirkungen in der Tätigkeit des Eierstockes geltend machen. Geradeso wie bei der Deutung meiner Versuche an Haushühnern sind wir also auch hier berechtigt, von psychischen Eindrücken zu sprechen. Sie sind, ebenso wie die nachweisbaren Veränderungen an den Eierstöcken aber nur erkennbare Veränderungen im Bau des Gesamtorganismus, die durch die Umgestaltung des Aufenthaltsortes veranlaßt sind. Die krankhaften Vorgänge an den Eierstöcken haben ihrerseits dann wieder den Stillstand des Laichens zur Folge. 
Ganz ähnliche Verhältnisse werden auch durch eine zu dichte Besetzung der Behälter bewirkt, die starke andauernde Unruhe, erzeugt durch die Anwesenheit der vielen Tiere, verhindert die Weibchen am Laichen. Auch hier sehen wir in der Folge anatomisch nachweisbare Veränderungen, schwere Rückbildungen an den Eierstöcken auftreten ${ }^{1}$ ).

Sehr sinnfällig ist des weiteren der Einfluß der Ernährung während der eigentlichen Brunstzeit. Hunger oder spärliche Fütterung bringen die Eiablage in kürzerer oder längerer Zeit zum Stillstand, reichliche Nahrungszufuhr, bei sonst günstigen Bedingungen steigert die Laichtätigkeit.' Das gegenseitige Abhängigkeitsverhältnis der beiden Erscheinungen ist ein so sinnfälliges und so leicht verständlich, daß ich es hier nicht näher erörtern muß. Beim Hunger werden zunächst die im Körper und vor allem im Fettkörper gespeicherten Nährstoffe zum Aufbau der Eier verwendet, erst wenn sie bis zu einem gewissen Grade verbraucht sind, kommt die Eiablage zum Stillstand.

Merkwürdigerweise werden dabei aber nicht alle großen, mit gelbem Dotter beladenen Follikel ausgestoßen und niemals findet eine Rückbildung von mehreren solchen Follikeln statt, während gleichzeitig andere in den Eierstöcken des gleichen Tieres weiter wachsen, also gewissermaßen auf Kosten der zugrunde gehenden ausreifen. Sondern stets ist die Eiablage beendet, wenn wirklich eine größere Anzahl von gelben Follikeln gleichzeitig der Atresie verfallen. Tch komme auf diese Erscheinung noch später zurück.

1) Ein unmittelbarer Einfluß von seiten des Zentralnervensystems anf die Keimdrüsen, wie ihn Ceni (1914) und de Lisi (1921) annehmen, kommt dabei nicht in Frage. Durch Eingriffe in das Nervensystem, die ein solches Abhängigkejtsverhältnis dartun sollen, wird $\mathrm{ja}$, wie ioh schon früher (1914) gezeigt habe, stets eine schwere Schädigung des Gesamtkörpers gesetzt, die dann ihrerseits erst die Rückbildungsvorgänge an den Keimdrüsen bedingt. Dabei ist es selbstverständlich, daß die Entfernung größerer Hirnabschnitte um so sehwerere Allgemeinschäden und damit um so tiefgreifendere Veränderungen an den Keimdrüsen setzen muB, je besser das Nervensystem entwickelt ist, je höher das betreffende Tier also steht. Bei niederen Arten, wie z. B. bei den Schildkröten (de Lisi 1921) wird durch die Enthirnung der Allgemeinzustand verhältnismäßig wenig beeinträchtigt. Dementsprechend sind bei ihnen die Veränderungen an den Keimdrüsen nach der Operation nur gering. Es ist aber nicht richtig, so wie de Lisi dies tut, aus den Ergebnissen der bisher vorliegenden Versuche zu schließen, bei Säugetieren und Vögeln sei die Keimdrüsentätigkeit unmittelbar abhängig von der Funktion des Vorder- und Mittelhirnes, bei Reptilien aber nioht. Es läßt sich vielmehr nur feststellen, daß bei gewissen Reptilienarten die Entfernung größerer Hirnteile nur geringe Allgemeinschädigungen und damit unbedeutende Keimdrüsenveränderungen bedingt, während bei Warmblütern der nämliche Eingriff stets eine schwere Allgemeinschädigung and im Anschluß daran schwere Rückbildungen an den Keimdrüsen nach sich zieht. 
Zum Schluß ist noch der Einfluß des Lichtes zu erwähnen. Zum regelmäßigen Ablauf der Brunst ist zeitweise Besonnung der Behälter unbedingt notwendig, fehlt sie, so kommt die Eiablage nach kurzer Zeit zum Stillstand, auch hier läßt sich der Einfluß nur so erklären, daß der dauernde Aufenthalt im Schatten gewisse Veränderungen am Körper setzt; vielleicht gehen auch diese mit dem Gefühl des Unbehagens einher, vielleicht läßt das Fehlen der Besonnung auch wichtige chemische Veränderungen, die uns bisher noch unbekannt sind, in Wegfall kommen. Daß es nicht einfach die geringere Wasserwärme ist, die den Stillstand der Eiablage bedingt, koninte ich ja durch entsprechende Versuche zeigen.

Im Freien sind die Laichtümpel der Molche vielfach der Sonne sehr stark ausgesetzt, häufig genug konnte ich die Tiere in Sandgruben auffinden, in denen schon im Juni die Wasserwärme an der Oberfläche des öfteren auf $25-30$ Grad stieg, allerdings nur vorübergehend. Die Molche verkriechen sich dann während der heißesten Tageszeit meistens im Schlamm, trotzdem wirkt aber die unmittelbare Bestrahlung offenbar günstig auf sie ein, jedenfalls bewirkt ihr Ausfall den Stillstand der Brunst.

Alle besprochenen Störungen unterdrücken die Laichtätigkeit bei kurzer Dauer nur vorübergehend, bei nicht zu langem Bestehen kommt die Fortpflanzungstätigkeit, selbst wenn sie ganz unterbrochen war, wieder in Gang, sobald die Tiere wieder in günstige Lebensbedingurgen gebracht werden. Allerdings nur dann, wenn der schädigende Einfluß kein zu langer war.

Auch diese Feststellung bedarf jedoch einer gewissen Einschränkung. Bei weitester Begrenzung vollzieht sich die Eiablage von Triton vulgaris in der Zeit zwischen dem 10. April und 15. Juli. Sie beginnt frühestens anfangs April, spätestens Mitte. Mai. Durch entsprechende Maßnahmen, nämlich niedrige Wasserwärme und spärliche Fütterung läßt sich auch in der Gefangenschaft der Beginn des Laichens bis Mitte Mai hinausschieben und kommt erst dann bei entsprechenden äußeren Verhältnissen wieder in Gang. Andererseits läßt sich der Anfang der Brunst auch verfrühen, nämlich bei Tieren, die in ungewöhnlicher Weise den Winterschlaf abgehalten haben, zu früh aus ihm erwachen und dann schon Mitte März oder noch früher in Brunst treten ${ }^{1}$ ). Durch keine Maßnahme gelingt es aber bei Molchen,

1) Auf die oben erwähnte Tatsache, daß Molche in Gefangenschaft unter entsprechenden Bedingungen auch im Herbst in Brunst treten können, will ich hier nicht eingehen. Offenbar wird in diesem Falle nur die Zeit des Winterschlafes, in dem sonst alle Lebensworgänge fast ganz zum Stillstand kommen, ausgeschaltet: das Leben geht in Herbst den gleichen Gang weiter, den es sonst naoh 6 monatlicher, fast völliger Unterbrechung im Frühjahr eingeschlagen hätte. 
die im Frühjahr gefangen wurden oder in der gewöhnlichen Weise in der Gefangenschaft ihren Winterschlaf verbrachten, die Eiablage vor Mitte März in Gang zu bringen oder ihren Beginn über die Mitte des Mai hinauszuschieben. Natürlich gilt diese Feststellung nur für Tiere, die im Frühjahr, im Februar oder März nach dem Erwachen aus dem Winterschlaf das Wasser aufsuchen. Durch entsprechende Versuche müßte noch ermittelt werden, ob nicht bei künstlicher Verlängerung des Winterschlafes die Laichzeit weiter verschoben werden kann, in ähnlicher Weise wie sie durch Verkürzung der Winterruhe in der Gefangenschaft häufig verfrüht eintritt.

Sicher ist des weiteren, daß der Molchkörper nach dem Winterschlaf eine Zeitlang nicht zur Eiablage befähigt ist. Nur unter Berücksichtigung dieser angegebenen Grenzen läßt sich also die Laichzeit durch Änderungen in den äußeren Bedingungen verschieben. Setzt dagegen die reichliche Ernährung zu früh ein, so verhindert sie das Zustandekommen der Brunst, treten die günstigen Bedingungen zu spät ein, so kommt die Eiablage nicht mehr in Gang. Desgleichen führt eine Unterbrechung der Brunst, gleichgültig wodurch sie bedingt ist, um so eher ihren völligen Stillstand herbei, je später in der Laichzeit sie eintritt und je länger sie dauert, je mehr sie sich also der äußersten Grenze des natürlichen Brunstendes nähert.

Durch die veränderten äußeren Bedingungen läßt sich die Eiablage also innerhalb gewisser Grenzen zeitlich verändern, nicht aber beliebig verschieben. Der zeitgemäße Vollzug der Fortpflanzungstätigkeit ist offenbar eine dem Körper innewohnende Eigenschaft, die sich nur innerhalb gewisser, in der ganzen Anlage der Art bedingter Grenzen abändern läßt. Auch auf diese Tatsache werde ich nach der Besprechung der an den Eierstöcken erhobenen Befunde noch zurückkommen.

\section{Die Veränderungen an den einzelnen Oocyten.}

Wie aus der Besprechung der Versuchsreihen deutlich zu ersehen ist, sind alle Veränderungen im Ablauf der Fortpflanzungstätigkeit von mehr oder weniger tiefgreifenden anatomisch nachweisbaren Umgestaltungen der Eierstöcke begleitet, beziehungsweise durch sie bedingt. Alle Erscheinungen die dabei zu Tage treten, lassen sich jedoch nur dann richtig verstehen, wenn wir den gewöhnlichen Verlauf der Eireife kennen. Mit sciner Schilderung will ich daher auch beginnen, ohne mich in einer genauen Beschreibung der Oogenese zu verlieren, sie soll gegebenenfalls in einer besonderen Mitteilung erfolgen.

Die Reifung des Tritoneneies verläuft im großen und ganzen in den nämlichen Bahnen wie die des Olmeies, die ich früher $(1920 \mathrm{~b}$, 1921a) geschildert habe. Nur die Nukleolen zeigen etwas anderes Verhalten. 
In den Eierstöcken aller Molche lassen sich ohne Rücksicht auf die Jahreszeit und die Lebensverhältnisse stets Oogonien und vereinzelte Oogonienteilungen nachweisen. Jeweils nach der Eiablage scheint es zu einer lebhafteren Oogonienvermehrung zu kommen.

Die jüngsten Oocyten besitzen einen verhältnismäßig großen Kern bei kleinem Protoplasmaleib, sie wachsen rasch zu einem bestimmten Umfang heran. Während dieser ersten Zeit des Wachstums ist der ganze Kern gleichmäßig von einem feinen Chromatingerüst durchsetzt. Eine große Anzahl von jungen Oocyten geht unmittelbar nach der Entstehung physiologischerweise zugrunde, ihre Kerne bilden zunächst unregelmäßige, gelappte, auch hantelartige Formen und zerfallen schließlich, während die ganze Zelle fettig entartet.

Am Ende der ersten Wachstumsperiode, der Zeit des "proportionalen Kernwachstums " (Boveri, 1904), ist das anfängliche Mißverhältnis in der Kernplasmarelation ausgeglichen, die Oocyte besitzt jetzt einen Durchmesser von $30-35 \mu$, bei einer Kerngröße von 20 bis $24 \mu$.

Nunmehr vollziehen sich wichtige Umgestaltungen am Kerngerüst: die Vorbereitungen zur ersten Reifungsteilung. Es kommt zur Ausbildung eines Monospirems, das sich polar anordnet ("Bukettstadium «), der Länge nach spaltet und schließlich in die Einzelchromosomen zerfällt. Während dieses Vorganges entstehen an den Kernschleifen feine seitliche Ausläufer, es bilden sich die "Lampenzylinderputzerchromosomen« (Rückert, 1892).

In der Folgezeit verlängern sich diese seitlichen Chromosomenausläufer mehr und mehr, sie verändern gleichzeitig ihr chemisches Verhalten und nehmen bald nicht mehr die gewöhnlichen alkalischen Kernfarbstoffe auf, sondern lassen sich mit sauren Plasmafarben darstellen. Nach kurzer Zeit durchsetzen sie den ganzen Kern als gleichmäßiges oxychromatisches Gerüst. Während dieser Veränderungen vergrößert sich die Oocyte nur wenig, sie hat jetzt einen Durchmesser von $50-60 \mu$ bei $32-36 \mu$ Kerngröße.

Plasmaleib und Kern nehmen dann ziemlich gleichmäßig an Ưmfang $\mathrm{zu}$, der Zelleib vergrößert sich allerdings etwas stärker, so lange bis der Gesamtdurchmesser der Oocyte etwa $600 \mu$ bei ungefähr $250 \mu$ Kerndurchmesser beträgt. Bis zu diesem Zeitpunkt durchsetzt den ganzen Kern ein gleichmäßiges, von den seitlichen Ausläufern der Chromosomen gebildetes Kerngerüst, es vergrößert sich im gleichen Verhältnis wie der ganze Kern und erfährt deutliche Umgestaltungen hinsichtlich seiner chemischen Reaktionsweise, jedoch nicht hinsichtlich seiner Form. Der Protoplasmaleib zeigt. während dieser Zeit feinen, netzigen Bau und keine Einlagerung von Dotterschollen.

Dieser zuletzt beschriebene Abschnitt der Eientwicklung erstreckt 
sich über sehr lange Zeit, er dauert monate-, vielleicht sogar jahrelang. Anscheinend kann während seines Bestehens das Wachstum zeitweise überhaupt ganz zum Stillstand kommen.

Erst bei größeren Oocyten beginnen wieder wesentliche Umgestaltungen, die sich verhältnismäßig rasch abspielen. Im Kern sondern sich die Einzelchromosomen aus dem gleichmäßigen Chromatingerüst ab und rücken in der Kernmitte zusammen, im Plasmaleib wird der grobschollige, gelbe Dotter gebildet, seine Ansammlung führt zur schnellen Vergrößerung des Zelleibes, während der Kern nurmehr ganz wenig an Masse zunimmt.

Hat die ganze Oocyte einen Durchmesser von 1000-1200 $\mu$ erreicht, so ist ihr Wachstum beendet. Der Kern besitzt jetzt eine Größe von etwa $200 \mu$ und liegt noch in der Mitte der Zelle. Offenbar können die Oocyten in diesem Zustand längere Zeit verharren. Man findet Follikel vom oben beschriebenen Bau in den Eierstöcken aller nicht beeinflußter Tiere zu jeder Jahreszeit.

Bevor ein $\mathrm{Ei}$ aus dem Eierstock ausgestoßen wird, wandert der Kern an die Oberfläche, dabei plattet er sich ab und verkleinert sich. Die Chromosomen bilden sich zu kleinen Schleifen um. Erst wenn das Keimbläschen unmittelbar unter der Oberfläche liegt, ist der Follikel sprungreif. In diesem Zustande können die Eier nicht längere Zeit verharren, wie deutlich genug aus der Tatsache hervorgeht, daß Follikel mit peripher gelegenem Kern nur in den Eierstöcken von Molchen aufgefunden werden, die in der Eiablage stehen.

Demnach können wir auch in der Entwicklung des Tritoneneies einzelne Abschnitte unterscheiden, die, ganz abgesehen vom Verhalten des Chromatins, durch ihr versehieden rasches Wachstum gekennzeichnet sind. Nämlich:

1. Die erste Wachstumsperiode, von der Entstehung der Oocyte bis zum Abschluß des proportionalen Wachstums.

2. Die Prophasen der ersten Reifungsteilung, beginnend mit der Ausbildung des Monospirem bis zu seinem Zerfall in Einzelchromosomen. Während dieser Zeit findet fast keine Vergrößerung statt.

3. Die zweite Wachstumsperiode, von der Ausbildung des gleichmäßig den ganzen Kern durchsetzenden Netzwerks bis zum Beginn der Wanderung des Kernes an die Oberfläche. Sie läßt sich in zwei Unterabteilungen sondern, nämlich:

a) den Abschnitt des langsamen Wachstums, während dessen das gleichmäßige Chromatingerüst den Kern durchșetzt, der sich ungefähr gleichmäßig wie der Plasmaleib vergrößert und

b) den Abschnitt der raschen Dotteranhäufung, während dessen der Kern kaum an Größe zunimmt, obwohl in seinem Inneren die Abgrenzung der Einzelchromosomen statthat. 
Schließlich folgt noch die Oberflächenwanderung des Kernes, der Follikelsprung und die erste Reifungsteilung.

Während der ersten Wachstumsperiode vergrößern sich Kern und Plasmaleib ziemlich gleichmäßig sehr rasch, während des ersten $\mathbf{A b}$ schnittes der zweiten Periode ist dagegen die VergröBerung beider Zellanteile eine sehr langsame, in ihr zeigt der Kern ein Verhalten ähnlich dem, das wir sonst bei ruhenden Zellen feststellen können, nämlich ein gleichmäßiges Gerüst, in dem sich die Einzelchromosomen nicht abgrenzen lassen ${ }^{\mathbf{l}}$.

Der zweite Abschnitt der zweiten Periode ist durch die besonders rasche Vergrößerung gekennzeichnet, sie betrifft jedoch ausschließlich den Protoplasmaleib.

In den Eierstöcken von Molchen, die während der Eiablage gefangen und sofort getötet wurden, findet man im allgemeinen nur ganz wenig atretische Follikel. Die Rückbildung betrifft stets nur Oocyten während der ersten Wachstumsperiode und ganz vereinzelte während des zweiten Abschnittes der zweiten Wachstumsperiode. Sie setzt also offenbar nur in solchen Entwicklungszeiten ein, in denen das Wachstum und damit auch die Aufnahme und Assimilation von Nahrungsstoffen eine sehr rege ist. Zunächst muß dieser Befund wundernehmen, wenn wir bedenken, daß im Eierstock der Säuger und Vögel eine sehr große Menge von Follikeln während der Reife physiologischerweise zugrunde geht, weit mehr als jemals zur Ablage ge: langt. Der Kampf der Eier ist also im Eierstock der Urodelen viel weniger heftig, als in dem der Warmblüter und erstreckt sich eigentlich nur auf die jüngsten Oocyten, lediglich bei ihnen erkennen wir auch Bilder, die auf eine gegenseitige Beeinflussung hinweisen, die Form wird durch die Nachbaroocyten verändert und oft in hohem Grade umgestaltet. Die großen Follikel dagegen besitzen fast immer kreisrunde Gestalt, eine unmittelbare Beeinflussung durch die Nachbarorgane ist hier also nicht zu erkennen.

Und doch läbt sich das versohiedene Verhalten der Eierstockseier bei den einzelnen Arten leicht erklären: Bei Vögeln und besonders bei Säugetieren kann nur eine ganze geringe Zahl von Eiern tatsächlich zur Befruchtung und Entwicklung kommen und zwar wegen der ausgedehnten Brutpflege, die das jugendliche Tier während der

1) Ich betone dabei aber ausdrücklich, daß bei der Eireifung der Tritonen die Kontinuität der Chromosomen niemals durch ein sogenanntes Zerstäubungsstadium " unterbrochen wird, sie läßt sich vielmehr beweisen, wenngleich es nicht gelingt, die Individualität jedes Einzelohromosoma während der ganzen Reifung zu verfolgen. Aber auch an ihr kann bei genauer Berücksiohtigung der Befunde kein Zweifel bestehen, niemals verwandeln sich die Kernschleifen in Nukleolen und umgekehrt. 
ersten Zeit nach der Befruchtung teils innerhalb, teils außerhalb des Organismus genießt. Die überwiegende Mehrzahl der Follikel muß also innerhalb des Eierstockes zugrunde gehen, nur eine ganz geringe Anzahl reift tatsächlich voll aus, wird befruchtet und trägt so zur Erhaltung der Art bei. Nach der Ansicht vieler Forscher [besonders His (1865) und v.Hansemann (1909)] handelte es sich bei den ausgestoßenen Eiern der Warmblüter um diejenigen Follikel, die sich im Kampf der Eier im Eierstock am besten bewährt haben, also um die kräftigsten und deshalb zur Erhaltung der Art tüchtigsten Zellen. Die Brutpflege der Eltern schütat die reifenden Embryonen und jungen Tiere dann weitgehend vor schädigenden Einflüssen, ihr ist es auch zuzuschreiben, daß die Vernichtungsziffer bei Warmblütern im allgemeinen gering ist. Das nämliche trifft im großen und ganzen auch für die Reptilien zu, auch bei ihnen erfahren die befruchteten Eier eine Brutpflege von seiten der Mutter, die um so länger währt, je ungünstiger die umgebenden Verhältnisse sind.

Anders bei der Mehrzahl der Amphibien und niederen Tiere. Von bestimmten Ausnahmen abgesehen erfahren bei ihnen die. Eier nach dem Verlassen des Eileiters keine Brutpflege und sind ebenso wie die ausgeschlüpften Jungen schutzlos dem Kampf ums Dasein preisgegeben. Die Vernichtungsziffer ist bei ihnen sehr hoch und dementsprechend sehen wir, daß bei allen diesen Arten auch eine sehr große Anzahl von Eiern abgelegt wird, um so größer, je mehr die junge Brut gefährdet ist. Im Eierstock selbst findet, da ja alle Eier wirklich befruchtet und abgelegt werden können, so gut wie kein Kampf der Eier statt, er beginnt erst in voller Stärke mit dem Augenblick der Ablage, von da ab ist jedes $\mathrm{Ei}$ nur auf die in ihm selbst enthaltenen Eigenschaften angewiesen, den äußeren Einflüssen preisgegeben.

Die Auswahl des Tüchtigsten unter den Eiern findet bei den Saugetieren und Sauropsiden größtenteils schon im Eierstock selbst statt, bei den meisten niederen Arten aber erst nach der Ablage. Dementsprechend sehen wir auch, daß bei den Molchen, die ja während ihrer Entwicklung besonders gefährdet sind, im Eierstock kaum Follikel zugrunde gehen, dagegen wird eine große Anzahl von Eiern abgelegt.

Kommt nun bei Tieren, die sich in voller Brunst befinden, die Eiablage infolge äußerer Schädigungen zum Stillstand, so werden zunächst alle Follikel, in denen der Kern sich schon auf der Wanderung zur Oberfläche befindet, noch ausgestoßen. Offenbar benötigt der Kern für diese Ortsveränderung nur sehr kurze Zeit, währenddessen machen sich die schädigenden Einflüsse noch nicht sinnfällig geltend. Damit soll jedoch nicht gesagt sein, daß die fraglichen Follikel, ebenso die 
Bauch- und Eileitereier nicht doch noch durch Störungen, die den Gesamtkörper des Muttertieres betreffen, verändert und geschädigt werden können. Ich halte einen solchen Einfluß sogar für recht wahrscheinlich, habe ihm jedoch bei meinen Untersuchungen keine Aufmerksamkeit zugewendet, sondern nur die morphologisch nachweisbare Wirkung auf die Eierstockseier geprüft. Bei ihnen läßt sich, wie schon gesagt, während der allerletaten Zeit der Eireifung kein Einfluß mehr feststellen.

Auch an den übrigen Follikeln lassen sich gröbere histologische Veränderungen nur dain beobachten, wenn die äußere Schädigung, die zur Unterbrechung der Eiablage führt, längere Zeit anhält. Bei kurzer Dauer von nur 2-4 Tagen lassen sich kaum größere Veränderungen nachweisen, obgleich auch hier die Zahl der großen atretischen Follikel zunimmt. Je länger die äußere Schädigung anhält, desto mehr Follikel gehen zugrunde und zwar vergrößert sich ihre Zahl um so rascher, je näher die Zeit des natürlichen Abschlusses der Brunst heranrückt.

Niemals werden jedoch alle Follikel eines Tieres gleichmäßig von der Rückbildung betroffen, obwohl doch zweifellos auf alle die Schädigung in gleicher Weise einwirkt. Wir sehen vielmehr, daß die Atresie nur solche Eierstockseier betriff, die sich in der ersten Wachstumsperiode oder im zweiten Teil der zweiten Wachstumsperiode befinden, in deren Kernen sich also wichtige Veränderungen an der chromatischen Substanz abspielen. Am sinnfälligsten sind die Umgestaltungen dabei an den Oocyten, in deren Leib sich grobscholliger gelber Dotter befindet, also in den größten Follikeln des Eierstockes, von 0,6-1,2 mm Durchmesser. Sie bilden sich stets zuerst zurück, dann folgt die überwiegende Mehrzahl der Follikel, die sich im Zustand des proportionalen Wachstums und in der Vorbereitung zur ersten Reifungsteilung befinden. Doch wird ihre Zahl gleichzeitig dauernd durch neue Oogonienteilungen ergänzt.

Fast nie betrifft dagegen die Atresie solche Eierstockseier, die sich in der ersten Hälfte der zweiten Wachstumsperiode befinden, bei denen sich Kern und Plasmaleib gleichmäßig vergrößern und in deren Kern die seitlichen Chromosomenausläufer ein gleichmäßiges Chromatingerüst bilden. Bei sehr langer Dauer der Beeinflussung besteht deshalb der ganze Eierstock nur noch aus Oocyten der eben beschriebenen Form und erst dann beginnen langsam auch von ihnen die größeren der Rückbildung zu verfallen. Dieser Vorgang führt jedoch niemals zu einem völligen Schwund aller Follikel, selbst wenn die Schädigung nach sehr langer Dauer den Tod des Tieres bewirkt, zeigen die Eierstöcke stets noch einen Bau wie ihn Abb. 9 wiedergibt, sie bestehen nur aus Follikeln in der ersten Hälfte der zweiten Wachs- 
tumsperiode, zwischen denen sich ganz vereinzelte Oogonien, Oogonienteilungen und kleinste Oocyten finden.

Die Tatsache, daß selbst so stark zurückgebildete Eierstöcke, wie die eben beschriebenen, beim Eintritt günstiger Lebensbedingungen ihre Tätigkeit wieder voll entfalten können, zeigt deutlich genug, daß die in ihnen verbliebenen Follikel gar nicht oder nur in geringstem Maße geschädigt sein können.

In der Entwicklung des Eierstockseies der Molehe können wir also zwei empfindliche Abschnitte (sensible Perioden) unterscheiden. In ihnen sind äußere, das ganze Tier treffende Schädigungen von hervorragendem Einfluß: Die Zeit von der Entstehung der Oocyte bis zur Ausbildung des gleichmäBigen Chromatingerüstes und die Zeit der Anhäufung des gelben Dotters, von der Auflösung des Chromatingerüstes bis zum Platzen des Follikels. Beide Abschnitte sind durch ihr rasches Wachstum und die tiefgreifenden Veränderungen gekennzeichnet die sich während ihrer Dauer an den Chromosomen abspielen.

Während des Bestehens des gleichmäBigen Chromatingerüstes, also in der Zeit des äußerst langsamen Wachstums sind die Oocyten fast ganz unempfindlich.

Wir erkennen hier also die nämlichen Erscheinungen, die ich schon früher (1918) am Eierstock des Haushuhnes feststellen konnte. Dabei verlaufen bei den Molchen die Rückbildungsvorgänge vollkommen gleichmäßig, ohne Unterschied hinsichtlich der Art der Schädigung, denen das Tier ausgesetzt ist. Verschieden ist nur die Geschwindigkeit in der sich die Rückbildungsvorgänge abwickeln, sie ist abhängig von der Ernährung und von der Ausbildung des Fettkörpers. Bei reichlicher Nahrungszufuhr erfolgt die Resorption der atretischen Follikel langsamer, bei spärlicher Ernährung und beim Hunger rascher. Auch diese Tatsache tritt besonders sinnfällig an den größten Follikeln in Erscheinung.

Andererseits aber sind alle Einflüsse hinsichtlich ihres Erfolges verschieden, je nach der Zeit in der sich ihre Wirkung geltend macht. Bei nichtbeeinflußten Molchen zeigt der Eierstock in der Zeit von Mitte März bis Ende Mai im großen und ganzen den gleichen Bau, erst von Anfang Juni an, bei Tieren die aus höheren Lagen stammen noch später, macht sich eine Abnahme der großen Follikel geltend. Der Einfluß der gleichen Schädigung tritt nun ganz verschieden stark in Erscheinung, je nachdem er im März oder erst im Mai beginnt.

In der Vorlaichzeit wirken Veränderungen im Aufenthaltsort, in der Ernährung, der Wasserwärme und der Beleuchtung um so tiefgreifender, je mehr sich die Molche dem Beginn der Brunst nähern. Während der Laichzeit selbst machen sich alle Schädigungen um so deutlicher 
geltend, haben um so raschere, sinnfälligere Rückbildungsvorgänge zur Folge, je mehr die Eiablage ihrem natürlichen Abschluß entgegen geht. Eine Schädigung, die im April bei kurzer Dauer noch kaum nachweisbare Veränderungen am Eierstock bedingt, hat im Mai die rasche Rückbildung aller großen Follikel zur Folge.

Die Eierstöcke zeigen also das Bestreben, ihren normalen jährlichen Entwicklungsgang in der gewöhnlichen Weise zu durchlaufen. Eine Veränderung in der Umgebung bedingt dabei um so leichter den AbschluB der Eiablage, je mehr sich diese ihrem natürlichen Ende nähert. Zudem wirken alle Einflüsse um so schädigender auf die Eierstöcke ein, je stärker sie von den, in der gleichen Zeit im Freileben herrschenden Bedingungen abweichen. Damit ist auch zu erklären, daß reichliche Ernährung im Vorfrühling, also dann, wenn die Tiere im Freien hungern oder nur sehr wenig Nahrung finden, schädlich wirkt, da hier der Körper offenbar nicht imstande ist überschüssig zugeführte Nahrungsmengen zum Aufbau der Eier zu verwenden. Es handelt sich hier um die nämlichen Erscheinungen, die wir bei Haustieren während der Mast beobachten können, auch bei ihnen bilden sich ja als Folge der übermäBigen Fütterung die Keimdrüsen zurück.

Andererseits bewirkt reichliche Ernährung während der Eiablage bei sonst günstigen äußeren Bedingungen eine Erhöhung der Eizahl, da hier der Körper offenbar imstande ist, alle überflüssige Nahrung den Ovarien zuzuführen.

Der Eierstock, beziehungsweise der ganze Organismus der Molche besitzt also angeborenerweise die Eigenschaft innerhalb eines Jahres einen gewissen bestimmten Entwicklungsgang zu durchlaufen, in ihr kommt das ererbte Lebensgeschehen zum Ausdruck. Dieses kann jedoch durch äußere Eingriffe, durch anorganisches Geschehen in bestimmter Weise beeinflußt werden. Der Einfluß dieses anorganischen Geschehens kann die spezifische Art des Lebensgeschehens aber nur innerhalb gewisser Grenzen abändern und nicht vollkommen ausschalten. Ist er sehr stark, so ist auch die Abänderung eine erhebliche, niemals jedoch so groB, daß sie das ererbte Lebensgeschehen vollkommen verwischt. Denn selbst bei stärkster Beeinflussung erkennen wir, daß der Eierstock sich in seiner veränderten Form an den ihm, beziehungsweise dem ganzen Tier innewohnenden Jahresrhythmus anpaBt. Auch die Zeit der Eiablage läBt sich nicht in völlig beliebiger Weise verschieben. Ist daher der Widerspruch awischen Lebensgeschehen und äuBerem EinfluB ein zu großer, so bedingt er den Stillstand der Tätigkeit, also Unfruchtbarkeit und bei längerer Dauer den Tod. Dies läßt sich am sinnfälligsten an der Tatsache zeigen, daß ein an und für sich für die Entwicklung günstiger Um- 
stand: die reichliche Ernährung, dann, wenn sie unzeitgemäß eintritt, schädlich wirkt, da sie dann eben in zu starkem Gegensatz zu dem ererbten Lebensgeschehen steht. Auch hier läßt sich also zeigen, daB der EinfluB des angeborenen Lebensgeschehens für die ganze Entwicklung des Organismus stärker und wichtiger ist, als die Wirkung äußerer Umstände, es gelingt auch hier nicht den natürlichen Entwicklungsgang der Keimzellen in beliebiger Weise abzuändern. Ich betone diese Tatsache im Gegensatz zu den neuesten Ausführungen von Uhlenhuth (1920), auf dessen Anschauungen ich später noch zu sprechen komme.

Bekanntlich unterscheidet Roux (1920) in der Entwicklung jedes Lebewesens vier Hauptabschnitte: der erste ist dadurch gekennzeichnet, daß seine typisch determinierenden Faktoren vererbte sind. Im zweiten ist fast jede Gestaltung durch Mitbeteiligung der Funktion doppelt determiniert. Die dritte Periode "beginnt mit dem Aufhören des vererbten selbständigen, somit des afunktionellen oder präfunktionellen Wachstums «, die vierte Periode ist die Zeit 》der normalen, von Erkrankung freien Senileszenz \&. Während aller dieser vier Zeitabschnitte sind aber noch vererbte Gestaltungspotenzen tätig, in der ersten Zeit alleinbestimmend, in der späteren nur mitbestimmend. Auch in der Entwicklung und Tätigkeit der Keimdrüsen lassen sich diese vier Abschnitte unterscheiden, wenngleich nicht so deutlich, wie bei den Organen, deren Entwicklung zum großen Teil durch tätige Beanspruchung beeinflußt wird.

Die erste Periode der Keimdrüsen betrifft die Anlage und geschlechtliche Sonderung, in ihr sind ausschließlich vererbte Faktoren tätig. Der zweite Abschnitt betrifft die Entwicklung bis zum Beginn der Geschleehtsreife, während seiner Dauer machen sich schon erhebliche Einflüsse von seiten des Gesamtorganismus geltend, die wir der funktionellen Beanspruchung anderer Organe gegenüber stellen können. Sie sind deutlich daran zu erkennen, daß die ganze Reife und Ausbildung der Keimdrüsen vom Zustand des Gesamtorganismus abhängt. Ist dieser ein außergewöhnlicher wie $\mathrm{z}$. B. bei in der Gefangenschaft aufgezogenen Tiere, so wird sehr häufig die Keimdrüsenentwicklung beeinträchtigt oder sie unterbleibt ganz. Daß dabei den Keimdrüsen eine bestimmte Tätigkeit im Körper zukommt, beweisen ja deutlich genug die Versuche Ribberts (1890) und seiner Schüler, bei denen nach Entfernung der einen Keimdrüse eine kompensatorische Hypertrophie der anderen auftrat.

Der dritte Abschnitt der Keimdrüsenentwicklung währt vom Beginn der Geschlechtsreife bis zu ihrem Ende, in ihm wird die Tätigkeit der Gonaden hauptsächlich vom Zustand des Gesamtorganismus beeinfluBt, sie kommt zum Stillstand wenn der Gesamtkörper, wie 
in den hier beschriebenen Versuchen, durch äußere Schädigungen verändert wird. Der vierte Abschnitt endlich betrifft den Zustand des sterilen Alters, in dem sich die Keimdrüsen zurückbilden.

Für meine Untersuchungen hier kommt ausschließlich die dritte Periode der Keimdrüsenentwieklung in Betracht und ich will zunächst noch entscheiden, ob sich ein solcher Abschnitt, in dem das vererbte, selbständige Wachstum vollkommen abgeschlossen ist, in der Lebensgeschichte der Keimdrüsen überhaupt abgrenzen läßt. Roux selbst räumt ja ein, daB man am Bestehen dieses dritten Entwicklungsabsehnittes der Organe zweifeln könne und berechtigt sei anzunehmen, daß in ihm nur das bezeichnende Vererbte zeitweilig sehr gegen das funktionell Bedingte zurücktrete. In dieser Hinsicht besteht also kein grundlegender Unterschied zwischen der zweiten und dritten Entwicklungsperiode.

Demgemä $B$ müssen wir auch feststellen, daß gerade bei der Entwicklung der Keimdrüsen sich der zweite und dritte Abschnitt nicht scharf gegenüberstellen läßt, beşonders nicht bei Tieren mit zyklischem Ablauf der Brunst, bei denen sich gewissermaßen die zweite Periode jährlich einmal wiederholt.

Betrachten wir aber, wie Roux dies in letzter Zeit (1911-1920) selbst tut, als das Hauptmerkmal des dritten Entwicklungsabschnittes 》das Aufhören des präfunktionellen oder afunktionellen Wachstums «, so können wir auch bei den Keimdrüsen von einem dritten Entwicklungsabschnitt sprechen. Er beginnt in dem Augenblick, in dem die eigentliche arterhaltende Tätigkeit, der Keimdrüsen, die Ausstoßung befruchtungsfähiger Eier oder Spermatozoen ihren Anfang nimmt. Von der inkretorischen Tätigkeit, durch die ja bei den höheren Tỉeren die bestimmt geschlechtliche Gestaltung des Körpers bedingt wird, will ich hier absehen, sie beginnt weit früher, sicher schon in der zweiten, vielleicht sogar schon in der ersten Periode.

Schließlich wäre noch zu überlegen, ob nicht bei der Entwicklung und Tätigkeit der Keimdrüsen, im Gegensatz, zu allen anderen Organen des Körpers der ganze zweite und dritte Entwicklungsabschnitt in Wegfall kommt, ob also Eierstöcke und Hoden während des ganzen Lebens bis zum Beginn der senilen Involution ihre Entwicklung nur aus inneren, in den Keimzellen selbst gelegenen Gründen, unbeeinflußt vom Organismus vollenden. Bei der scheinbaren Gegensätzlichkeit, die zwischen Körper und Keimzellen in manchen Beziehungen besteht, wäre eine solche Möglichkeit wohl zu erwägen; zahlreiche bekannte Vorkommnisse, auf die ich schon früher (1918) hingewiesen habe, vor allem auch die Ergebnisse der hier beschriebenen Versuche zeigen jedoch deutlich genug die Abhängigkeit der Keimdrüsen vom Gesamtorganismus und damit auch die Mitbeteiligung der Funktion an ihrer Entwicklung. 
Immerhin sind aber die den Keimdrüsen innewohnenden vererbten Gestaltungspotenzen sehr hohe, sie bedingen zum Teil sicher auch die periodische Entwicklung der Keimzellen und damit den zyklischen Ablauf der Brunst. Wirken nun äußere Reize der hier besprochenen Art auf den Körper und damit auch auf die Keimdrüsen ein, so tritt ihr EinfluB, beziehungsweise die Reaktion des Gesamtkörpers auf ihn, in Beziehungen zur Wirkung der vererbten Gestaltungspotenzen.

Da der äußere Einfluß bei den besprochenen Versuchen meist ein schädlicher war und den Stillstand der Eiablage bewirkte, so mußte er gewöhnlich im Gegensatz zu den vererbten Gestaltungspotenzen treten. Es bekämpften sich also gewissermaßen innerhalb des Organismus einerseits die angeborene Eigenschaft zu bestimmter Zeit Eier hervorzubringen, andererseits die Antwort auf die äußere Schädigung, die die Eiablage hemmte. Je stärker nun die äußeren Schädigungen waren, desto stärker war auch die Reaktion des Gesamtkörpers und desto stärker dementsprechend die Rückbildungsvorgänge an den Eierstöcken. In voller Mächtigkeit konnten sich die regressiven Veränderungen jedoch erst dann zeigen, wenn das vererbte Bestreben Eier hervorzubringen sich seinem naturgemäßen $A b s c h l u ß$ nähert, also gegen das Ende der Brunst hin. Erst zu dieser Zeit, etwa von der Mitte des Monats Mai an, bilden sich die Eierstöcke rasch zurück, bis dahin bewahren sie stets noch mehr oder weniger deutlich den gewöhnlichen Bau und damit auch die Fähigkeit beim Eintritt günstiger Bedingungen wieder Eier hervorzubringen.

Aber selbst während der schwersten Rückbildungsvorgänge macht sich dauernd noch das Bestreben geltend, den gesetzten Schaden auszugleichen und so die neue, volle Tätigleit des Eierstockes vorzubereiten. Dauernd wird ja auch in den stärkst beeinflußten Ovarien durch Oogonienteilungen der entstandene Verlust wenigstens teilweise gedeckt.

Ich brauche wohl nicht besonders darauf hinzuweisen, welch große Vorteile die eben besprochenen Erscheinungen im Kampf ums Dasein bieten. Bei kurzdauernden Veränderungen in den äußeren Bedingungen kommt die Eiablage zum Stillstand. Dadurch wird verhindert, $\mathrm{da} B$ die Eier in einer Umgebung abgelegt werden, die ihnen keine entsprechenden Entwicklungsbedingungen bietet, also ihr baldiges $\mathrm{Ab}$ sterben bedingt. Wird das Tier rechtzeitig wieder in günstige Verhältnisse versetzt, so beginnt dank der den Eierstöcken innewohnenden vererbten Gestaltungspotenzen die Eiablage von neuem. Sie sind der Grund dafür, daß eine einmalige, vorübergehende Schädigung nicht ohne weiteres den dauernden Stillstand und damit die Unfruchtbarkeit für das betreffende Jahr verursacht. 


\section{Das Verhalten und die Bedeutung des Fettkörpers.}

Besondere Beachtung verdient noch das Verhalten des Fettkörpers, über dessen Bedeutung sich ja bisher nur wenige Angaben in den einschlägigen Arbeiten finden. Er stellt bekanntlich ein Organ dar, das sich bei allen Amphibien, nach Wiedersheim (1902) vielleicht auch bei einigen Reptilien findet, während es den höheren Arten, Vögeln und Säugern, ebenso wie den niederen, den Fischen und Evertebraten, zu fehlen scheint. Schon bei der Besprechung der einzelnen Versuche habe ich stets darauf hingewiesen, daß die Ausbildung des Fettkörpers abhängig von der Ernährung ist. Er besitzt für gewöhnlich etwa ein Viertel der Größe eines normalen Eierstockes, bei reichlicher Nahrungszufuhr vergrößert, beim Hunger verkleinert er sich. Dies stellt ja an und für sich kein besonderes Vorkommnis dar, sehen wir doch bei allen Arten das Fettgewebe sich bei guter Ernährung verbreitern, bei schlechter aber vermindern, und zwar ganz unabhängig davon, ob sich die größte Fettansammlung des Körpers, wie bei den Säugern hauptsächlich unter der Haut, wie bei den Fischen hauptsächlich im Mesenterium findet. Wir können dabei meistens auch beobachten, daß einer bestimmten Fettansammlung an einer umschriebenen Körperstelle stets auch eine bestimmte physiologische Bedeutung zukommt: so dient, um nur ein Beispiel zu nennen, die Fettschicht der Säuger zum Wärmeschutz. Die ganze Lage des Amphibienfettkörpers deutet nun, ebenso wie sein Verhalten auf ein inniges Wechselverhältnis zwischen $\mathrm{ihm}$ und den Keimdrüsen hin.

Zunächst erkennen wir, daß während des gewöhnlichen Verlaufes der Brunst bei weiblichen Tritonen der Fettkörper seine Größe nicht wesentlich verändert und erst gegen das Ende der Eiablage eine geringe Massenzunahme erfährt. Diese hält während des Sommers bis zum Winterschlaf an. Wird während der Eiablage die Nahrungszufuhr verringert oder ganz eingestellt, so verkleinert sich sunächst der Fettkörper und bildet sich bis auf einen dünnen Strang zurück, der hauptsächlich aus lymphoidem Gewebe und spindelförmigen Bindegewebszellen besteht, denen aber stets noch vereinzelte Fettzellen eingelagert sind. Erst wenn sich der Fettkörper weitgehend zurückgebildet hat kommt, bei sonst günstigen Bedingungen, einzig und allein infolge des Nahrungsmangels die Eiablage zum Stillstand.

Bei reichlicher Ernährung während der Brunst ist dagegen keine wesentliche Vergrößerung des Fettkörpers zu beobachten, die überschüssigen Nahrungsmittel werden hier offenbar unmittelbar zum Aufbau der in großer Zahl heranwachsenden Follikel verwendet. Anders wenn die Mast zu einer Zeit erfolgt, in der keine Eier abgelegt werden, also hauptsächlich im Frühjahr vor dem Beginn oder im 
Herbst nach dem Ende der Brunst. Wir erkennen dann, daß sich der Fettkörper erheblich vergrößert, in vereinzelten Fällen so stark, dab er den Eierstock an Ausdehnung übertrifft.

Ist schon in diesen Erscheinungen ein unmittelbares Abhängigkeitsverhältnis dèr beiden Organe zu erkennen, so kommt diese Tatsache noch deutlicher bei allen den Versuchen zum Ausdruck, die eine Rückbildung der Eierstöcke zur Folge haben. Wir können zunächst feststellen, daß jede Schädigung, die mit verminderter Nahrungsaufnahme einhergeht, eine Verkleinerung des Fettkörpers zur Folge hat. Wird durch die Beeinflussung aber die Nahrungsaufnahme nicht beschränkt, so bewahrt der Fettkörper seine Größe und erfährt nach dem Stillstand der Eiablage stets eine Massenvermehrung. Auch diese Erscheinung bietet an und für sich nichts besonderes, denn es ist klar, daß auch hier beim Hunger die Fettzellen verbraucht, bei der Mast aber vermehrt werden. Dies trifft nicht nur für den Fettkörper allein, sondern mehr oder weniger für alle Gewebsarten des Organismus zu. Ein richtiges Verständnis der Vorgänge gewinnen wir erst dann, wenn wir die gleichzeitigen Veränderungen an den Eierstöcken berücksichtigen.

Dabei läßt sich beobachten, daß die Rückbildung der großen Follikel um so rascher verläuft und um so weiter um sich greift, je stärker der Fettkörper verbraucht ist. Bei hungernden Tieren bilden sich die großen Oocyten rasch zurück; bei gut genährten Molchen aber nur langsam. Der Unterschied wird am deutlichsten klar bei einem Vergleich der beiden Abbildungen Nr. 9 und 11, beide Tiere waren gleichlang beeinflußt. Das Tier von Abb. 9 hungerte, es magerte zusehends ab, der Fettkörper ist vollkommen zurückgebildet, während das Tier von $A b b .11$ gut ernährt wurde, es magerte nicht ab und bei der Sektion zeigte der Fettkörper die gewöhnliche Größe.

Die Geschwindigkeit, in der sich die Rückbildungsvorgänge am Eierstock abwickeln, ist also abhängig vom Ernährungszustand des Tieres, eine Tatsache, auf die früher schon Barfurth (1886) hingewiesen hat, die ich gleichfalls schon in meinen Hühnerversuchen (1918) bestätigen konnte.

In diesem Zusammenhang ist es auch zu verstehen, warum die unzeitgemäße Mast im Vorfrühling so schwerwiegende Störungen in der Tätigkeit der Eierstöcke bedingt. Als Folge der reichlichen Fütterung vergrößert sich dann der Fettkörper und im Eierstock gehen eine ganze Reihe von Follikeln zugrunde. Es ist nun eine bekannte Tatsache, die wieder zuerst von Barfurth (1886) beschrieben, von mir (1918) in den Hühnerversuchen bestätigt wurde, daB die Anwesenheit einer größeren Anzahl dotterreicher, atretischer Follikel im Eierstock das Heranreifen weiterer Eierstocks eier verhindert. Wird nun durch die überreichliche Ernährung und 
die außergewöhnlich starke Ausbildung des Fettkörpers die Resorption der abgestorbenen Follikel verzögert oder völlig gehemmt, so kann keine Neureifung weiterer Eier erfolgen, das betreffende Tier bleibt steril, bis eine längere Zeit des Hungers die Rückbildung des Fettkörpers bewirkt und damit die Entfernung der hemmenden atretischen Follikel aus dem Eierstock ermöglicht.

Bemerkenswert ist dabei auch noch, daß die Rückbildung des Fettkörpers, falls eine solche eintritt, niemals eine vollkommene ist. Selbst bei Molchen, die nach lang anhaltender schwerster Schädigung zum Skelett abgemagert offenbar an Unterernährung sterben, finden sich in dem dünnen, bindegewebigen Strang, der dann den Fettkörper darstellt, stets noch vereinzelte typische, große mit Fett beladene Zellen. Sie untersoheiden sich, wie ja das Fett des Fettkörpers überhaupt, vom übrigen Körperfett durch die Anwesenheit eines besonderen Farbstoffes, der ihm die leuchtend gelbe Farbe verleiht, nämlich des Carotins.

Die Ausbildung dieses Farbstoffes ist nun, wie die Kastrationsversuche $\mathrm{NuBbaums} \mathrm{(1909)}$ gelehrt haben, von der Anwesenheit der Keimdrüsen abhängig, bei verschnittenen Tieren verliert der Fettkörper seine gelbe Farbe und erscheint dann weiß, wie das übrige Körperfett. Auch aus dieser Tatsache läßt sich das innige Abhängigkeitsverhältnis zwischen Fettkörper und Gonaden erkennen. NuBbaum stellt dabei auch fest, daß bei Kastraten die Fettkörper zu ganz beträchtlicher Größe heranwachsen und schließt daraus, daß ihr Wachstum unabhängig von den Keimdrüsen erfolgt. Dís mag richtig sein, insofern als der Fettkörper sich auch bei verschnittenen Tieren entsprechend dem Ernährungszustand des Gesamtkörpers vergrößern und verkleinern kann. Er erfährt jedoch bei Kastraten zumeist eine außergewöhnliche Massenzunahme, da die normale Abgabe der in ihm gespeicherten Nahrungsmengen an die Keimdrüsen unterbleibt. Bei ihnen tritt also der nämliche Fall ein, wie bei meinen in der Vorlaichzeit gemästeten Molchen, bei denen die Eierstöcke noch nicht zur Eiablage befähigt sind.

Genauere Aufschlüsse über das Wechselverhältnis beider Organe müssen erst Versuche liefern, in denen der Fettkörper entfernt wird. Aller Wahrscheinlichkeit nach wird durch einen solchen Eingriff die Tätigkeit der Keimdrüsen zunächst nicht gestört, da ja dann die Nahrungsabgabe vom Körper unmittelbar an Eierstöcke und Hoden erfolgt, wie dies auch sicher zum Teil schon normalerweise während der Eiablage stattfindet. Doch muß sich bei fettkörperlosen Tieren jede Verringerung in der Nahrungszufuhr sehr rasch in der Tätigkeit der Gonaden geltend machen, da eben der Fettspeicher fehlt, der für gewöhnlich die Folgen einer kurzen Hungerszeit ausgleicht. 
Auch Wiedersheim (1902) nimmt an, daß der Fettkörper »in sehr wichtigen physiologischen (ernährenden) Beziehungen zu den Geschlechtsdrüsen stehen mußs, denn nur so lasse es sich erklären, " da $\beta$ die aus langem Winterschlaf erwachenden und viele Monate lang ohne Nahrung gebliebenen Tiere, sofort, das heiBt häufig schon in den ersten Tagen des Frühlings tausende von Nachkommen zu erzeugen imstande sind.« Ich muß diese Anschauung nur dahin berichtigen, daß die Molche im Gegensatz zu den Fröschen immer einiger Zeit bedürfen, um sich von den Folgen des Winterschlafes zu erholen, bevor sie zur Fortpflanzung befähigt sind. Außerdem wird ja die überwiegende Menge der Nahrungsstoffe, die zum Aufbau der Eier benötigt werden, schon während des Sommers in den Keimidrüsen aufgespeichert, diese besitzen im Horbst stets den gleichen Bau wie im Frühjahr. Während des Winterschlafes ruht das Leben fast völlig und der Körper enthält im Frühjahr fast ebenso viele Nährstoffe wie im Herbst, er muß aber offenbar zunächst die Schlacken ausstoßen, die sich während der langen Ruhezeit in ihm angesammelt haben. Der Fettkörper dient dann dazu um über die erste Zeit des Frühlings, in der sich noch wenig Nahrung findet, hinweg zu helfen und ihn hier vor einer Schädigung zu schützen.

Bei Berücksichtigung aller bisher bekannten Tatsachen dürfen wir also sagen, daß der Fettkörper einen Speicher darstellt für Nahrungsmittel, die zum Aufbau der Keimzellen verwendet werden. $\mathrm{Er}$ besitzt bei gewöhnlicher Ernährung mittlere Ausdehnung, vergrößert sich in der Geschlechtsruhe und bei reichlicher Fütterung und verkleinert sich beim Hunger, besonders während der Laichzeit. Der Fettkörper ist also imstande während der Eiablage geringe Schwankungen in der Ernährung auszugleichen und vermittelt dadurch den ungestörten Ablauf der Fortpflanzungstätigkeit. Andererseits aber verhindert seine zu starke, außergewöhnliche Vergrößerung die rasche Rückbildung atretischer Follikel. Wir sehen ein solches Vorkommnis aber nur unter unnatürlichen, im Versuch herbeigeführten Bedingungen eintreten, wie sie im Freien wohl niemals zusammentreffen.

Alles in allem dürfen wir also dén Fettkörper als ernährendes Hilfsorgan der Keimdrüsen bezeichnen, eine Anschauung, die schon Rathke (1818) vertritt und der sich auch Gegenbaur (1901) anschlieBt.

Ein solches strophisches Hilfsorgan" findet sich ja auch in den Keimdrüsen der höheren Tiere, der Vögel sowohl als auch der Säuger, in Gestalt der von Leydig (1850) entdeckten Zwischenzellen. Thnen kommt ja wie alle Forscher bestätigen, die ihre Anschauung auf genaue histologische Befunde stützen, die Aufgabe zu, die zum Aufbau der Keimzellen nötigen Nährstoffe zu liefern. Die Ansicht vereinzelter Unter- 
sucher, die Zwischenzellen seien eine besondere, hormonabsondernde Drüse hat sich ja, wie ich schon früher (1919/1921) gezeigt habe, als unrichtig erwiesen. Auch die $Z$ wischenzellen enthalten stets Fett und Pigment, sie gleichen in dieser Hinsicht den Fettkörperzellen und auch in dem Umstand, daß sie aus spindelförmigen Bindegewebszellen entstehen und sich durch Fettabgabe wieder in solche verwandeln können.

Als weiterer Beweis für die Wahrscheinlichkeit dieser eben vertretenen Anschauung kommt noch der Umstand, daß in den Keimdrüsen der Urodelen beider Geschlechter typische Zwischenzellen, wie überhaupt alle Gebilde, die sich diesen gegenüberstellen lassen, vollkommen fehlen (Stieve, 1920b/21a). Die nämlichen Verhältnisse finden wir in den Eierstöcken der Anuren. Bei ihnen sind aber im männlichen Geschlecht, wo der Hoden auch in seiner äußeren Form rom Bau des Urodelentestikels abweicht, und mehr dem der höheren Arten gleicht, einerseits Zwischenzellen vorhanden, von ähnlichem Bau wie bei Säugern und Vögeln, andererseits aber ein gut ausgebildeter Fettkörper. Er zeigt jedoch hinsichtlich seiner Gestalt und seiner Lage gewisse Unterschiede gegenüber dem der Urodelen.

Bei Gymnophionen besteht nach Gegenbaur (1901) der Fettkörper aus einzelnen Abteilungen, er ist sehr stark in die Länge gestreckt. Bei Fischen läßt sich eine ähnliche Bildung nicht nachweisen, doch finden sich hier in der Zeit der Geschlechtsruhe große Fettmassen im Mesenterium, die sich zu Beginn der Fortpflanzungszeit mehr oder weniger stark zurückbilden. Sie entbehren zwar der Pigmenteinlagerungen, werden aber offenbar zum Aufbau der Keimdrüsen verwendet. Bekannt ist ja, daß bei den Fischen unmittelbar vor und während der Laichzeit eine starke Rückbildung des Fettgewebes und der Muskulatur erfolgt, da alle im Körper vorhandenen, irgendwie verfügbaren Stoffe zum Aufbau der in ungeheurer Menge erzeugten Keimzellen verwendet werden.

In der Reihe der Wirbeltiere erfolgt demnach eine langsame, aber ganz gut verfolgbare Umgestaltung des trophischen Hilfsorganes für die Keimdrüsen. Bei Fischen ist das Fett noch in der ganzen Bauchhöhle verteilt, pigmentlos. Bei Gymnophionen finden sich in der Nähe der Keimdrüsen mehrere umschriebene Fettablagerungen, sie sind bei Urodelen zu einem Fettliörper vereint, dessen Bedeutung klar zu erkennen ist. Die nämlichen Verhältnisse treffen wir bei weiblichen Anuren. Bei männlichen Anuren tritt das trophische Hilfsorgan einerseits noch in der nämlichen Form wie bei Schwanzlurchen, als ein außerhalb der Keimdrïsen gelegener, umschriebener Fettkörper auf, andererseits aber zerstreut zwischen den Hodenkanälchen. Bei den Reptilien sind die Verhältnisse noch nicht genügend untersucht, 
wie die Angaben von Leydig (1850) und Mazzetti (1912) lehren kommen in ihren Hoden Zwischenzellen von ähnlichem Bau wie bei den Vögeln vor. Andererseits finden sich nach Wiedersheim (1908) auch bei vielen Kriechtieren, fettige, lymphadenoide Massen im Leibesraum, besonders mächtig und mannigfaltig ausgebildet sind sie bei manchen Echsenarten, bei Schlangen erstrecken sie sich meist durch die ganze Leibeshöhle. Eine Abhängigkeit von den Keimdrüsen ist noch nicht erwiesen, erscheint nach Wiedersheim jedoch wahrscheinlich.

Bei Vögeln und Säugetieren endlich ist der extraglanduläre Fettkörper völlig verschwunden, an seiner Stelle haben die Zwischenzellen den höchsten Grad der Ausbildung erreicht.

Die vergleichende Anatomie gibt uns also weitere Anhaltspunkte über die Bedeutung des Fettkörpers. Auch sie zeigt, ebenso wie das Ergebnis der hier besprochenen Befunde, daB er ein trophisches Hilfsorgan, ein Nahrungsspeicher für die Keimdrüsen ist, das wir wohl den Zwischenzellen der höheren Arten gegenüberstellen dürfen.

\section{Zusammenfassung der Befunde.}

Meine Versuche haben also gezeigt, da $B$ bei Molchen eine Beeinflussung der Keimdrüsen durch äußere Bedingungen möglich ist. Veränderungen in der Umgebung, wie in den Lebensbedingungen überhaupt, machen sich bei Tritonen stets in der Tätigkeit der Keimdrüsen geltend und führen, falls sie schädigen, bei längerer Daver $\mathrm{zu}$ Rückbildungsvorgängen, also $\mathrm{zu}$ anatomisch nachweisbaren Veränderungen der Keimdrüsen, ohne daß der entwickelte Gesamtkörper, das Soma Weis manns, zunächst in erkennbarer Weise umgestaltet wird. Am sinnfälligsten und raschesten tritt diese Erscheinung während der Brunst zutage, hier unterbleibt unmittelbar pach Beginn der Schädigung die weitere Reifung großer Follikel und damit die Eiablage.

Die aufgefundenen Tatsachen lassen es ohne weiteres verständlich erscheinen, daß ähnliche oder andere Einflüsse von nicht so tiefgreifender Art die Fortpflanzungstätigkeit zwar nicht unterbrechen, jedoch an den Keimzellen selbst Veränderungen setzen, die sich dann an der Beschaffenheit der Nachkommen geltend machen. Bei Triton vulgaris habe ich solche Einwirkungen nicht festgestellt, wohl aber konnte ich sie bei Triton alpestris beobachten. Nachkommen dieser Art aus in der Gefangenschaft abgelegten Eiern entwickeln sich nur langsam, und es gelingt nur sehr schwer sie bis zur Verwandlung am Leben zu halten. Niemals ist es mir aber geglückt im Aquarium aufgezogene Junge des Alpenmolehs in der Gefangenschaft wieder zur Fortpflanzung zu bringen. Die Jungtiere magern nach der Metamor- 
phose gewöhnlich rasch $a b$ und gehen zugrunde. Oder aber sie nehmen bei sonst 'gleicher Behandlung schnell an Körperfülle zu, bleiben aber im Wachstum stehen und schreiten niemals zur Fortpflanzung. Die nämlichen Erfahrungen machte auch Wolterstorff (1920). Es mag aber noch dahingestellt bleiben, ob es sich bei diesen Erscheinungen um die Folgen der Elternbeeinflussung handelt oder aber um eine unmittelbare Schädigung der aufwachsenden Jungtiere. Immerhin erscheint es sehr merkwürdig, daß sich die Nachkommen zweier Molcharten (vulgaris und alpestris), deren Eltern aus dem gleichen Tümpel stammen und ganz gleich behandelt wurden, bei ebenfalls gleicher Pflege so verschieden verhalten. Ohne $Z$ weifel deutet dies auf eine verschiedene Reaktionsweise der beiden Arten hin.

Wie die histologische Untersuchung der Eierstöcke ergibt, werden von den Folgen einer äußeren Schädigung nicht alle Follikel eines beeinflußten Tieres in gleicher Weise betroffen, sondern nur die größten, mit gelben Dotter beladenen Eierstockseier, die sich in der zweiten Hälfte der zweiten Wachstumsperiode befinden; außerdem noch die jüngsten Oocyten, unmittelbar nach ihrer Entstehung. Diese Erscheinung verdient besondere Aufmerksamkeit. Wie ich schon früher (1918/1921a) gezeigt habe, gehen nach $A$ bschlu $B$ der Oogonienteilungen in den Eierstöcken aller Tierarten zahlreiche der kleinsten Oocyten physiologischerweise zugrunde. Die ungünstige Kernplasmarelation, die wir im Anschluß an die rasch aufeinanderfolgenden Oogonienteilungen an ihnen beobachten können, außerdem ungeeignete Ernährungsbedingungen für so zahlreiche neue Zellen, also der Kampf der Eier im Ovar, der Spermatogonien im Hoden, sind wohl für diesen natürlichen Ausfall verantwortlich zu machen. Diese Erscheinung steigert sich nun bei äußeren Schädigungen, da dann offenbar die Ernährungsbedingungen für die neugebildeten Zellen noch schlechter sind, die gegenseitige Beeinflussung muß also eine noch stärkere sein. Wir sehen hier also nur eine außergewöhnliche Steigerung eines physiologischen Geschehens. Nach Beendigung des proportionalen Wachstums, also dann, wenn die erste Vergrößerung abgeschlossen ist, sind die Ernährungsbedingungen im Eierstock der Molche für alle Oocyten gut, da dann jede Eizelle von einer besonderen Follikelzellenhülle umgeben ist. Rückbildungsvorgänge kommen dann nur noch selten zur Beobachtung. Bei niederen Tieren, die wie die Urodelen alle Eierstockseier ablegen, ist der Kampf der Eier im Ovar dann so gut wie beendet, alle Follikel können in gleicher Weise heranreifen, Rückbildungsvorgänge gehören zu den Ausnahmen. Bei den höheren Arten dagegen, bei denen nur der kleinste Teil aller Oocyten abgelegt werden kann, hält die gegenseitige Beeinflussung, als deren Folge die größte Menge der wachsenden Eierstockseier hier zugrunde geht, noch an. 
Während der längsten Zeit ihrer Entwicklung sind die Molcheier dann auch gegen äußere Schädigungen so gut wie unempfindlich, sie bleiben bis zum Tode des Lebewesens erhalten und stellen zusammen mit den Oogonien den Stamm dar, von dem aus beim Eintritt günstiger Lebensbedingungen die Regeneration der ganzen Keimdrüse erfolgt.

In höchstem Maße empfindlich sind aber die Eizellen während der letzten Zeit ihrer Entwicklung innerhalb des Eierstockes, wenn sich die Chromosomen aus dem gleichmäßigen Kerngerüst absondern und sich der Plasmaleib durch Aufnahme gelben Dotters in ungeheurem Maße vergrößert. Dieser Abschnitt muß als die sensible Periode in der Entwicklung der Eierstockseier bezeichnet werden. Es mag sein, dả die während seiner Dauer feststellbaren Veränderungen zum Teil dadurch bedingt sind, daß mit den reichlichen, den Körpersäften entnommenen Nährstoffen, durch die ja die rasche Vergrößerung der Follikel bedingt ist, auch schädigende Substanzen aufgenommen werden. Sie müssen $j a$ in den Säften des beeinflußten Tieres vorhanden sein, als Folge der Umgestaltung des Gesamtkörpers, die dieser durch die äußere Schädigung bzw. als Antwort auf sie erfährt. Doch müssen diese Stoffe auf alle Keimzellen in allen Entwicklungsstadien einwirken, sind sie doch alle hinsichtlich ihrer Ernährung dem Körper untergeordnet. Nachweisbare Veränderungen erzeugen die schädlichen im Körper kreisenden Stoffe aber nur in den Abschnitten der Reife, in denen die Keimzellen empfänglich für solche Einwirkungen und Schädigungen sind und dieser Abschnitt ist die letzte Zeit der Entwicklung.

Bei Beeinflussungen der hier geschilderten Art sind die am Körper gesetzten Veränderungen so tiefgreifend, daß sie zur Vernichtung der in der sensiblen Periode stehenden Keimzellen führen. Die bekannten Versuche von Tower (1906) haben aber gezeigt, daß andere, offenbar schwächere Einflüsse zwar nicht zum Absterben der Eier führen, jedoch Umgestaltungen an ihnen bewirken, die sich in simnfälliger Weise an den Nachkommen geltend machen. Diese entwickeln sich in Formen, die von denen der älteren Tiere abweichen, selbst wenn sich an diesen keine Veränderungen beobachten lassen, weil ihre Körperzellen die Entwicklung beendet und damit die sichtbare Reaktionsfähigkeit auf den Reiz verloren haben.

Auch in seiner neuesten Arbeit $(1918)^{1}$ ) weist Tower nach, daß es genügt, die Elterntiere von Leptinotarsa während der Wachstumsperiode der Keimzellen dem Einfluß verschiedener Klimata auszusetzen, um bei den Nachkommen mannigfache Veränderungen zu

1) Die betreffende Veröffentlichung war mir im Urdruck nicht zugänglich, ich erwähne sie nach, dem Referat, das mir Herr Dr. Alverdes in liebenswürdigster Weise zur Verfügung stellte (1921). 
erzeugen. Auch bei Leptinotarsa ist also die Wachstumsperiode der Keimzellen die sensible Periode. In der gleichen Weise konnte ich ja auch in meinen Hühnerversuchen feststellen, da $\beta$ von den Folgen äuBerer Einwirkungen in erster Linie diejenigen Eierstockseier betroffen werden, die sich im letzten Abschnitt des Wachstums, also in der Zeit der raschen Dotterbildung und der Absonderung der Chromosomen befinden. Besonders wichtig erscheint es dabei auch, daß die hohe Empfindsamkeit der Keimzellen stets in solche Entwicklungszeiten fällt, in denen sich grundlegende Veränderungen an den Chromosomen abspielen. Erneut weist dieser Umstand auf die hohe, wenn auch nicht ausschließliche Bedeutung hin, die gerade den Kernschleifen beim Vererbungsgeschehen zukommt.

Auf jeden Fall ist durch das Ergebnis meiner Versuche der Einwand Semons (1912) und seiner Anhänger widerlegt, eine beliebige Veränderung in der Umgehung könne nicht auf die Keimdrüsen einwirken, da der durch sie hervorgerufene Reiz wohl den Körper treffe, aber nicht bis zu den Keimzellen dringen könne. Der Reiz selbst dringt auch bei meinen Versuchen nicht zu den Keimdrüsen vor, auch bei, ihnen bewirkt er niemals Umgestaltungen an irgendwelchen umschriebenen Körperstellen oder an den Keimdrüsen, er veranlaßt nur eine Umgestaltung des Gesamtorganismus, die als Antwort auf den Reiz eintritt und diese erst bewirkt an allen reaktionsfähigen Stellen früher oder später erkennbare Veränderungen. Sie sind an den Keimzellen, als den empfindlichsten Gebilden des ganzen Körpers, weit deutlicher als an allen anderen Organen.

Es ist deshalb falsch anzunehmen, daß als Folge des Reizes zuerst irgendwelche Veränderungen variabler Eigenschaften am Körper auftreten müssen, die dann auf geheimnisvolle und äußerst verwickelte Weise den Keimzellen und durch sie den Nachkommen mitgeteilt werden, sondern die Keimzellen werden als Folge des Reizes in der gleichen Weise wie der ganze Körper in ihrer Zusammensetzung umgestaltet. Auf Grund dieser Umgestaltung verändern sich bei beiden die reaktionsfähigen Zellen und diese Erscheinung wurde bisher als Vererbuing erworbener Eigenschaften bezeichnet. In Wirklichkeit handelt es sich dabei aber niemals um einen solchen Vorgang, schon allein deshalb nicht, weil niemals der.Körper eine wirklich neue Eigenschaft erwarb. Stets wurde nur die nämliche Eigenschaft dank ihrer ererbten Variabilität bei Eltern und Nachkommen abgeändert und zwar nur innerhalb der gleichfalls ererbten Variationsbreite. Uber diese hinaus ist bisher noch niemals eine Abänderung erzielt worden, es sei denn durch operative Eingriffe, deren Erfolge, die Verletzungen und Verstümmelungen sich aber nicht vererben.

Auch für diese Feststellung lassen sich die neuen Towerschen 
Versuche als Beweis anführen, denn auch bei ihnen konnte gezeigt werden, daß die Abänderungsmöglichkeiten für die Farbflächen nicht unbegrenzt sind, sondern ssich stets nach wenigen, wohlgekennzeichneten Richtlinien vollziehen « (Alverdes, 1921). Alle diese Tatsachen beweisen, daB. das dem Körper innewohnende Entwicklungsgeschehen zwar durch äußere Faktoren beeinflußbar ist, niemals aber kann, so wie Uhlenhuth (1920) dies annimmt, die Wirkung des anorganischen Geschehens den Einfluß des Entwicklungsgeschehens übertreffen oder ganz auslöschen.

Ohne mich auf eine Besprechung aller einschlägigen Arbeiten einzulassen, sie würde ja viel zu weit führen, will ich das eben Gesagte zum Schluß noch kurz an einigen Beispielen erläutern, die gerade in der letzten Zeit manchmal als Beweise für die Möglichkeit einer Vererbung erworbener Eigenschaften angeführt werden.

In erster Linie kommen hier die Angaben Semons (1913) über die Fußsohle des Menschen in Betracht. Durch genaue histologische Untersuchungen hat Semon feststellen können, daß die beim Erwachsenen nachweisbare Verdickung und Verhornung umschriebener Bezirke der menschlichen Fußsohlenhaut schon bei Embryonen und Kindern vorhanden ist, also lange bevor noch eine stärkere Inanspruchnahme der betreffenden Hautteile erfolgt. Die beobachteten Verdickungen beschränken sich stets auf die drei Bezirke, die beim Erwachsenen in der Hauptsache durch Druck belastet werden, auf die Ferse, den Großzehen und Kleinzehenballen. Des weiteren untersuchte Semon noch einen Klumpfuß, der infolge angeborener Veränderungen niemals in der gewöhnlichen Weise gebraucht worden war. Bei ihm fand sich im Bereich derjenigen Hautteile, die eigentlich dem Fußrücken angehörend, durch die krankhafte Stellung zum Druckpunkt geworden waren, also beim Gehen am stärksten beeinflubt wurden, umschriebene Schwielen. Sie zeigten histologisch den nämlichen Bau, wie die Schwielen an der Sohle eines gewöhnlich benutzten Menschenfußes.

Aus diesen Befunden, die gröBtenteils von Shattock (1911) auch für die Hand bestätigt wurden, zieht nun Se mon folgende Schlüsse: Die menschliche Haut ist befähigt an allen Stellen des Körpers auf einen Druckreiz mit Schwielenbildung zu antworten. Gewöhnlicherweise ist nur die Haut der Fubsohle und der Handinnenfläche an ganz bestimmten Stellen einem solchen dauernden Druckreiz ausgesetzt; infolgedessen finden sich für gewöhnlich nur hier gut ausgebildete Schwielen. Sie stellen also eine während des individuellen Lebens erworbene Eigenschaft dar. Da sich die erste Anlage zu diesen Schwielen, eine Verdickung der Haut, schon bei Embryonen und Säuglingen nachweisen läßt, also in einer Zeit, in der sie noch nicht durch die 
stärkere Beanspruchung bewirkt sein kann, so liegt hier ein Fall von Vererbung erworbener Eigenschaften vor. Eine Parallelinduktion im gewöhnlichen Sinne ist ausgeschlossen, denn es ist nicht möglich, daß der Druck, der an der Fußsohle und Handinnenfläche die Schwielenbildung bedingt, auch die Keimzellen in gleicher Weise beeinflußt.

Auch die von mir angenommene körperliche Gleichbeeinflussung ist in diesem Falle nicht wahrscheinlich. Es ist zwar sicher, daß jeder Hautreiz, selbst wenn er nur eine so umschriebene Stelle der Körperoberfläche trifft, wie die Fußsohle, eine Umgestaltung des Gesamtorganismus bewirkt: der Blut- und Lymphstrom wird in stärkerem Maße der gereizten Stelle zufließen, außerdem bewirkt der Druck auch stets eine gewisse Gewebsschädigung, meist treten leichte Entzündungserscheinungen auf, alles Vorgänge, die den Gesamtzustand des Körpers und damit auch die Keimzellen in gewisser Hinsicht beeinflussen müssen. Ich erinnere nur daran, wie auch andere, umschriebene, allerdings durch Bakterien bewirkte Veränderungen einer kleinen Körperstelle nachweisbare Umgestaltungen im Bau des Gesamtorganismus bedingen, ein kleiner Furunkel ruft eine allgemeine Leukocytenvermehrung, häufig auch eine Temperatursteigerung hervor und in ähnlicher Weise, natürlich nicht so stark, haben wir uns auch die Veränderungen am Gesamtkörper zu denken, die bei lokalen Druckwirkungen auftreten. Sie bleiben solange bestehen, bis als Antwort des Gesamtkörpers auf den Reiz eine umschriebene, schützende Hautverdickung entsteht. Es wäre schließlich auch denkbar, daß diese Veränderung des Gesamtkörpers, die ja auch die Keimzellen betrifft, an diesen wieder ähnliche Bedingungen hervorruft, so dab bei der Entwicklung der Nachkommen eine erhöhte Reaktionsfähigkeit der ganzen Haut auf äuß̨eren Druck vorliegt. Ich halte aber die Vererbung einer solch umgrenzten Umgestaltung einzelner Körperstellen nicht für wahrscheinlich, obwohl der eben ausgeführte Vorgang sicherlich nicht unmöglicher ist, als der, den Semon annimmt.

Tatsächlich können wir aber sagen, daß die Ausbildung der Fußsohle beim Menschen in der von Semon angenommenen. Art und Weise nur dann eingetreten sein könnte, wenn der Mensch von Vorfahren abstammte, deren Haut an allen Teilen der Körperoberfläche ganz gleiche Beschaffenheit besa $\beta$, also ursprünglich an Händen und Füßen keinen anderen Bau zeigte als an den übrigen Bezirken. Die betreffenden Vorfahren müßten sich also fliegend durch den Weltraum bewegt haben und dürften ihre Gliedmaßen niemals zu Gangund Greifwerkzeugen benutzt haben, wenigstens dürfte dabei die Haut der Handinnenflächen und Fußsohlen nicht stärker als an anderen Körperstellen beansprucht worden sein. Nur wenn diese 
Annahme zutrifft, besteht die Semonsche Anschauung zu Recht. Nur dann ist die Schwielenbildung an Händen und Füßen wirklich als Folge der stärkeren gebrauchlichen Inanspruchnahme neu erworben und nur dann haben wir es hier wirklich mit einer Vererbung erworbener Eigenschaften zu tun, wiewohl die Fähigkeit zur Schwielenbildung auch diesen Lebewesen angeboren sein mußte. Denn war dies nicht der Fall, so bewirkte ja eine stärkere Reizung dex Haut nur ihre rasche Abnutzung.

Zweifellos stammt der Mensch aber von Vorfahren ab, die sich, wie er selbst mit Hilfe ihrer Gliedmaßen auf dem Erdboden fortbewegten, gleichgiltig ob diese Vorfahren nun den heute noch lebenden Affenarten ähnlich waren oder nicht. In jedem Fall hatte bei ihnen eine wesentlich stärkere Beeinflussung der Haut an Fußsohle und Handinnenfläche stattgefunden als beim heute lebenden Menschen, da diese Stellen ja noch nicht durch Erzeugnisse der Kultur geschuitzt waren. Dementsprechend mußte die Haut an den beeinflußten Stellen wesentlich größere und stärkere Schwielen aufweisen als bei den heute lebenden Menschen und es ist eher zu verwundern, daß die fraglichen Bezirke entsprechend der biogenetischen Wiederholungsregel nicht im Embryonalleben stärker ausgebildet sind als bei Erwachsenen.

Schon diese Erwägungen allein führen zu der Schlußfolgerung, daß die Veränderungen an der Fußsohlenhaut nicht eine durch funktionelle Anpassung entstandene Erscheinung sind. Vielmehr muß sich der Menschenfu $B$ in der gleichen Weise wie der aller Lebewesen ausgebildet haben, und die Veränderung, die seinen Hautüberzug von den übrigen Körperstellen unterscheiden, sind im Sinne Weismanns (1913) durch Selektion entstanden, ebenso wie alle die versehiedenen Formen der Gliedmaßen bei den anderen Vertretern des Tierreiohes.

Es ist ja ganz selbstverständlich, daß eine angeborenerweise dickere und deshalb gegen Druck widerstandsfähigere Fußsohlenhaut einen ganz erheblichen Vorteil bei der Erlernung des Gehens bietet. Wie schwer sich eine nicht von Natur aus verdickte Hautstelle dem Druck anpaßt, können wir ja häufig genug beobachten wenn Leute, denen eine untere Extremität verloren ging, sich an das Tragen eines künstlichen Beines gewöhnen müssen. Selbst wenn die Uberkleidung des Amputationsstumpfes noch so gut gelungen ist, so bietet doch die Gewöhnung des deckenden Hautlappens an die neuen Druckverhältnisse stets die größten Schwierigkeiten und erst langsam paßt sich die Epidermis den neuen Anforderungen an. Dieser Vorgang bereitet dem Verstümmelten meist sehr große Schwierigkeiten und Schmerzen, obwohl doch der Teil der Prothese, der mit dem Stumpf in Berührung kommt, stets weich gepolstert ist, also niemals eine 
so schwere Hautreizung bewirkt wie der nackte Erdboden, dem der FuB unserer Vorfahren bei den ersten Gehversuchen ausgesetzt war. Ähnliche oder noch viel größere Schwierigkeiten wie bei der Gewöhnung an einen Stelzfuß müßten jedem Menschen bei der Erlernung des Gehens begegnet sein, wenn wirklich die Anpassung der Fußsohlenhaut eine rein funktionelle gewesen wäre. Es ist also klar, daB jede angeborene Verdickung der beeinfluBten Hautstellen hier einen großen Vorteil im Kampf ums Dasein bedingt, also Selektionswert besitzt und schon aus diesem Grunde sind die Semonschen Schlußfolgerungen unzutreffend, denn sie können nur auf eine Erscheinung angewendet werden, auf die dieser Umstand nicht zutrifft.

Daß während des Lebens bei der Ausbildung der Fußsohlenhaut der funktionelle Reiz eine hervorragende Rolle spielt, soll dabei in keiner Weise bestritten werden, wohl aber muß die Möglichkeit der Vererbung der während des Lebens erlangten Fußsohlendicke in Abrede gestellt werden. Warum, muB man schließlich fragen, hat sich zudem stets nur die Hautveränderung der FuBsohle und Handinnenfläche vererbt, nicht aber eine der zahlreichen Schwielen, die sich beim schuhtragenden Menschen häufig genug an allen möglichen Stellen des Fußes finden? Ich meine die Hühneraugen, die ja doch den Schwielen der FuBsohle ganz ähnliche, verhornte und umschriebene Hautverdickungen darstellen, aber hinsichtlich der Mächtigkeit ihrer Ausbildung die gewöhnlichen Vorkommnisse an der Fußsohle weit übertreffen. Und doch ist ihre Vererbbarkeit noch niemals beobachtet worden. Warum wird also von zwei sonst gleichen Erscheinungen nur die eine auf die Nachkommen übertragen, die andere nicht?

Die richtige Antwort auf diese Frage lautet zweifellos: weil die Hautverdickungen an der Fußsohle einen Vorteil im Kampf ums Dasein bieten, also Selektionswert besitzen, die Hühneraugen nicht. Semon dagegen sagt: weil der Reiz, der zur Verdickung der Sohlenhaut führt, durch viele Geschlechter gleichmäBig eingewirkt hat, während der Reiz, der zur Bildung der Hühneraugen fülurt, erst wenige Generationen betrifft; denn zweifellos stellen die Clavi eine Neuerwerbung der letzten Jahrhunderte dar. Eine solche Erklärung hätte vielleicht einiges für sich, wiewohl ich sie nicht anerkenne, wenn nicht auf der anderen Seite von den Anhängern erworbener Eigenschaften Beispiele zur Rechtfertigung ihrer Ansicht herangezogen würden, bei denen sich angeblich die Wirkung noch viel kürzerer Reize an Eltern und Nachkommen bemerkbar macht. Es handelt sich hauptsächlich um die Ausbildung der Brunstschwielen bei der Geburtshelferkröte, über die Kammerer (besonders 1919) berichtet ${ }^{1}$ ).

1) Es erscheint ja wohl berechtigt, so wie $\mathrm{E}$. Baur (1920) in der neuesten Auflage seiner Vererbungslehre dies tut, die Ergebnisse der Untersuchungen 
Das Hauptergebnis der Untersuchungen Kammerers darf ich als bekannt voraussetzen und mich deshalb nur auf die Besprechung der hier in Frage kommenden Einzelheiten beschränken. Im Gegensatz zu allen anderen Anurenarten, bei denen die Ausbildung der Brunstschwielen nur eine relative Unabhängigkeit von der Hormonwirkung der Hoden zeigt, soll die Brunstschwiele der männlichen Geburtshelferkröte hinsichtlich ihrer Ausbildung vollkommen unabhängig von Hodeninktreten sein: "Thre periodische Evolution wird bei totalen beiderseitigen Kastraten ohne jede Abschwächung fortgesetzt.«

Im "Naturzustand "soll das Männchen der Geburtshelferkröte auch während der Paarungszeit keine Brunstschwielen besitzen. Diese Angabe entspricht nun zunächst nicht den Tatsachen. Offenbar hat Kammerer nur eine geringe Anzahl solcher Männchen im "Naturzustande « untersucht und gibt vor allem nicht an, ob er die Daumenschwielen derjenigen Männchen einer genauen histologischen Prüfung unterworfen hat, die bei gewöhnlicher Temperatur von unter 25 Grad ihre Eier im Wasser ablegen.

Die Geburtshelferkröte geht nämlich im Freien nicht allzuselten von der gewöhnlichen Art der Fortpflanzung ab und legt ihre Eier ins Wasser: In Gegenden, in denen sie in großer Anzahl vorkommt, findet man häufig im Frühjahr Laichballen imWasser liegen, auch in der Gefangenschaft finden sich unter einer größeren Anzahl von Geburtshelferkröten meist auch einige, die ihre Eier im Wasser ablegen. Ich brauche mich hier nicht auf meine eigenen Beobachtungen zu stützen, sondern kann die eigenen Mitteilungen $\mathrm{Kam}$ merers als Beweise anführen. Er berichtet (1906): 》Ich fand bei Appenzell wiederholt in Straßengräben und Tümpeln lose Eiballen « und nimmt an, sie seien von den betreffenden Männchen vorzeitig abgestreift

Kammerers vollständig aus jeder wissenschaftlichen Erörterung auszuscheiden. Denn zweifellos sind sie nicht mit der Sorgfalt ausgeführt, die wir bei einem wissenschaftlichen Versuch voraussetzen müssen. Äußert sich dooh der langjährige Mitarbeiter Kammerers, Megušar (1914), in folgender Weise über sie: "Vorgänge, von welehen $\mathrm{Kammerer}$ uns berichtet, konnte ich weder in seinen Versuchen, nooh in meinen eigenen feststellen, obwohl ich seine äußerst unexakt geführten Versuche durch nahezu 10 Jahre in Evidenz erhielt, indem ich die Laboranten bei der Bedienung seiner Experimente kontrollierte und dieselben durch einige Jahre hindurch persönlich betreute. "Die Darstellungen Kammerers enthalten grobe Unwahrheiten und Fälschungen der tatsächlichen Verhältnisse." Auch die Eröffnungen Baurs (1914) lassen die Arbeitsweise Kammerers in eigentümlichem Licht erscheinen. Ich will jedoch im folgenden nicht nachprüfen, ob seine Versuche sorgfältig ausgeführt wurden oder nicht, ich werde nur zeigen, daß ihre Ergebnisse, selbst wenn sie vollkommen richtig wären, doch niemals Beweise für die von ihm und von Semon vertretene Anschauung darstellt. 
worden. Wenn man aber berücksichtigt, wie fest die einmal angetrockneten Eischnüre an den Schenkeln der Männchen haften und außerdem bedenkt, daß doch alle gefesselten Männchen täglich mehrmals baden, ohne ihre Eischnüre zu verlieren, so darf man wohl daraus schließen, daß die im Wasser liegenden Eiballen mit unentwickelten Embryonen nicht "zufällig verloren gegangen sind", sondern von allem Anfang an im Wasser abgelegt wurden.

Kammerex selbst beobachtete außerdem (1906, Seite 69) an seinen im Terrarium bei gewöhnlicher Temperatur gehaltenen Geburtshelferkröten, daß eine ganze Reihe der Männchen sich nicht mit den Eischnüren belud, sondern sie einfach liegen ließ. "Die herausbeförderten Eischnüre lagen dann überall im Behälter herum: Auf der Erde, auf und unter dem Moos, an Steinen angeklebt und last not least - im Wasserbecken. Ich ïberraschte die Tiere auch etliche Male, wie sie hier die Kopulation vollzogen. " Die Erklärung, die Kammerer für diese Tatsache zu geben versucht, ist reichlich gekünstelt und befriedigt in keiner Weise.

Wohl aber zeigen diese Beobachtungen, da $B$ die Geburtshelferkröte auch unter gewöhnlichen Bedingungen nicht immer an der bekannten Art der Fortpflanzung festhält, sondern häufig genug ihre Eier ins Wasser ablegt. Alytes obstetricans ist also, wie sehr viele Amphibien, poikilothok und das, was Kammerer in seinen Versuchen durch äuBere Einwirkung neu hervorgerufen zu haben glaubt, ist in Wahrheit keine neue Eigenschaft, sondern nux eine Form der Fortpflanzung, die innerhalb der Variationsbreite der Geburtshelferkröte gelegen ist. Nach dieser Feststellung ist jedes weitere Eingehen auf die betreffenden Versuche, vor allem auch auf das angebliche Mendeln der verschiedenen Fortpflanzungsarten überflüssig.

Ich will jedoch noch kurz das Verhalten der Daumenschwielen besprechen, sie sollen angeblich bei Geburtshelferkröten, die sich mehrere (sechs) Generationen lang nur durch Eiablage im Wasser fortgepflanzt haben eine etwas stärkere Ausbildung erfahren. Kammerer behauptet zwar, daß die Brunstschwiele dabei neu entstände, da sie ja angeblich im "Naturzustand " fehle. Die Brunstschwiele besteht nun in der Hauptsache aus mehreren Drüsen und der darüber gelegenen Epidermisschicht. Während und vor der Fortpflanzungszeit vergrößern sich auch bei im "Naturzustand" befindlichen Männchen und Weibchen die Drüsen recht erheblich, die Epidermisschicht verdickt sich, ohne allerdings zu verhornen, wenigstens ist bei den Sehwielen, die Kammerer als Grundlage zu seinen Abbildungen benutzt (Taf. XI, Abb. 1, 2 u. 3, 1.c. 1919), keine Verhornung zu erkennen. Zweifellos geht aus diesen Abbildungen aber hervor, daß 
sich auch beim gewöhnlichen Alytes-Männchen, in schwächerer Weise sogar beim Weibchen, Brustveränderungen an den Schwielen abspielen, gleichlaufend mit denen, die wir bei anderen Froscharten beobachten, jedoch nicht so stark ausgebildet. Bei Geburtshelferkröten, die sich im Wasser begatten und dort ihre Eier ablegen, zeigen nun die Schwielen die eben beschriebenen Brunstumgestaltungen in höherem Maße, die Drüsen vergrößern sich stärker und die oberflächlichen Epidermisschichten verhornen.

Bei diesen Vorgängen handelt es sich aber nicht, wie Ka m merer meint, um das Auftreten einer ganz neuen Eigenschaft, sondern nur um die stärkere Betonung einer Erscheinung, zu der die Veranlagung schon im ganzen Organismus gegeben ist. Die Brunstschwielen werden ja nicht neu erzeugt, sondern nur etwas stärker ausgebildet; hätte Ka mmerer zu seinen Versuchen eine andere Art, um den Vergleich anschảulich zu machen etwa eine Reptilien- oder Säugerart benützt, bei der keine Brunstschwiele vorhanden ist, so wäre es ihm niemals geglückt: erstens die Form der Fortpflanzung abzuändern und zweitens eine Verhornung der während der Kopula gedrückten Epidermisteile zu erzielen.

Kammerer behauptet nun, die Brunstschwiele »qualifiziere sich als funktionelle Anpassung", und zwar ausschließlich als solche. Jedwede anderen Einflüsse, so besonders 》die direkte Bewirkung durch das Versuchsmilieu und durch die innere Sekretion des Hodens", sollen sich ausschließen lassen und zwar natürlich mit so vollkommener Sicherheit, wie sie nur Kammerer aufzubringen vermag.

Während der Kopulation wird nun ein-, höchstens zweimal im Jahr für kurze Zeit ein Druck auf die fraglichen Hautstellen ausgeübt, die an und für sich nach der Anschauung Ka mmerers nicht mehr zur Schwielenbildung befähigt sind, als jede beliebige Körperstelle, und dieser kurze Reiz soll genügen, um nicht nur bei dem zunächst betroffenen Tier, sondern auch bei den Nachkommen eine vollkommen neue Eigenschaft in Gestalt einer verhornten Schwiele hervorzurufen! Unwillkürlich drängt sich hier wieder der Vergleich mit dem Hühnerauge auf, auch bei ihm haben wir es ja mit einer durch lokalen, allerdings sehr lang anhaltenden Druck entstandenen, verhornten Schwiele zu tun, die sich vollkommen unabhängig von der übrigen Beschaffenheit der Umgebung und von der Hormonabsonderung der Keimdrüsen ausbildet - und sich doch nicht vererbt.

Die stärkere Ausbildung der Brunstschwielen bei den beeinflußten Alytes-Männchen kann also garnicht die Folge des kurzen, während der Begattung einwirkenden Druckes sein. Wie müßten sonst die Nachkommen von Alytes und von allen Arten des Tierreiches, einschließlich des Menschen, aussehen, wenn jede durch äußere Ein- 
wirkung entstandene Hautverdickung sich auf die Nachkommen übertrüge?

Wie ich schon oben gezeigt habe, ist die Geburtshelferkröte hinsichtlich der Art ihrer Fortpflanzung variabel. Das eine Tier neigt offenbar mehr zur gewöhnlichen Art der Eiablage, das andere mehr zur Wasserablage. Beide Formen sind im Bau des ganzen Körpers begründet und wahrscheinlich werden eingehendere Untersuchungen ergeben, daß bei den "Wassertieren « die Brunstschwielen ohnehin stärker ausgebildet sind, als bei den Landtieren; aber nicht als Folge des lokalen Reizes, er ist ja viel zu kurz, um eine tiefere Veränderung zu setzen, sondern als Folge einer anderen Beschaffenheit des Körpers, die an sich eben die verschiedene Fortpflanzungsweise bedingt. Wird nun im Versuch durch veränderte äußere Verhältnisse die Form der Eiablage bei allen Versuchstieren geändert - dies gelingt, da ja die Möglichkeit

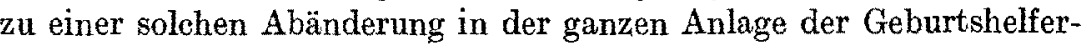
kröte gegeben ist - so erfährt bei den beeinflußten Tieren zunächst die chemisch-physiologisohe Zusammensetzung des ganzen Körpers eine Umgestaltung. Die höhere Wärme, die ja häufig im Versuch die Ursache für die Wasserablage ist, bedingt stärkere Wasserverdunstung und damit Veränderungen im Stoffwechsel und erstreckt sich in ihren Wirkungen, wie ja meine Molchversuche zeigen, auch auf die Keimdrüsen. Als Folge dieser Umgestaltungen neigt der ganze Organismus mehr zur Fortpflanzung im Wasser und erfährt in allen reaktionsfähigen Teilen eine Abänderung, die ihn für diese Art der Fortpflanzung tauglich macht. Dazu gehört auch die stärkere Ausbildung der Brunstschwiele.

Bei den Nachkommen machen sich diese Erscheinungen in erhöhtem Maße geltend, eines Teiles weil schon die Eier und Samenfäden durch die Umgestaltung des elterlichen Körpers beeinflußt wurden, dann aber auch, weil sich die Beeinflussung während der Wasserentwicklung fortsetzt. Hier wirkt nun auch in höchstem Maße die Selektion mit, indem alle Tiere, die sich der Wasserfortpflanzung nicht anpassen können, schon im $\mathrm{Ei}$, spätestens während des Larvenlebens absterben. Wir haben es hier also mit einer innerhalb der Variationsbreite der Geburtshelferkröte gelegenen Abänderung des Fortpflanzungsaktes zu tun, nicht aber mit der Hervorrufung einer neuen Eigenschaft. Die Veränderungen an den Daumenschwielen stellen dabei nur eine untergeordnete Teilerscheinung des ganzen Vorganges dar, sie wickeln sich gleichzeitig und gleichsinnig mit den anderen Veränderungen ab. Alle diese Umgestaltungen sind aber nur möglich, weil die Geburtshelferkröte ererbterweise zu ihnen befähigt ist. Als Beweise für die Vererbung erworbener Eigenschaften sind sie nicht zu verwerten, stellen sie doch keine neu erworbenen Eigenschaften dar. 
Das nämliche läßt sich auch von anderen Tatsachen sagen, über die Schultz (1920 u. a.a. O.) berichtet. Er stellt in sehr genauen Versuchsreihen fest, daß beim Russenkaninchen die Haarfarbe durch die Wärme der umgebenden Luft beeinflußt wird. Ist sie gering, so sind die Haare schwarz, ist sie hoch, so sind sie weiß. Damit läßt es sich auch in Einklang bringen, daß das Russenkaninchen ausgesprochen vakromegalisch" schwarz gefärbt ist. Werden bei einem gewöhnlich gezeichneten Tier die weißen Haare entfernt, so wachsen sie in der Kälte schwarz, in der Wärme weiß nach. Umgekehrt läßBt sich auch die schwarze Farbe der Ohren und Pfoten durch Wärmeanwendung in weiß verwandeln. So gründlich und schön diese Untersuchungen nun sein mögen, auch sie lassen sich nicht als Beweise für die Vererbung erworbener Eigenschaften anführen. Das Russenkaninchen besitzt eben die Fähigkeit, sich in der Haarfarbe der umgebenden Temperatur anzupassen, auf Grund dieser Eigenschaft ist ja wohl seine besondere Färbung entstanden. Werden die gleichen Versuche mit weißen oder schwarzen Tieren anderer Rassen ausgeführt, so bleiben sie ergebnislos, da diesen Rassen eben die Fähigkeit der Wärme- und Kälteanpassung fehlt.

In letzter Zeit bringt nun De moll (1920) eine weitere Mitteilung, die nach seiner Anschauung eine Stütze für die Vererbbarkeit funktioneller Anpassungen darstellt: Im Gebiß eines Karpfens fand sich rechterseits ein Mahlzahn, der stärkste der inneren Reihe, dessen Krone nicht nach oben stand, sondern unter den Nachbarzahn verschoben war. Eine Beteiligung am Kauakt war infolgedessen ausgeschlossen, und trotzdem zeigte bei dem schiefen Zahn die Kaufläche die nämliche Form wie bei den stark benützten Nachbarzähnen. Nach der Angabe Demolls sind nun die Zähne des Karpfens ursprünglich spitz und nützen sich erst durch den Gebrauch ab, indem sich die Spitze zur Kaufläche abschleift. „Zur Beurteilung der Sachlage ist es notwendig zu wissen, daB ein Zahnwechsel bei diesen Formen nicht stattfindet.《

Bei dem schiefgestellten Zahn hatte sich demnach die Umwandlung der Spitze in eine breite Kaufläche wie bei einem gewöhnlich gestellten Zahn vollzogen, ohne daß eine Abschleifung durch den Kauakt in Frage kam. Da nun die Abnützung der Zähne und ihre dadurch bedingte Gestaltsveränderung eine erst während des individuellen Lebens erworbene Anpassung darstellt, so macht uns die Mitteilung Demolls mit einem ganz besonderen Vorkommnis bekannt, das sicher von sehr hoher Bedeutung für alle Vererbungsfragen wäre. Allerdings mußte es dem unbefangenen Leser seiner Arbeit merkwürdig erscheinen, daß sich die Zähne des Karpfens so grundlegend anders verhalten, als die aller anderen Tiere, bei denen 
eine Abnützung ja nur infolge des Gebrauches eintritt, ja sogar anders als alle übrigen organischen und selbst anorganischen Substanzen. Nirgends auf der ganzen Welt findet sich ja sonst ein Beispiel dafür, daB ein nichtbeeinträchtigter und nicht benützter Körper sich in der gleichen Weise abschleift, wie ein stark geriebener Gegenstand. Es wäre ja leicht zu zeigen, daß schon auf Grund dieser Ausführungen die Demollsche Angabe unzutreffend sein muß, allein wir haben es hier nicht nötig, unsere Zuflucht zu theoretischen Erörterungen zu nehmen, nachdem De moll selbst uns mitteilt (1921), daB seine ersten Angaben in ihrer wichtigsten Voraussetzung falsch sind.

Er ließ nämlich durch eine Schülerin (Stoß) die Zahnentwicklung bei Karpfen nachprüfen und stellte dabei fest, dab seine Annahme, es finde kein Zahnwechsel bei diesen Arten statt, unzutreffend ist: vielmehr erfolgt bei ihnen eine vierfache (1) Dentition. Aber nur die Zähne des ersten Gebisses, die angeblich niemals zum Kauen verwendet werden, zeigen den schlanken, spitzen Bau der gewöhnlichen "Weilfischzähne «, diejenigen der zweiten Dentition aber werden von vornherein als Mahlzähne angelegt. - $\Vdash$ Es bleibt also der Funktion nicht mehr viel zu tun übrig, um die Zähne ihrer endgültigen Funktion zuzuführen. " Der schiefgestellte Zahn, den De moll in seiner ersten Abhandlung beschreibt und auf den er seine weitgehenden Schlußfolgerungen stützt, hatte also seine Form nicht erst durch einen geheimnisvollen, in ihm selbst begründeten, vom Gebrauch unabhängigen, Abnützungsvorgang erhalten, sondern war niemals etwas anderes gewesen als ein Mahlzahn. Der Versuch De molls, trotzdem noch die Zahnform im allgemeinen als Beweis für die Vererbung erworbener Eigenschaften heranzuziehen, ist vollkommen miBglückt und soll wohl nur dazu dienen, den Fehler, der ihm bei seiner ersten Veröffentlichung unterlaufen ist, etwas zu verdecken oder zu entschuldigen.

Gerade die verschiedenen Zahnformen können niemals als Ergebnis einer funktionellen Anpassung angesehen werden. Denn es handelt sich ja bei den Zahnkronen, wie Roux (1920) auch dartut, um ein "von zwei Matrices aus produziertes Gebilde, dessen äußere, die Größe1) bewirkende Matrix, das Schmelzorgan, zur Zeit der Benutzung des Zahnes bereits geschwunden ist, also nicht mehr vergrößerungstätig sein kann." Allerdings läßt sich die Bildung der noch im Zahnsäckchen gelegenen, also unfertigen, noch nicht fungierenden Zahnkrone durch Kauen von festweichen Dingen etwas fördern (Roux), doch dürfte dieser Einfluß kein allzu großer sein.

Trotz alledem wäre es aber falsch, den Zähnen jede Fähigkeit zur funktionellen Anpassung abzusprechen, sehen wir doch am Dentin

1) und Form.

Archiv für Entwickilungsmechanik Bd. 49. 
dessen funktionelle Matrix, die Odontoblasten, zeitlebens erhalten bleibt, infolge der durch den Gebrauch bedingten Reizung Veränderungen vorgehen, die bei nicht benutzten Zähnen ausbleiben, nämlich die Bildung des Ersatzdentins. Sie stellt alsó eine funktionelle Anpassung dar, die sich aber nicht vererbt. Denn die Zähne jugendlicher Lebewesen besitzen stets den Bau wie die Zähne der Eltern im Jugendalter und nicht wie die stark abgekauten mit reichlichem Ersatzdentin beladenen des Greises. Die verschiedenen Zahnformen, die wir bei den einzelnen Arten, besonders der Wirbeltiere beobachten, können also nicht durch funktionelle Anpassung, sondern nur'durch Mutation und Selektion entstanden sein.

Auch der Versuch Demolls, die Veränderungen an den Fischzähnen deshalb, weil sie noch des Schmelzes entbehren als funktionelle Anpassung zu erklären, ist nicht stichhaltig. Er stützt sich ja hauptsächlich auf den Umstand, daß beim Karpfen nur diejenigen Zähne der zweiten und aller weiteren Dentitionen Mahlform zeigen, die wirklich zum Kauen verwendet werden, wohingegen die vordersten Zähne der medialen Reihe »die zur Funktionslosigkeit verurteilt sind«, spitze Höcker besitzen. Bei dieser Folgerung fehlt zunächst der Beweis, daß die betreffenden Zähne tatsächlich völlig unbenutzt sind und nicht doch noch, wie das wohl wahrscheinlich ist, beim Erfassen der Nahrung als Greifzähne in Tätigkeit treten. Finden sich doch auch im Kiefer vieler Säugetiere Zähne, besonders die Canini; die auch nicht zum Mahlen verwendet werden und doch nicht als funktions- und damit als zwecklos bezeichnet werden können. Ähnliche Verhältnisse liegen wohl auch bei den Karpfenzähnen vor, und es ist zum mindesten verfrüht, aus den an ihnen gewonnenen Befunden weitgehende Schlüsse zu ziehen, so lange nicht unsere Kenntnisse über das Karpfengebi $\beta$ überhaupt mehr gefestigt sind, so daB wir vor solchen Uberraschungen, wie sie uns Demoll in seinen beiden Arbeiten bereitet, sicher sein können.

Bei den Säugetieren kann jedenfalls die Ausbildung der Zahnkronen nicht durch funktionelle Anpassung geschehen sein, da sie ja in der Zeit ihrer Beanspruchung keine Anpassungsfähigkeit besitzen. Der Schmelz, der in erster Linie, ja man darf sagen ausschließlich die Kronenform bildet, hat dann seine Entwicklung abgeschlossen und besitzt, da seine Matrix, das Schmelzorgan, längst verschwunden ist, nicht mehr die Fähigkeit der Gestaltsveränderung. Auf ihn treffen deshalb die nämlichen Verhältnisse zu, die Weis mann (1913) für den Chitinpanzer vieler Insekten beschreibt, denn auch diesem geht die funktionelle Anpassungsfähigkeit $\mathrm{ab}$ und trotzdem zeigt er allenthalben zweckdienliche Gestaltung.

Andere Hartgebilde des Körpers, nämlich die Knochen, besitzen 
dagegen eine dauernde hochgradige Anpassuugsfähigkeit; selbst bei alten Leuten vermögen sich ja die Spongiosastrukturen noch vollkommen den veränderten Druckverhältnissen anzupassen, die durch eine unzweckmäBige Verheilung von Knochenbrüchen erzeugt werden. Das Endergebnis dieser Anpassung überträgt sich aber nicht auf die Nachkommen, denn bei ihnen finden wir stets diejenigen Strukturverhältnisse, die dem Mittel der gewöhnlichen Beanspruchung entsprechen und sie werden während des Wachstums als Folge des Gebrauches in der einen oder der anderen Richtung verändert. Auch in ihrem Verhalten kommt die Variabilität und die individuelle Anpassungsfähigkeit zum Ausdruck, die jedem Lebewesen innewohnt und es befähigt, seine Gestalt und alle Lebensverrichtungen innerhalb gewisser Grenzen abzuändern.

Darüber kann ja heute kein Zweifel mehr bestehen, daß die ganze Umgebung, die Beschaffenheit des Aufenthaltsortes, des Klima und der Ernährung von hervorragender Bedeutung für die Entwicklung und Gestaltung der Lebewesen sind. Sie setzen an ihnen bestimmte Veränderungen, deren Folgen sich, wie ja meine Versuche gezeigt haben, auch an den Keimdrüsen geltend machen und dadurch auch die Nachkommen bzw. ihre Entwicklung in bestimmter Weise beeinflussen müssen.

ÄuBere Einflüsse können also in allen den vier von Roux festgestellten Perioden ungestaltend oder mitgestaltend auf die Entwicklung eines Lebewesens einwirken, ihr Erfolg muB in den einzelnen Abschnitten verschieden sein und sich am stärksten in der Periode I geltend machen. Diese beginnt für das Einzellebewesen mit der ersten Furchungsteifung, schon vorher aber durchlaufen $\mathrm{Ei}$ und Samenzellen im elterlichen Körper einen Entwicklungsgang, während dessen sie, allerdings unter gewissen Einschränkungen, schon als selbständige Wesen bezeichnet werden müssen und auch durch Veränderungen des elterlichen Körpers umgestaltet werden können. Ihre Reaktionsfähigkeit ist am größten während der sensiblen Periode, deren tatsächliches Bestehen ja auch in dieser Arbeit gezeigt werden konnte.

Wenn also tatsächlich am Bestehen eines Einflusses von seiten der äuBeren anorganischen Bedingungen auf die einzelnen Lebewesen nicht gezweifelt werden kann, so muB dabei doch immer betont werden, da 3 dieser EinfluB stets nur gering ist im Vergleich $z u$ dem Lebensgeschehen, das jedem Lebewesen selbst angeboren, in ihm determiniert ist und in erster Linie seine ganze Entwicklung bedingt und leitet.

Alle Abweichungen vom normalen Bau eines Lebewesens, die 
bisher im Versuch erzielt werden konnten, betreffen, wie ich schon eingangs erwähnte, ja nur variable Eigenschaften und sind verhältnismäßig unbedeutend, im Vergleich zur Organisation des Gesamtkörpers, deren Ausbildung trotzdem in den typischen Bahnen verläuft. Im Grunde genommen ist es ja gleichgültig, ob ein Salamander mehr gelbe oder mehr schwarze Flecken hat, ob er ganz gelb oder ganz schwarz ist, auch gleichgültig, ob er Eier legt oder lebendige Junge gebiert. Die Hauptsache ist schließlich, daß das betreffende Tier, um anschaulich zu sprechen, ein Salamander von typischem Körperbau wird und nicht etwa ein Krokodil, ein Fisch oder ein Dachshund. Die Fähigkeit sich zum Vertreter der spezifischen Art auszubilden wohnt jedem Ei in erster Linie inne, sie ist die Grundeigenschaft des Lebens und sie kann durch äußere Einflüsse nicht verändert werden, sie ist vererbt und soweit wir bisher wissen, vollkommen unabänderlich. Wenn Uhlenhuth (1920) dagegen die Anschauung vertritt, daß die Entwicklung eines Lebewesens durch die Vererbung nicht bestimmt werde, sondern daß für sie nur äußere, anorganische Faktoren verantwortlich zu machen seien, da ja z,um Beispiel ohne Sauerstoff die Entwicklung ausbleibe, so trifft dies nicht zu.

Jedes Lebewesen benötigt für seine Entwicklung und sein Bestehen gewisse Vorbedingungen, eine gewisse Beschaffenheit der Umgebung, die als »Realisationsfaktor" (Roux) ihm eben die Entwicklung möglich macht, aber nicht die Art ihres Geschehens bewirkt. Ist sie ungeeignet, so findet entweder eine Anpassung statt, wenn die Abweichung von den gewöhnlichen Lebensbedinungen keine zu große ist, oder die Entwicklung unterbleibt vollständig: das Leben erlischt, wenn die organischen Bedingungen zu ungünstig sind. Die Ursachen für das eigentliche Entwicklungsgeschehen aber sind spezifisch organischer Art, sie sind ererbt. Die artspezifische Entwicklung spielt sich stets unabhängig von den organischen Bedingungen $a b$, selbst dann, wenn der Ansto $B$ zu ihrem Beginn, die Befruchtung des Eies wie in den Versuchen von Loeb (1908) und anderen durch einen anorganischen Vorgang ersetzt wird.

Uhlenhuth (1914) glaubt durch seine Versuche das Fehlen der funktionellen Anpassungsmöglichkeit bei Amphibien erwiesen zu haben: Bei Salamandern erfolgt nämlich die Regeneration der vorher degenerierten Netzhaut selbst an einem in den Hals transplantierten Auge bei einem in völliger Dunkelheit gehaltenen Tier. Diese Tatsache bekundet, wie ja schon Roux (1920) einwendet, jedoch nur, daß zur Regeneration der Netzhaut des Salamanders funktionelle Anpassung nicht nötig ist, sie besagt jedoch noch nicht, daß den Amphibien überhaupt jede Fähigkeit zur funktionellen Anpassung fehlt. 
Denn was für die Netzhaut zutrifft, muß nicht für alle Organe des gleichen Lebewesens Geltung haben.

Als funktionelle Anpassung im weitesten Sinne müssen wir wohl auch die Veränderungen im Farblleid des Feuersalamanders bezeichnen, außerdem auch einige der hier beschriebenen Vorgänge im Eierstock, nämlich alle diejenigen, bei denen durch die Veränderungen der äußeren Bedingungen anfangs eine Unterbrechung der Eiablage erfolgte, wo aber nach Gewöhnung an die neuen Verhältnisse die Brunst wieder in Gang kam. Gerade die hier beschriebenen Versuche zeigen ja einerseits die hohe Empfindlichkeit und auch Anpassungsfähigkeit der Amphibien gegenüber Veränderungen der anorganischen Bedingungen, sie beweisen aber deutlich genug, da $B$ eine gewisse Grenze der Änderung dieser anorganischen Bedingungen nicht überschritten werden darf, ohne daß dadurch das Lebensgeschehen schwer geschädigt wird. Das Lebensgeschehen läßt sich eben nur innerhalb der ererbten Grenzen variieren, aber nicht vollkommen neuen Verhältnissen anpassen. Dies müßte aber der Fall sein, wenn die anorganischen Faktoren die ausschließlich maßgebende Rolle im Entwicklungsgeschehen spielten.

Uhlenhuth will ja überhaupt den Begriff der Reizbarkeit ganz aus der Biologie ausgeschaltet wissen und sieht »die von den Organismen ausgehenden Leistungen als solche Leistungen an, die einfach der von außen eingeleiteten passiven Störung angehören«.

Es ist dabei, wie schon erwähnt, selbstverständlich, daß jedes Lebewesen von der Beschaffenheit der Umgebung abhängig ist, das heißt, es kann nur bei einer bestimmten Zusammensetzung der Umwelt die eigentlichen Lebensfunktionen verrichten. Des weiteren ist es selbstverständlich, daß vereinzelte Leistungen der Organismen eine Fortsetzung anorganischer Leistungen sind, wie zum Beispiel der Oxydationsproze $\mathbb{B}$ bei der Atmung. Die Beschaffenheit der anorganischen Umgebung bildet eben den Boden für die Entwicklung des Einzelwesens, die Bahnen aber, in denen sich diese Entwicklung abspielen $m u ß$, sind im Lebewesen selbst vorgezeichnet, sie sind ererbt. Wäre dies nicht der Fall, käme wirklich, wie Uhlenhuth dies annimmt, den organischen äußeren Faktoren der ausschließliche Anteil am Lebensgeschehen zu, dem der Organismus ohne jede ererbte Anlage folgen müßte, so müBten alle Pflanzen auf dem gleichen Boden, alle Tiere im gleichen Tümpel sich ganz gleich entwickeln, denn die äußeren Bedingungen sind hier ja für alle gleich und waren es bei vielen Formen, besonders denen, die im Meere leben seit Jahrtausenden.

Und trotzdem erkennen wir bei solchen Lebewesen, die zum Beispiel gemeinsam einen bestimmten Meeresteil bevölkern, also seit langem unter ganz gleichen äußeren Bedingungen leben, die ver- 
schiedensten Bildungen, wir finden gleichzeitig einfache und höchst verwickelt gebaute Organismen, die alle die gleiche anorganische Umgebung auf Grund ihrer ererbten Verschiedenheit in verschiedener Weise für ihr verschiedenes Lebensgeschehen ausnützen.

Gerade die Vielgestaltigkeit der Lebewesen, die einen Aufenthaltsort von gleichmäßiger Beschaffenheit bevölkern, zeigt deutlich, daß die Umgestaltung der Arten, die sich im Verlaufe der Jahrtausende vollzog, nicht einzig und allein durch Veränderungen in der anorganischen Umgebung bedingt sein können. Diese bewirkt, soweit die Ergebnisse der jetzigen Versuche lehren, immer nur eine Abänderung der variablen Eigenschaften innerhalb der ererbten Variationsbreite; vielleicht kann sie diese auch etwas verschieben, niemals ist sie jedoch imstande, wirklich Neues zu schaffen. Denn wenn die äußere Veränderung so tiefgreifend ist, da $\beta$ sie ein Fortleben der Organismen innerhalb der ererbten Variationsbreite nicht mehr zuläßt, dann gehen die beeinflußten Lebewesen selbst oder ihre Keimzellen zugrunde. Wie viele freilebende Arten sind in der Gefangenschaft trotz der besten Pflege dem Aussterben verfallen, weil die vom Freileben abweichenden Bedingungen zwar noch ein Fortleben des ausgewachsenen Tieres ermöglichen, jedoch die Entwicklung der Keimzellen und damit die Fortpflanzung hemmen. Gerade die hier beschriebenen Versuche haben ja die hohe Empfindsamkeit der Gonaden gezeigt.

Und doch ist es möglich, daß sich eine Art im Verlaufe der Zeit veränderten Bedingungen anpaßt und daß dann die anfängliche. Unfähigkeit zur Fortpflanzung schwindet. Ganz allgemein muß dies bei der Domestikation eingetreten sein, wir sehen den Vorgang aber auch heute noch bei manchen wildlebenden Arten, ich erwähne nur das oben besprochene Beispiel des Elephanten. Er pflanzt sich jetzt in der Gefangenschaft sogar in Europa fort, zum Teil wohl deshalb, weil die Pflege jetzt eine bessere ist als früher, zum Teil aber sicher auch deshalb, weil unter den vielen in Gefangenschaft gehaltenen Elephanten sich eben vereinzelte anpassungsfähige befinden.

Gerade bei domestizierten Arten zeigt es sich aber, dab der Einfluß der äußeren Bedingungen auf die Keimdrüsen trotz der scheinbaren völligen Anpassung noch nicht erloschen ist, denn sehr häufig finden sich unter den in der Gefangenschaft gezüchteten Nachkommen, Lebewesen, die sich in einer oder in mehreren Eigenschaften grundlegend vom Mittel der Art entfernen, also wirklich neue Formen darstellen. Alle heute bekannten Rassen der Haustiere und Hauspflanzen sind ja wahrscheinlich durch solche Mutationen entstanden und entstehen noch heute durch sie. Auch sie zeigen an, daß die Keimzellen durch Veränderungen in der Umgebung in tiefgreifender Weise verändert werden können, so daß die Nachkommen sich manchmal in der einen 
oder der anderen Eigensehaft auch auBerhalb der Variationsbreite verändern. Mit diesen Formen, ihrer Entstehung und künstlicher Erzeugung muß sich die weitere Forschung mehr als bisher beschäftigen, um zu zeigen, ob ihr Zustandekommen tatsächlich von Veränderungen in der Umgebung abhängt.

Aber selbst wenn dieser Beweis, was ja sehr wahrscheinlich ist, gelingt, so wird er doch nicht imstande sein, die Lebensvorgänge auf Loistungen der von außen eingeleiteten anorganischen Störungen zurückzuführen.

Das eigentliche Lebensgeschehen ist, wie ich zum Schluß hier nochmals betonen will, dem Organismus angeboren, es ist ererbt, bedarf zu seiner Entwicklung und Ausbildung jedoch einer bestimmten Beschaffenheit der äußeren Umgebung und ist von ihr hinsichtlich seiner Ernährung abhängig. In der gleichen Weise etwa wie eine Dampfmaschine, soll sie gehen, der Heizung und des Wassers bedarf und doch nicht aus solchen Substanzen entstehen kann. Uhlenhuth unterschätzt ja vollkommen den Anteil des ererbten Lebensgeschehens und überschätzt den Einfluß der anorganischen Faktoren, ein Vorgehen, zu dem kein Grund vorliegt. Erkennen wir ja doch stets, daB alle Lebensvorgänge einschlieBlich der Entwicklung sich in der spezifisch ererbten Weise abspielen und zwar immer in der Form, die für die betreffende Art und nicht für die Beschaffenheit der Umgebung bezeichnend ist. Wie Roux sagt, werden also die eigentlichen Lebensvorgänge durch Autodetermination der Lebewesen bewirkt.

Ich glaube im Vorhergehenden gezeigt zu haben, daß den äußeren Bedingungen ein hoher Einfluß auf den Ablauf der Lebensvorgänge, besonders der Fortpflanzungstätigkeit zukommt. Veränderungen in der Umgebung können die Entwicklung der Keimzellen hemmen und selbst dann tiefgreifende Rückbildungen an ihnen bedingen, wenn der ïbrige Körper noch keine nachweisbaren Umgestaltungen zeigt. Bei der Art der von mir angewendeten Reize erscheint es unmöglich, daß diese selbst unmittelbar auf die Keimzellen eingewirkt haben, die hier besprochenen Versuche lassen sich also, wie ich schon in der Einleitung angedeutet habe, nur in der Art erklären: Jede, auch die kleinste Veränderung der Umgebung wirkt auf den Gesamtkörper als Reiz und bedingt an ihm gewisse Umgestaltungen. Diese sind nur die Antwort des Körpers auf den Reiz, zu der er auf Grund des ererbten Lebensgeschehens befähigt ist, sie stellen eine Abwehrmaßnahme dar. Thr Erfolg ist für uns jedoch stets nur an den abänderungsfähigen Zellen zu erkennen und in erster Linie an den empfindlichsten Gebilden des gesamten Organismus überhaupt, an den Keimzellen.

Sind die äußeren Reize sehr stark, so stellen die Keimellen ihre Tätigkeit ganz ein, sie bilden sich teilweise zurück, solange, bis der 
Körper die Schädigung ausgeglichen, sich angepaßt hat und dann das Mißverhältnis zwischen neuer Umgebung und seiner eigenen Organisation ausgleichen konnte.

Alle diese Versuche beweisen also die überaus hohe Empfindsamkeit der Keimdrüsen, sie lassen es leicht verständlich erscheinen, $\mathrm{dab}$ gewisse innerhalb der angeborenen Variationsbreite gelegene Veränderung bestimmter Stellen des Körpers in gleicher oder ähnlicher Weise auch bei den Nachkommen auftreten. Sie stellen niemals die unmittelbare Wirkung des Reizes dar, sondern sind immer nur die Folge der durch den Reiz bedingten Umgestaltung des Gesamtkörpers, die alle Zellen betrifft, aber nur an den abänderungsfähigen Bezirken für uns erkennbar werden. Die aufgefundenen Tatsaohen erklären also zwanglos die Erscheinungen, die bisher irrtümlich als Beweise für die Vererbung erworbener Eigenschaften angeführt wurden.

Leipzig, im Januar 1921.

\section{Erwähnte Arbeiten.}

Alverdes, F. 1921. Die neuen Towerschen Versuche an Leptinotarsa zur Lösung des Artbildungsproblems. Zeitschr. f, induktive Abstammungs- $u$. Vererbungslehre. Heft 25. - Barfurth, D. 1886. Biologisobe Untersuchungen über die Bachforelle, Arch. f. mikr. Anat. Bd. 27. - Baur, E. 1914. Bemerkungen zu Kammerers Abhandlung: Vererbung erzwungener Farbveränderungen. IV. Dieses Ärch. Bd. 38. - Derselbe. 1919. Einführung in die experimentelle Vererbungslehre. 3. u. 4. Aufl. Berlin, Gebrüder Borntraeger. Born, G. 1892. Die Reifung des Amphibieneies und die Befruchtung unreifer Eier bei Triton taeniatus. Anat. Anz. Bd. 7. - Derselbe. 1894. Die Struktur des Keimbläschens im Ovarialei von Triton taeniatus. Aroh. f, mikr. Anat. Bd. 43. - Boveri, Th. 1904. Ergebnisse über die Konstitution der chromatischen Substanz des Zellkernes. Jena. - Bronn, H. G.. 1873. Die Klassen und Ordnungen des Tierreiches. Bd. 6/1I. - Ceni, C. 1914. Die Genitalzentren bei Gehirnerschütterung. Dieses Arch. Bd. 39. - Congdon, E. D. 1912. The surroundings of the germ plasm. 3. The internal temperature of warmbloodet animals (Mus decumanus, $M$. musculus, Myoxus glis) in the artificial climates. Dieses Arch. Bd. 33. - Darwin, Ch., Gesammelte Werke, bes.: Das Variieren der Tiere und Pflanzen im Zustande der Domestikation. Deutsch v. Carus. 1878. - Demoll; R. 1920. Zur Frage nach der Vererbung rom Soma erworbener Eigenschaften. Díeses Arch. Bd. 46. - Derselbe. 1921. Die Vererbbarkeit somatischer Erwerbungen. (Neue Tatsachen zur Beurteilung dieser Frage.) Dieses Arch. Bd. 47. - Detto, C. 1904. Die Theorie der direkten Anpassung. Jena. - Dürigen, B. 1897. Deutschlands Amphibien und Reptilien. Magdeburg, Creutzsche Verlagsbuchhandl. - Fick, R. 1921. Bemerkungen zur "Vererbung erworbener Eigenschaften". Anat. Anz. Bd. 53, Nr. 18/19. - Fi ischel, A. 1920. Ursachen tierisoher Farbkleidung. Dieses Arch. Bd. 46. - Gegenbaur, C. 1901. Vergleichende Anatomie der Wirbeltiere mit Berüeksichtigung der Wirbellosen. II, Bd. Leipzig, W. Engelmann. - Hansemann, D. v. 1909. Der Kampf der Eier im Ovarium. Dieses Arch. Bd. 35. - His, W. 1865. Beobachtungen über den Bau des Sängetiereierstookes. Arch. f. mikr. Anat. Bd. 1. - Kam- 
merer, P. 1904. Beitrag zur Kenntnis der Verwandtschaftsverhältnisse von Salamandra atra und maculosa. Experimentelle und statistische Studie. Dieses Arch. Bd. 17. - Derselbe. 1906. Experimentelle Veränderungen der Fortpflanzungstätigkeit bei Geburtshelferkröte (Alytes obstetricans) und Laubfrosoh (Hyla arborea). Dieses Arch. Bd. 22. - Derselbe. 1908. Vererbung erzwungener Fortpflanzungsanpassungen. I. und II. Mitteilung. Die Nachkommen der spätgeborenen Salamandra maculosa und frühgeborenen Salamandra atra. Dieses Arch. Bd. 25. - Derselbe. 1913. Vererbung erzwungener Farbveränderungen. IV. Mitteilung. Das Farbkleid des Feuersalamanders (Salamandra maculosa Laurenti) in seiner Abhängigkeit von der Umwelt. Dieses Arch. Bd. 36. - Krefft, P. 1907. Das Terrarium. Berlin, Verl. von Pfennigstorff. - Leydig, F. 1850. Zur Anatomie der männlichen Gesehlechtsorgane und Analdrüsen der Säugetiere. Zéitschr. f. wissensch. Zool. Bd. 2. - Derselbe. 1867. Uber die Molche (Salamandrina) der württembergischen Fauna. Arch. f. Naturgesch. - Li isi, de. 1921. Über die Funktion der Hoden und des Eierstockes der enthirnten Schildkröten. Dieses Arch. Bd. 47. - L o e b, J. 1908. Uber den chemischen Charakter des Befruchtungsvorganges und seine Bedeutung für die Theorie der Lebenserscheinungen. Vorträge u. Aufsätze über Entwicklungsmech. Heft II. - Mazzetti, L. 1911. I caratteri sessuali secun dari e le cellule interstitiale del testiculo. Anat. Anz. Bd. 38. - Me gu ša r, F. 1914. Uber den Einfluß äußerer Faktoren und über Vererbung bei Crustaceen, Insekten, Mollusken und Amphibien. 85. Verhdl. d. Ges. Deutsch. Naturf. u. Arzte in Wien. Bd. 2. 1. Teil. - Nussbaum, M. 1909. Hoden und Brunstorgane des braunen Landfrosches (Rana fusca). Pflügers Arch. f. d. gesamte Physiologie. Bd. 126. - Pérez, Ch. 1903. Sur la résorption phagocytaire des ovules par les cellules folliculaires sous l'influence du jeûne chez le Triton. Compt, rend. Soc. biol. Bd. 55. - Derselbe. 1903. Sur la résorption phagocytaire des ovules chez les Tritons. Ann. Inst. Pasteur. 1903. S. 617-630. - Rathke, H. 1818. De Salamandris corporibus adiposis, ovarii et oviducti. Dissertatio Berolini 1818. Ribbert. 1890. Uber kompensatorische Hypertrophie der Geschlechtsdrüsen. Virchows Arch. Bd. 120. - Roux, W. 1911. Uber die bei der Vererbung blastogener und somatogener Eigenschaften anzunehmenden Vorgänge. Verhandl. des Naturhistorischen Vereins zu Brünn. Bd. 50. - Derselbe. 1913. Dasselbe, 2. verbesserte Anfl. Leipzig, Engelmann. - Derselbe. 1911. Die vier kausalen Hauptperioden der Ontogenese, sowie das doppelte Bestimmtsein der organisehen Gestaltungen, Mitteil. d. naturforsch. Ges. zu Halle. - Derselbe. 1920. Bemerkungen zur Analyse des Reizgeschehens und der funktionellen Anpassung, sowie zum Anteil dieser Anpassung an der Entwicklung des Reiches der Lebewesen. Dieses Arch. Bd. 46 u. a. a. O. - Rückert, J. 1892. Zur Entwioklungsgeschjohte des Ovarialeies bei Selachiern. Anat. Anz. Bd. 7. - Schultz, W. 1915. Schwarzfärbung weißer Haare. Dieses Arch. Bd. 41. - Derselbe. 1918. Versteqkte Erbfaktoren der Albinos usw. Zeitschr. f. induktive Abstammungs- u. Vererbungslehre. Bd. 20. - Derselbe. 1921. Kälteschwärzung eines Säugetieres und ihre allgemein-biologischen Hinweise. Dieses Arch. Bd. 47. - Śécerov, S1, 1912. Uber das Farbkleid von Feuersalamandern, deren Larven auf gelbem Grund erzogen waren. Dieses Arch. Bd. 33. - Derselbe. 1912. Die Umwelt des Keim. plasmas. IV. Der LichtgenuB im Lacerta-Körper. Dieses Arch. Bd. 34. - Derselbe. 1913. Licht, Farbe und die Pigmente. Beiträge zu einer Pigmenttheorie. Vorträge u. Aufsätze über Entwicklungsmech. d. Organismen, herausgegeb. v. W. Roux. Heft 18. - Semon, R. 1912. Das Problem der Vererbung nerworbener Eigenschaften $\%$ Leipzig, W. Engelmann, u. a. a. O. - Derselbe. 1913. Die Fußsohle des Menschen. Eine Studie über die unmittelbare und die erbliche Wirkung der Funktion. Arch. f. mikr. Anat. Bd. 82. - Shattock, S. G. 1911. Lamarckism and Callosties. Proceed. R. Soc. of Med. London. Bd. 4. - Stieve, 
H. 1918. Uber experimentell, durch veränderte äußere Bedingungen hervorgerufene Rückbildungsvorgänge am Eierstock des Haushuhnes (Gallus domesticus). Dieses Arch. Bd. 44. - Derselbe. 1919. Das Verhältnis der Zwischenzellen zum generativen Anteil im Hoden der Dohle (Colaeus monedula). Dieses Arch. Bd. 45. - Derselbe. 1920. Der Einfluß von veränderten änßeren Bedingungen auf die Ovarien der Molche. Verhandl. d. anatom. Gesellsch. zu Jena. - Derselbe. 1920a. Anatomische Untersuchungen über die Fortpflanzung des Grottenolmes. Anatom. Hefte. Bd. 56. - Derselbe. 1920b. Die Entwicklung der Keimzellen des Grottenolmes (Proteus anguineus). I. Die Spermatogenese. Arch. f. mikr. Anat. Bd. 93. - Derselbe. 1921. Entwicklung, Bau und Bedeutung der Keimdrüsenzwischenzellen. Eine Kritik der Steinachschen Pubertätsdrüsenlehrer. München, J. F. Bergmann, u. Ergebnisse d. Anat. u. Entwicklungsgeseh. Bd. 23. - Derselbe. 1921 a. Die Entwicklung der Keimzellen des Grottenolmes (Proteus anguineus). II. Dio Wachstumsperiode der Oocyte. Aroh. f. mikr. Anat. Bd. 95. - Tornier, G. 1896. Uber Hyperdactylie, Regeneration und Verexbung mit Experimenten. Dieses Arch. Bd. 3. - Tower, W. L. 1906. An Investigation of Evolution in Chrysomelid Beetle of the Genus Leptinotarsa. Carnegie Instit. of Washington Publ. 48. - Derselbe. 1918. The Mechanism of Evolution in Leptinotarsa. Carnegie Instit. of Washington Publ. 263. (Erwähnt nach Alverdes, 1921.) - Uhlenhuth, E. 1914. Die Bedeutung des funktionellen Reizes für die Erhaltung transplantierter Amphibienaugen. 85. Verhandl. d. Ges. Deutsch. Naturf. u. Ärzte in Wien. Bd. 2. 2. Teil. - Derselbe, 1920. Kritisohe Bemerkungen über den Wert der Reizpsychologie. Dieses Arch. Bd. 46 (u. a. a. O.). - Wi edersheim. 1902. Vergleichende Anatomie der Wirbeltiere. V. Aufl. Bd. 2. Jena, G. Fischer. - Weismann, A. 1913. Vorträge über Deszendenztheorie. III. Aufl. Jena, G. Fischer (u. a. a. O.). - Wolterstorff, W. 1920. Zur Aufzucht des Triton alpestris und Triton palmatus. Blätter f. Aquarien- u. Terrarienkunde. Bd. 31. - 1920a. Der Finfluf niederer Temperatur auf die Lebenstätigkeit der Molche. Blätter f. Aquarien- u. Terrarienkunde. Bd. 31 (S. 90).

\section{Erklärung der Abbildungen.}

\section{Tafel I und II.}

Alle hier abgebildeten Eierstöcke stammen von Triton vulgaris und sind in Sublimateisessig fixiert, in Paraffin eingebettet, $10 \mu$ dick geschnitten. Färbung Delafieldsches Hämatoxylin-Erythrosin. Vergrößerung durchweg $10^{1} / 2$ fach. Die Zeichnungen wurden von Frl. B. Neresheimer in München angefertigt.

Abb. 1-4. Eierstöcke nicht beeinflußter Molche.

Abb. 1. Eierstock im Spätherbst und Vorfrühling. Der betreffende Moleh wurde am 5. Mai 1918 gefangen und getötet (Tr.vulg. Nr. 6).

Abb. 2. Eierstock 3-4 Wochen nach Beginn der Eiablage. Der betreffende Molch wurde am 18. V. 1918 gefangen und getötet. Die Laichzeit hatte etwa am 20. IV. begonnen (Tr. vulg. Nr. 66).

Abb. 3. Eierstock gegen Ende der Eiablage. Der Molch hatte in der Zeit vom 4. V. bis 7. VI. 1918 über 480 Eier abgelegt, am 7. VI. 1918 getötet. In den Eileitern rechts 14, links 9 Eier, 6 Baucheier (Tr. vulg. Nr. 110).

Abb. 4. Eierstock nach Beendigung der Eiablage. Der betreffende Molch hatte in der Zeit vom 23. IV. bis zum 1. VI. 1919 gegen 600 Eier abgelegt, verläßt am 2. VI das Wasser, wird am 3. VI. getötet. Eileiter leer, keine Baucheier ( $T r$. vulg. Nr. 114). 


\section{Abb. 5-12. Eierstöcke beeinfluBter Tiere.}

Abb. 5. Eierstock nach 3 tägiger Beeinflussung. Der Molch wurde am 5. V. 1918 gefangen, in leerem GlasgefäB gehalten, laicht am 6. und 7. V. Am 8. V. getötet. Beide Eileiter leer, keine Baucheier ( $T r$. vulg. Nr. 18).

Abb. 6. Eierstock nach 12 tägiger Beeinflussung. Der Moloh wurde am 5. V. 1918 gefangen und im Behälter ohne Bodenschicht gepflegt. Legt am 6 . und 7 . V. Laich $a b$, von da ab nicht mehr. Beide Eileiter leer, keine Baucheier. Die Mehrzahl der großen Follikel in Rückbildung (Tr. vulg. Nr. 39).

Abb. 7. Eierstock nach 29 tägiger Beeinflussung. Der Moleh wurde am 5. V. 1918 gefangen und im Aquarium ohne Bodenschicht gehalten. Laicht am 6., 7. und 8. V., von da ab nicht mehr. Wird am 3. VI. 1918 getötet, Eileiter leer, keine Baucheier. In den Eierstöcken zahlreiche atretische Follikel im letzten Stadium der Rüekbildung ( $T r$. vulg. Nr. 53).

Abb. 8. Eierstock nach 29 tägiger Beeinflussung. Der Molch war ebenso behandelt, wie der bei Abb. 7 beschriebene. Abb. 7 und 8 sollen die individuellen Sehwankungen in der Reaktionsweise zeigen. Auch dieser Moloh hatte am 6. und 7. V. 1918 in Gefangensehaft gelaicht, von da ab bis zum 3. VI. 1918, wo er getötet wurde, nicht mehr. Beide Eileiter leer, keine Baucheier (Tr.vulg. Nr. 52).

Abb. 9. Eierstock nach 60 tägiger Beeinflussung, zeigt den höohsten Grad der Rückbildung. Der Molch wurde am 5. V. 1918 gefangen, legt am 6. und 7. V. Laich ab, von da ab nicht mehr, wird im Aquarium ohne Bodenschicht gehalten und spärlich gefüttert. Magert von Anfang Juni an rasch ab, am 3. VII. 1918 getötet, Gewicht 0,847 g. Eileiter leer, keine Baucheier, Fettkörper makroskopisch nicht zu erkennen (Tr. vulg. Nr. 73).

Abb. 10. Eierstook nach 23 tägiger Beeinflussung. Der Moloh wurde am 5. V. 1918 gefangen, im Normalbehälter bei ansschließlicher Daphnienfütterung gehalten. Am 28. V. 1920 getötet, Eileiter leer, keine Baucheier, Fettkörper makroskopisch nicht zu erkennen (Tr. vulg. Nr. 46).

Abb. 11. Eierstock nach 60tägiger Beeinflussung. Der Molch wurde am 5. V. 1918 gefangen und im Normalbehälter vollkommen im Schatten gepflegt. Wasserwärme 8-15 Grad. Legt bis zum 14. V. 1918 etwa 30 Eier ab, von da an nicht mehr, magert nicht ab, verläBt ab Ende Mai zeitweise das Wasser. 3. VII. 1918 getötet. Eileiter leer, keine Baucheier, Fettkörper groß, Gewicht 1,537 g (Tr. vulg. Nr. 67).

Abb. 12. Eierstock eines Molches, der vor der Laichzeit gemästet wurde. Gefangen am 15. III. 1920, im Normalbehälter bei Wasserwärme von 4-8 Grad, die tagsüber manchmal auf $15 \mathrm{Grad}$ steigt, gehalten und gemästet. VerläBt am 11. IV. 1920 das Wasser, am 13. IV. 1920 getötet, Eileiter leer, keine Bancheier, Fettkörper sehr groß (Tr. vulg. Nr. 98). 

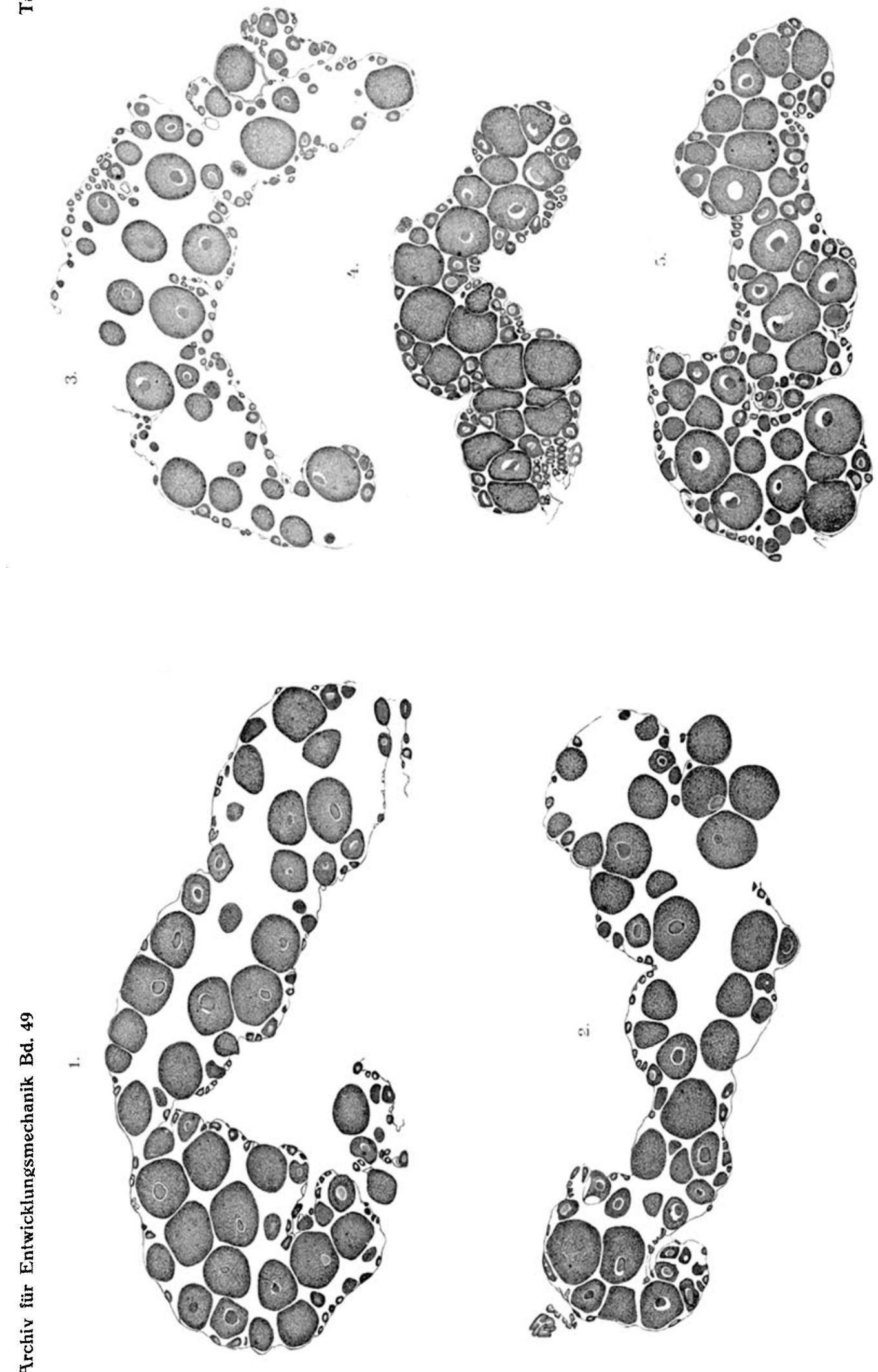

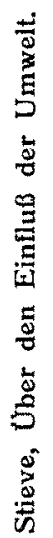



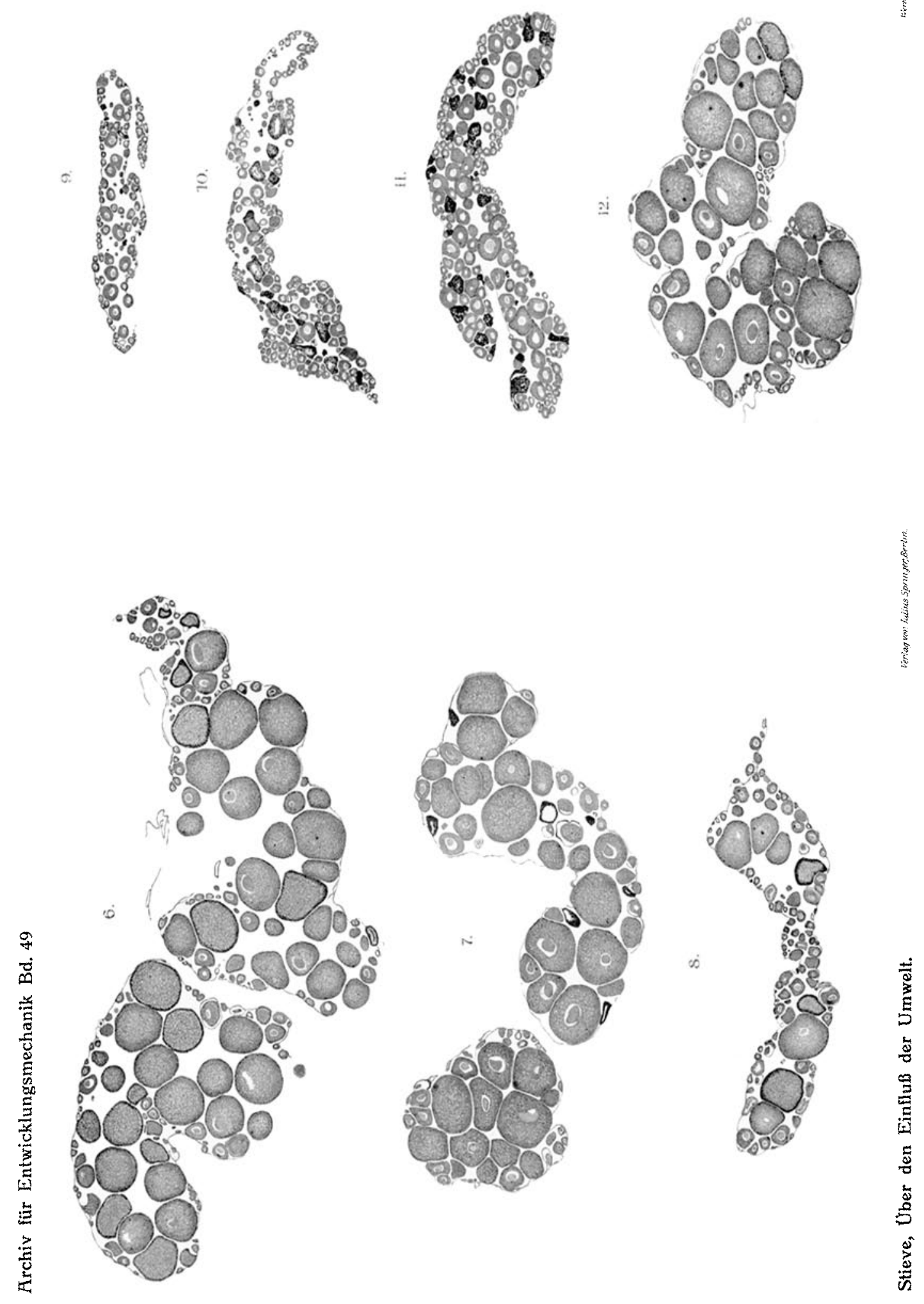